Eduardo Moreira de Queiroga

\author{
Linfoma de Burkitt: características clinicopatológicas, \\ imunoistoquímicas e associação com o vírus de Epstein-Barr \\ (EBV) em populações adulta e pediátrica em diferentes \\ regiões geográficas no Brasil
}

Tese apresentada à Faculdade de Medicina da Universidade de São Paulo para obtenção do título de Doutor em Ciências

Área de concentração: Patologia

Orientador: Prof. Dr. Carlos Eduardo Bacchi

SÃO PAULO

2008 


\section{DEDICATÓRIA}

A Deus, mestre de todos nós, por iluminar um caminho cercado de desafios e aprendizados.

À minha esposa, Adriana Wludarski, por tudo o que significa em minha vida, por todo o nosso amor e cumplicidade e aos "filhos" Melanie e Malthus pelo carinho e afeição.

Ao meu pai, José Moreira (in memorian), e a minha mãe, Maria Salomé, pelas lições de vida essenciais para a minha realização enquanto ser humano.

Aos meus irmãos, Laênia e Daniel, os meus eternos amigos.

E, para não incorrer em injustiças, pois muitos deveriam ser os nomes aqui relacionados, dedico este trabalho a todos os meus familiares, que são fonte de incentivo e apoio para que o aprendizado não tenha limites ou fronteiras. 


\section{AGRADECIMENTOS}

Ao Prof. Dr. Carlos E. Bacchi, um verdadeiro mestre e modelo de devoção pela Patologia, pessoa a quem devo o eterno agradecimento pela oportunidade de desenvolver os estudos de pósgraduação na Faculdade de Medicina da Universidade de São Paulo, bem como de fazer parte da família Consultoria em Patologia.

À Dra. Maura M. Bacchi pela generosidade, amizade, confiança e apoio.

À Dra. Gabriela Gualco, os meus sinceros agradecimentos pelo empenho e ajuda nas diversas etapas que viabilizaram esse trabalho.

Aos patologistas da Consultoria em Patologia, em especial à Dra. Sheila Wludarski e ao Dr. Lisandro Ferreira Lopes, pela convivência e aprendizado profissional.

À Dra. Lucimara Chioato e à Dra. Luciana Hayashi, biólogas do Genepath, pela realização da PCR e hibridização "in situ".

Aos técnicos dos laboratórios de histologia e imunoistoquímica da Consultoria em Patologia pela realização dos procedimentos essenciais à concretização desse trabalho.

Aos profissionais do setor de Tecnologia da Informação da Consultoria em Patologia, pelo auxílio na diagramação e formatação de textos. 
Enfim, a todos que de alguma forma contribuíram para a concretização desta tese e para minha realização profissional: simplesmente, o meu muitíssimo obrigado. 
Esta tese está de acordo com as seguintes normas, em vigor no momento desta publicação:

Referências: adaptado de International Committee of Medical Journals Editors (Vancouver)

Universidade de São Paulo, Faculdade de Medicina, Serviço de Biblioteca e Documentação. Guia de apresentação de dissertações, teses e monografias. Elaborado por Anneliese Carneiro da Cunha, Maria Jullia de A. L. Freddi, Maria F. Crestana, Marinalva de Souza Aragão, Suely Campos Cardoso, Valéria Vilhena. 2a ed. São Paulo: Serviço de Biblioteca e Documentação; 2005.

Abreviatura dos títulos dos periódicos de acordo com List of Journals Indexed in Index Medicus. 


\section{SUMÁRIO}

Lista de abreviaturas

Resumo

Summary

1 INTRODUÇÃO

1.1 Histórico do linfoma de Burkitt (LB) e descoberta do vírus de Epstein-Barr (EBV).

1.2 LB: definição, epidemiologia, características clínicas, patológicas, moleculares e diagnóstico diferencial.....

1.3 MUM1/IRF4: função, expressão em neoplasias linfóides, incluindo LB...........10

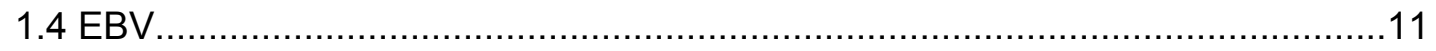

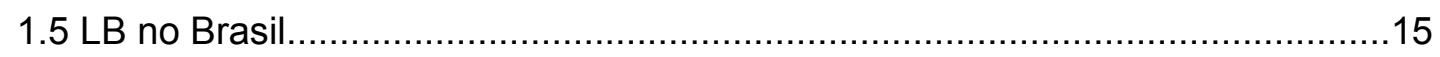

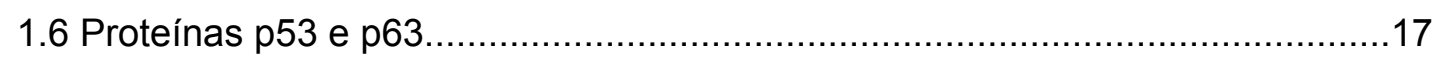

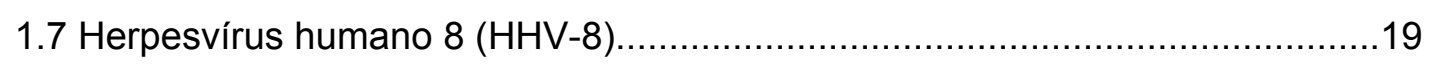

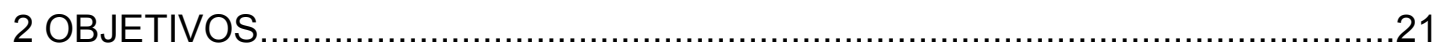

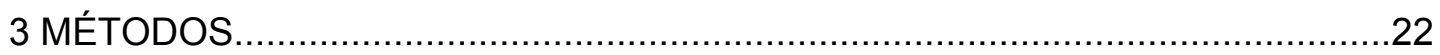

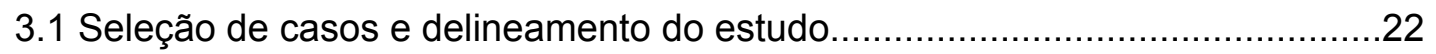

3.2 Levantamento de informações clínicas........................................................24

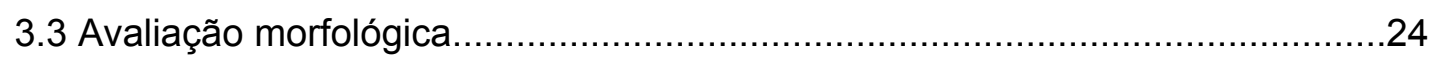

3.4 Construção dos blocos de "array" de tecido ("tissue microarray" - TMA).........25

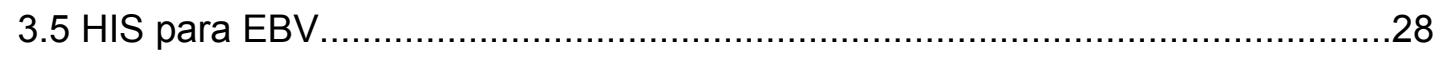

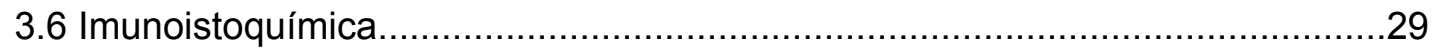

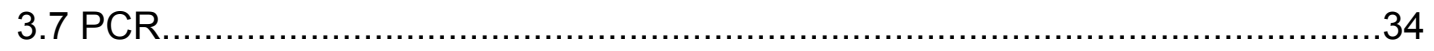

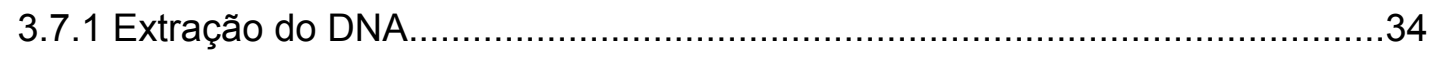

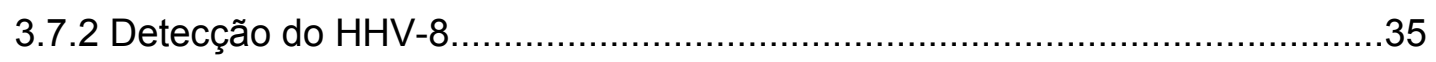

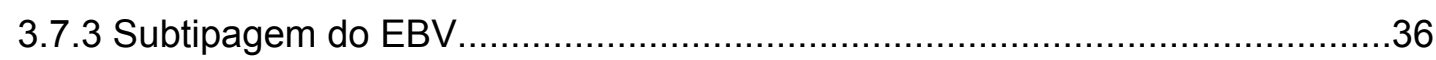

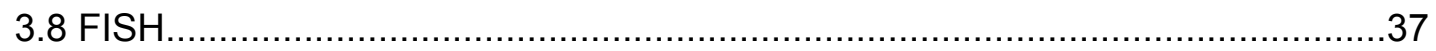

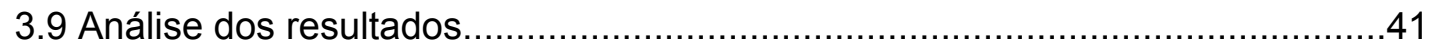

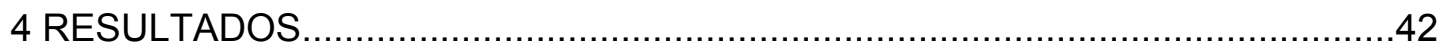

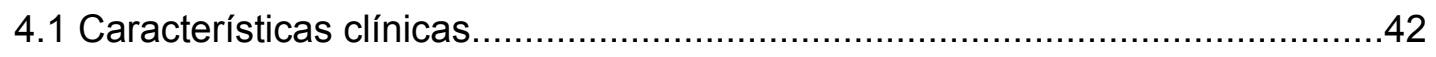

4.1.1 Características clínicas nas diferentes regiões geográficas do Brasil............46

4.2 Características morfológicas..................................................................49

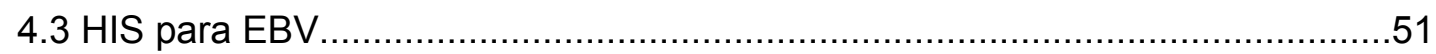

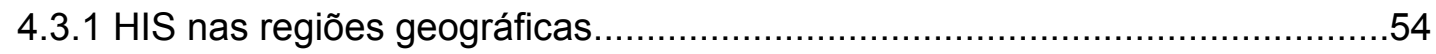

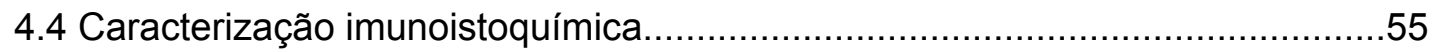


4.4.1 Associação entre expressão da proteína p53 e HIS-EBV. .59

4.4.2 Associação entre MUM1/IRF4, BCL-6 e infecção pelo EBV .........................60

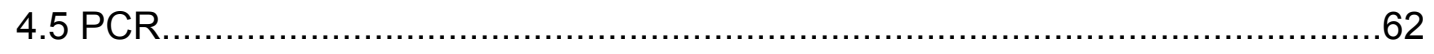

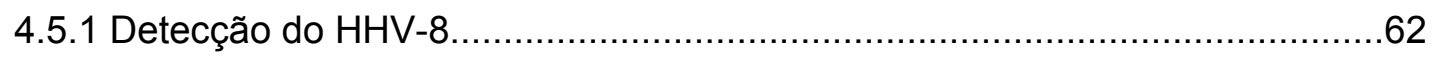

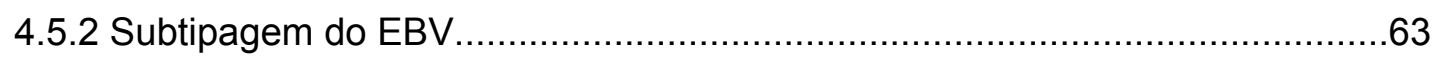

4.5.2.1 Distribuição dos tipos de EBV nas regiões geográficas.............................64

4.6 Características clínicas dos casos HIV positivos............................................65

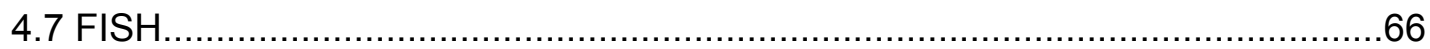

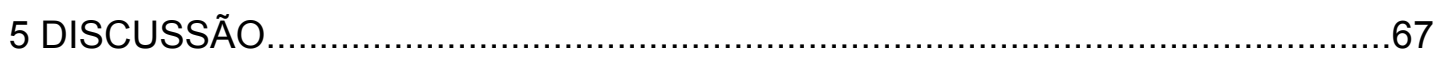

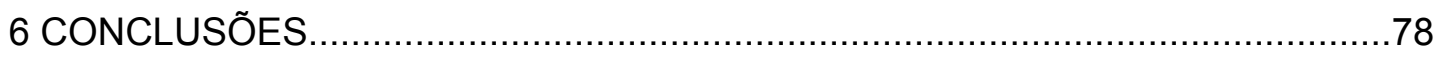

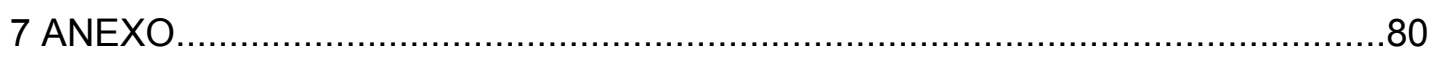

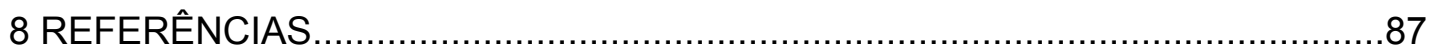

Apêndice 


\section{LISTA DE ABREVIATURAS}

bp: pares de bases

EBV: vírus de Epstein-Barr

EBNA: antígeno nuclear do vírus de Epstein-Barr et al.: e outros

EUA: Estados Unidos da América

FISH: hibridização "in situ" por fluorescência

HHV-8: Herpesvírus humano 8

HIS: hibridização "in situ"

HIV: vírus da imunodeficiência humana

IGH: cadeia pesada de imunoglobulina

LANA-1: antígeno nuclear associada à latência-1

LB: linfoma de Burkitt

LDBCB: linfoma difuso de grandes células $B$

LMP: proteína latente de membrana

LNH: linfoma não Hodgkin

MCD: doença de Castleman multicêntrica

MRLM: modelo de regressão logística multinomial

OMS: Organização Mundial da Saúde

ORF: seqüência aberta para leitura do HHV-8

PBS: solução salina tamponada

PCR: reação em cadeia da polimerase

PEL: linfoma de efusão primária

SIDA: síndrome da imunodeficiência adquirida

SOE: sem outra especificação

TdT: deoxinucleotidil transferase

TMA: "tissue microarray" 


\section{RESUMO}

de Queiroga EM. Linfoma de Burkitt: características clinicopatológicas, imunoistoquímicas e associação com o vírus de Epstein-Barr (EBV) em populações adulta e pediátrica em diferentes regiões geográficas no Brasil [tese]. São Paulo: Faculdade de Medicina, Universidade de São Paulo; 2008.

O linfoma de Burkitt (LB) é neoplasia linfóide de células B de alto grau que apresenta translocação constante envolvendo o proto-oncogene $C-M Y C$. A associação com o vírus de Epstein-Barr (EBV) varia de acordo com a forma clinicopatológica. $\mathrm{O}$ presente estudo tem por objetivo analisar as características clinicopatológicas, imunoistoquímicas, incluindo a expressão do fator de transcrição MUM1/IRF4 e das proteínas p53 e p63, e investigar a associação com infecção pelo Herpesvírus humano 8 (HHV-8) e EBV, através de hibridização "in situ" e PCR, em 234 casos bem caracterizados de LB no Brasil, provenientes das 5 regiões geográficas em pacientes pediátricos e adultos, incluindo casos associados ao HIV. As características clínicas do LB no Brasil, de maneira geral, foram semelhantes às observadas na forma esporádica do LB ocorrendo nos países desenvolvidos. A infecção pelo EBV foi observada em $52,5 \%$ dos casos. A maior associação com EBV foi verificada nas regiões Norte e Nordeste e a menor na região Sul. Através de PCR, demonstrou-se predomínio de EBV do tipo A, sendo exceção a região Centro-Oeste. O fator de transcrição MUM1/IRF4 foi expresso em $39,2 \%$ dos tumores e apresentou correlação inversa com 
infecção pelo EBV. A expressão das proteínas p53 e p63 foi observada em $16,2 \%$ e $3,8 \%$ dos casos, respectivamente. Não se identificou infecção pelo HHV-8. O LB no Brasil apresenta características clinicopatológicas variáveis entre as regiões geográficas. A associação com infecção pelo EBV é intermediária entre a forma endêmica de LB e a forma esporádica ocorrendo em países desenvolvidos, sendo maior em regiões com indicadores sociais menos favoráveis.

Descritores: 1. Linfoma de Burkitt 2. Herpesvírus humano 43. Imunoistoquímica 4. Hibridização "in situ” 5. Herpesvírus humano 8 6. Brasil 


\section{SUMMARY}

De Queiroga EM. Burkitt lymphoma: clinicopathologic, immunohistochemical and association with Epstein-Barr virus (EBV) in adult and pediatric population in different geographical regions of Brazil [thesis]. São Paulo: "Faculdade de Medicina, Universidade de São Paulo"; 2007.

Burkitt lymphoma $(\mathrm{BL})$ is a high grade $\mathrm{B}$ cell lymphoma with a consistent translocation involving the proto-oncogene C-MYC. The association with the Epstein-Barr virus (EBV) varies depending on the clinicopathological form. This study aims to analyze the clinicopathologic, immunohistochemical features, including the expression of transcription factor MUM1/IRF4 and p53 and p63 proteins, and investigate the association with infection by human herpesvirus-8 (HHV-8) and EBV, by in situ hybridization and PCR, in 234 well-characterized cases of $\mathrm{BL}$ in Brazil from the 5 different geographic regions, in adult and pediatric patients, including HIV associated cases. The clinical characteristics of $B L$ in Brazil, in general, were similar to those observed in the sporadic form of $\mathrm{BL}$ occurring in developed countries. EBV infection was seen in $52.5 \%$ of cases. The strongest association with EBV was found in the North and Northeast and the lowest in the South. PCR study demonstrated predominance of EBV type A, except in the Central-West region. The transcription factor MUM1//RF4 was expressed in $39.2 \%$ of the tumors and showed inverse correlation with EBV infection. The expression of p53 and p63 proteins was observed in $16.2 \%$ and $3.8 \%$ of cases, 
respectively. No evidence of HHV-8 infection was found. The BL in Brazil is clinicopathologic diverse and regionally distinct. The association with EBV infection is intermediate between the endemic form of $\mathrm{BL}$ and sporadic form occurring in developed countries and is higher in regions with the less favorable social indicators.

Descriptors: 1. Burkitt lymphoma 2. Human herpesvirus 43 . Immunohistochemistry 4. In situ hybridization 5. Human herpesvirus 86 . Brazil 


\section{INTRODUÇÃO}

1.1 Histórico do linfoma de Burkitt (LB) e descoberta do vírus de Epstein-Barr (EBV)

Em 1957, o cirurgião inglês Denis Burkitt, enquanto trabalhava no Hospital de Mulango em Kampala, capital da Uganda, foi consultado por um colega sobre uma criança apresentando tumoração na face, envolvendo a mandíbula. Em seguida, percebeu que, naquela região geográfica, tumor acometendo os ossos da face era manifestação comum, estava freqüentemente associado a tumoração em outros sítios e, por vezes, apresentava-se sem envolvimento mandibular. Dessa forma, concluiu que essas diferentes apresentações eram todas manifestações de um mesmo complexo tumoral bastante comum na primeira década de vida em Uganda (Epstein, 2005). Em 1958, Burkitt publicou seu primeiro estudo sobre essa neoplasia, descrevendo 38 crianças com tumores de localização preferencial na região mandibular, sendo diagnosticados inicialmente como sarcomas e relatando as primeiras características epidemiológicas, o papel dos fatores climáticos e a provável associação com algum agente infeccioso devido à similaridade de distribuição com outras doenças transmitidas por mosquitos. Todavia, essa primeira publicação não atraiu muita atenção na época e só se tornou citação clássica em 1983. Foi somente quando Denis Burkitt recorreu à colaboração do patologista O'Conor, que diagnosticou o tumor 
como um linfoma incomum (Burkitt e O'Conor, 1961; O'Conor, 1961), que os seus trabalhos em conjunto levaram ao início do interesse sobre essa neoplasia, posteriormente, denominada de linfoma de Burkitt (LB) (Epstein, 2005).

Em 1961, Denis Burkitt compartilhou amostras de LB com Michael Epstein que, em 1964, juntamente com Achong e Barr, identificou, através de microscopia eletrônica, partículas virais a partir de culturas de células linfoblastóides derivadas do LB de crianças africanas. Essas partículas virais apresentavam aspectos morfológicos semelhantes a vírus do grupo Herpes. Esse novo vírus foi denominado de vírus de Epstein-Barr (EBV) (Epstein et al., 1964). Essa foi a primeira descrição de um vírus envolvido na patogenia de um tumor em humanos (Ferry, 2006).

1.2 LB: definição, epidemiologia, características clínicas, patológicas, moleculares e diagnóstico diferencial

O LB é definido pela Organização Mundial da Saúde (OMS, 2001) como um linfoma altamente agressivo, apresentando-se freqüentemente em localização extranodal, ou raramente como leucemia aguda, constituído por células de imunofenótipo $B$, monomórficas, de médio tamanho, com citoplasma basofílico, exibindo numerosas figuras de mitoses e apresentando translocação constante envolvendo o proto-oncogene $C$ MYC. 
Três variantes clínicas de LB são reconhecidas: a endêmica, a esporádica e a associada à imunodeficiência. Cada uma dessas formas apresenta manifestações clínicas diferentes e variáveis freqüências de associação com o EBV.

A forma endêmica do LB ocorre na África Equatorial e também em Papua-Nova Guiné, havendo correlação com fatores climáticos (temperatura, índice pluviométrico, etc.), que correspondem à distribuição geográfica da malária. Na África Equatorial estima-se que a incidência do LB é 50 vezes maior do que nos Estados Unidos da América (EUA), correspondendo à neoplasia maligna mais comum da infância, com pico de incidência entre 4 e 7 anos de idade. Nesta forma, é freqüente o envolvimento de ossos da face, principalmente de mandíbula, maxila e órbita, porém, acometimento de íleo distal, ceco, fígado, rins e mama são também observados. Neste tipo de LB a infecção pelo EBV está presente em virtualmente todos os casos (Diebold et al., 2001; Blum et al., 2004).

O LB esporádico ocorre no resto do mundo, não tem associação com fatores geográficos ou climáticos e apresenta baixa incidência, correspondendo a 1-2\% dos linfomas em adultos e cerca de 40$50 \%$ de todos os linfomas em crianças nos EUA e Europa Ocidental. O abdome, em especial a região íleo-cecal, é o local mais comumente envolvido, sendo incomum o acometimento de ossos da face. $O$ envolvimento linfonodal é mais freqüentemente observado em adultos do que em crianças. A associação com EBV, nesta forma clínica, é menor, variando de 15 à 30\% (Ferry, 2006; Kelly e Rickinson, 2007). Em algumas 
regiões geográficas, como por exemplo, no norte da África e na América do Sul, incluindo o Brasil, a incidência do LB é intermediária entre as formas endêmica e esporádica (Diebold et al., 2001; Hassan et al., 2008).

O LB associado à imunodeficiência é mais freqüentemente observado em associação com a infecção pelo vírus da imunodeficiência humama (HIV) e também tem sido relatado, embora com menor freqüencia, em pacientes submetidos a transplante de órgãos e em estados de imunodeficiência congênita (Stewart, 2006). O LB corresponde a cerca de um terço dos casos de linfoma não Hodgkin (LNH) diagnosticados em pacientes HIV positivos e comumente representa a manifestação inicial da síndrome da imunodeficiência adquirida (SIDA) (Navarro e Kaplan, 2006; Ferry, 2006). Nesta forma de LB é comum o envolvimento linfonodal e infecção pelo EBV é encontrada em 30 a 40\% dos casos (Diebold et al., 2001; Kelly e Rickinson, 2007).

Em relação à morfologia, o LB clássico caracteriza-se pela proliferação de células monomórficas entre si, de tamanho intermediário, com núcleos redondos apresentando vários pequenos nucléolos basofílicos e citoplasma variando de anfofílico a basofílico, às vezes vacuolizado. É freqüente o encontro de figuras de mitoses e, caracteristicamente, observase o padrão em "céu-estrelado" devido à presença de numerosos histiócitos fagocitando restos celulares apoptóticos. Além da forma clássica do LB, a OMS reconhece duas variantes morfológicas: LB atípico/Burkitt-símile e o LB com diferenciação plasmacitóide. O LB atípico/Burkitt-símile apresenta achados morfológicos superponíveis ao LB clássico, porém, essa variante 
exibe maior pleomorfismo caracterizado por certa variação do tamanho e forma nuclear, mostra nucléolo proeminente e em menor número. O LB com diferenciação plasmacitóide também exibe pleomorfismo nuclear e apresenta citoplasma amplo e basofílico, com núcleo excêntrico. Esta variante morfológica pode ser observada em crianças e é mais freqüentemente associada à imunodeficiência (Diebold et al., 2001; Ferry, 2006).

Imunofenotipicamente, as células do LB expressam IgM de membrana e antígenos da superfície celular próprios de linfócitos B (CD19, CD20, CD22), além de CD10 e BCL-6, com negatividade para CD3, BCL-2, CD5, CD23, deoxinucleotidil transferase (TdT) e IgD. $O$ índice de proliferação celular, avaliado através da detecção do antígeno Ki-67, é alto e próximo de 100\% (Chuang et al., 2007; Rodig et al., 2008). É importante ressaltar que estudos têm demonstrado expressão variável de CD10, BCL-6 e, ainda, expressão aberrante de BCL-2 (Frost et al., 2004; Cogliati et al., 2006; Chuang et al., 2007; Chuang et al., 2008).

Todos os casos de LB, independentemente da forma clínica, apresentam alterações citogenéticas envolvendo o gene C-MYC, no cromossomo 8, na banda q24. A alteração mais comum, que ocorre em $80 \%$ dos casos, é a translocação recíproca $t(8 ; 14)(q 24 ; q 32)$, colocando o gene $C$ MYC próximo ao gene da cadeia pesada de imunoglobulina (IGH). Em cerca de $15 \%$ dos casos a translocação envolve o gene da cadeia leve kappa $[(t 2 ; 8)(2 p 11 ; 8 q 24)]$ e em cerca de $5 \%$ o gene da cadeia leve lambda [(t8;22)(8q24;22q11)] (Leder et al., 1983; Benchet al., 2007). É importante 
ressaltar que a translocação $\mathrm{t}(8 ; 14)$ foi a primeira translocação cromossômica descrita em associação com uma doença linfoproliferativa e pode ser detectada através de hibridização "in situ" por fluorescência - FISH (Siebert et al., 1998). A família MYC de proto-oncogenes está envolvida em vários processos celulares, incluindo proliferação, diferenciação e apoptose. Embora a desregulação do $C-M Y C$ desempenhe um papel fundamental na tumorigênese do LB, o mecanismo exato de todo esse processo ainda não está completamente esclarecido (Shiramizu et al., 1991; Kelly e Rickinson, 2007)

Há considerável heterogeneidade nas quebras cromossômicas no LB, uma vez que na t(8;14) a quebra se dá na região $5^{\prime}$ de $C-M Y C$, enquanto que nas translocações $t(2 ; 8)$ e $t(8 ; 22)$ a quebra ocorre na região 3' de C-MYC (Hsi e Gascoyne, 2007). Foram encontradas diferenças no local de ruptura do cromossomo 8 entre as formas endêmica e esporádica de LB. No LB endêmico a quebra ocorre distante de 5' de C-MYC (mais de 100 kb das seqüências codificatórias e regulatórias do gene) e a quebra no locus da IGH ocorre dentro do segmento J (região juncional). Nos LB esporádico e associado ao HIV o ponto de ruptura, em geral, ocorre entre os exons 1 e 2 do gene C-MYC e a junção no cromossomo 14 ocorre na região "switch" (Barriga et al., 1988; Shiramizu et al., 1991). Estes achados sugerem que a transformação neoplásica afeta células B em diferentes estágios de maturação (Shiramizu et al., 1991). Em ambos os casos, mesmo que as seqüências regulatórias estejam intactas ou removidas pela translocação, a conseqüencia é que o gene passa a ser regulado como um 
receptor imune (Klumb, 2001). A figura 1 ilustra os pontos de quebra cromossômica no LB.

\section{Diagrama 1}

Cromossomo 8 c-Myc

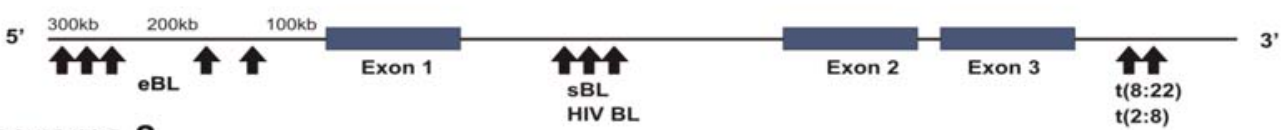

\section{Diagrama 2}

Cromossomo 14: IgH

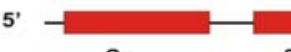

$\mathrm{C}_{\mu}$
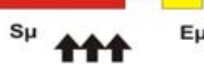

Diagrama 3

$$
\text { HIV BL }
$$

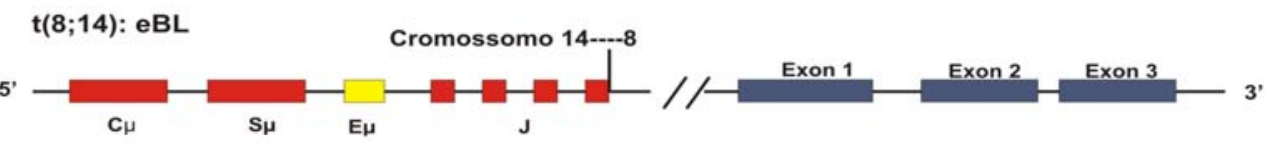

Diagrama 4

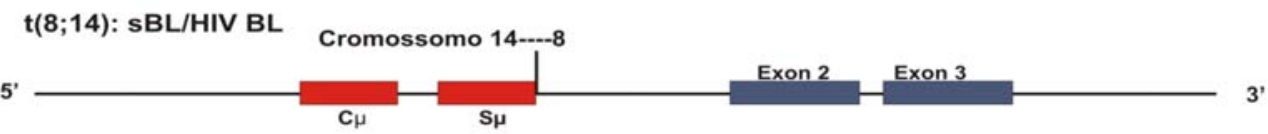

Diagrama 5

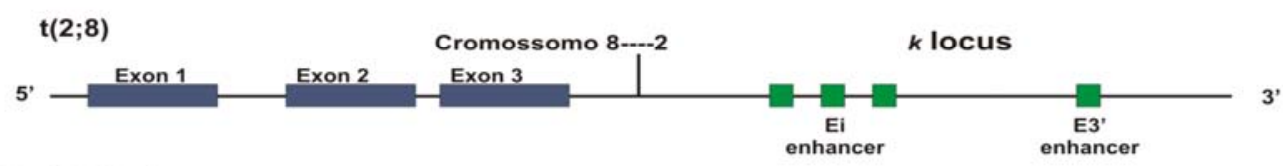

Diagrama 6

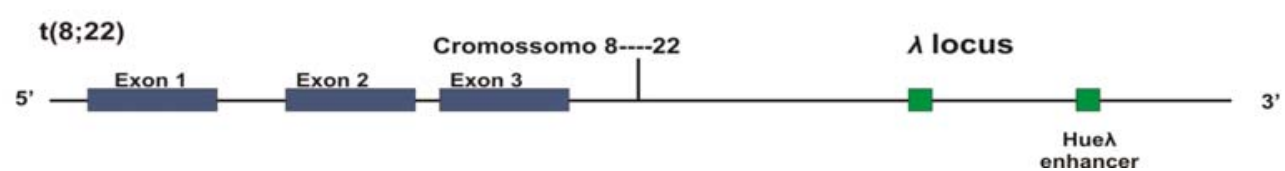

Figura 1. Posições de quebras cromossômicas nas translocações $t(8 ; 14)$, $\mathrm{t}(2 ; 8)$ e $\mathrm{t}(8 ; 22)$. Os locais de quebra na $\mathrm{t}(8 ; 14)$ no LB endêmico, esporádico e associado ao HIV são apresentadas. Diagrama 1: gene $C-M Y C$ no cromossomo 8q24. Diagrama 2: gene IGH no cromossomo $14 q 32$. Diagramas 3 e 4 : rearranjos na $t(8 ; 14)$ no LB endêmico e LB esporádico e associado ao HIV, respectivamente. Diagramas 5 e $6: t(2 ; 8)$ e $t(8 ; 22)$, respectivamente

eBL, LB endêmico; sBL, LB esporádico; HIV BL, LB associado ao HIV; $\mathrm{C} \mu$, região constante da cadeia pesada; $D$, região de diversidade; $E \mu$, segmento "enhancer"; J, região juncional; S $\mu$, região "switch". V, região variável.

Fonte: Blum et al., 2004. 
Gutiérrez et al. (1992) estudaram os padrões de quebra cromossômica em LB na América do Sul, analisando casos oriundos do Brasil, Chile e Argentina. Observou-se que a distribuição dos pontos de ruptura do cromossomo 14 foi semelhante ao LB esporádico dos EUA. Todavia, em relação ao cromossomo 8 , observou-se que $41 \%$ dos casos apresentaram pontos de ruptura em região próxima ao $5^{\prime}$ do $C-M Y C$, sugerindo a existência de um terceiro subtipo molecular de LB. Além disso, não se evidenciou associação entre infecção pelo EBV e um local específico de quebra cromossômica. Os motivos para a existência de diferentes pontos de quebra cromossômica em diferentes regiões geográficas não são totalmente conhecidos.

Os diagnósticos diferenciais do LB incluem outros linfomas difusos de alto grau como por exemplo, o linfoma/leucemia linfoblástica aguda e o linfoma de células do manto variante blastóide, que são facilmente diferenciados do LB pelas características morfológicas e imunofenotípicas: expressão de TdT no linfoma linfoblástico/leucemia linfoblástica aguda e de ciclina D-1 e CD5 no linfoma de células do manto (Hsi e Gascoyne, 2007). O principal diagnóstico diferencial, contudo, é com o linfoma difuso de grandes células B (LDGCB), uma vez que estas duas neoplasias podem apresentar características morfológicas e imunofenotípicas superponíveis e, além disso, a $t(8 ; 14)$, característica do LB, pode ser encontrada em 5 a $10 \%$ dos casos de LDGCB (Leoncini et al., 2005; Haralambieva et al., 2005; Leich et al., 2007). A distinção entre estas duas entidades é de grande importância clínica, uma vez que os tratamentos são significativamente diferentes 
(Rosenwald e Ott, 2008). Nos últimos anos, a introdução da tecnologia de "microarray" permitiu que pesquisadores pudessem definir assinaturas gênicas das neoplasias. Estas assinaturas são baseadas na expressão de vários genes (Yustein e Dang, 2007). Recentemente, dois estudos independentes (Hummel et al., 2006; Dave et al., 2006), empregando a tecnologia de "microarray", analisaram o perfil de expressão gênica para estabelecer uma assinatura molecular do LB e, dessa forma, melhorar a acurácia no diagnóstico do LB. Os dois estudos diferem em alguns aspectos, mas apresentam conclusões semelhantes: a) o perfil de expressão gênica de casos classificados como LB estabelece uma assinatura molecular característica do LB que claramente o distingue do LDGCB; b) os critérios diagnósticos atuais usados na distinção entre LB e LCGCB não são totalmente adequados, uma vez que $17 \%$ (Dave et al., 2006) e $34 \%$ (Hummel et al., 2006) dos casos com assinatura molecular de LB foram inicialmente classificados como LDGCB ou linfoma B de alto grau não classificável. Além disso, segundo Hummel et al. (2006), linfomas B de alto grau sem assinatura gênica de LB, mas apresentando rearranjo no gene $C$ MYC apresentaram evolução clínica desfavorável. De acordo com Harris e Horning (2006), os genes identificados na assinatura molecular do LB, através da tecnologia de "microarray", poderiam ser usados na prática diagnóstica, através de FISH, reação em cadeia da polimerase (PCR) ou por métodos imunoistoquímicos (como CD44, MUM1/IRF4, TCL-1, HLA-1) e, em última análise, para o desenvolvimento de terapias-alvo. 
1.3 MUM1/IRF4: função, expressão em neoplasias linfóides, incluindo LB

O gene MUM1 (oncogene 1 do mieloma múltiplo)/IRF4 (fator 4 regulador do interferon) foi identificado como um oncogene associado ao mieloma e é ativado como resultado da translocação cromossômica $\mathrm{t}(6 ; 14)(\mathrm{p} 25 ; \mathrm{q} 32)$. O produto desse gene pertence a uma família de fatores de transcrição reguladores do interferon e desempenha um importante papel na proliferação e diferenciação celular. A deficiência de MUM1 resulta em redução dos níveis séricos de imunoglobulinas e diminuição da quantidade de plasmócitos e células T ativadas (Tsuboi et al., 2000; Ponzoni et al., 2007; Naresh, 2007). A expressão de MUM1/IRF4 é restrita a células linfóides e melanocíticas (Natkunam et al., 2001; Ponzoni et al., 2007). Em tecido linfóide normal e reativo a expressão de MUM1/IRF4 é observada em plasmócitos, em uma pequena fração de células B localizadas na zona clara do centro germinativo (com morfologia de centrocito) e também em células $T$ ativadas (Tsuboi et al., 2000; Falini et al., 2000). Dessa forma, a expressão de MUM1/IRF4 corresponde à fase final de diferenciação das células B intragerminal, estágio de centrocito, bem como aos passos subseqüentes para diferenciação em células plasmocitárias, podendo ser considerado como marcador histogenético de célula B tardia intragerminal e de célula B pós-germinal (Gaidano e Carbone, 2000; Carbone et al., 2001). É importante ressaltar que, enquanto em células linfóides B normais a expressão de MUM1/IRF4 e da proteína BCL-6 é mutuamente exclusiva, as células 
tumorais em aproximadamente 50\% dos LDGCB MUM1/IRF4 positivas, coexpressam a proteína BCL-6 (Falini et al., 2000).

Nas neoplasias linfóides, a expressão para MUM1/IRF4 é observada principalmente nos casos de mieloma múltiplo/plasmocitoma, linfoma linfoplasmacítico, linfoma de efusão primária (PEL), linfoma plasmablástico, linfoma de Hodgkin forma clássica, linfoma anaplásico de grandes células CD30 positivo, linfomas foliculares, principalmente os de grau 3, e em cerca de $75 \%$ dos casos de LDGCB (Tsuboi et al., 2000; Carbone et al., 2000; Falini et al., 2000; Carbone et al., 2001; Natkunam et al., 2001; Vegga et al., 2004; Naresh, 2007). Em relação ao LB, os trabalhos iniciais analisam um número bastante limitado de casos (Tsuboi et al., 2000; Falini et al., 2000; Carbone et al., 2000; Natkunam et al., 2001). Recentemente, Chuang et al. (2007, 2008) e Garcia et al*. (2008) demonstraram expressão para MUM1/IRF4 em 18\%, 23\% e 39\% dos casos de LB analisados, respectivamente.

\subsection{EBV}

O EBV, ou Herpesvírus humano 4, é um vírus de DNA e pertence à família Herpesviridae, subfamília Gammaherpesvirinae. O EBV é um microorganismo amplamente disseminado no ambiente. Mais de $90 \%$

"Garcia M, Dickason TJ, Lin P, Medeiros LJ. (M.D. Anderson Cancer Ctr, Houston, TX). TCL-1, MUM-1 and CD23 in the differential diagnosis of Burkitt lymphoma and diffuse large B-cell lymphoma. [Poster. 2008 Annual Meeting United States and Canadian Academy of Pathology; Denver]. 
dos adultos acima de 30 anos são seropositivos para EBV e, nos países em desenvolvimento, esse percentual é identifcado antes dos 5 anos de idade (Cohen, 2000; Rickinson, 2002; Klumb et al., 2004). O vírus é secretado na saliva e a infecção ocorre por transmissão oral, geralmente no início da vida, porém quando a infecção é retardada até à adolescência ou vida adulta, freqüentemente resulta no quadro clínico da mononucleose infecciosa (Williams e Crawford, 2006; Sixbey et al., 1984;). O EBV está classicamente associado ao LB, principalmente à forma endêmica e tem sido associado a várias neoplasias em humanos, incluindo neoplasias hematopoiéticas (linfomas B, T/NK e linfoma de Hodgkin), epiteliais (carcinoma indiferenciado de nasofaringe, "subset" de carcinomas gástricos) e mesenquimais (pseudotumor inflamatório do fígado e do baço, e neoplasias de músculo liso associadas ao HIV) (Rezk e Weiss, 2007).

O EBV infecta os linfócitos B e induz a proliferação policlonal de células $B$ linfoblastóides que são muito semelhantes a células de vários linfomas B associados ao EBV (Farrel et al., 1997). São reconhecidos dois padrões de infecção pelo EBV: a) a forma lítica, ou replicativa, ocorre episodicamente e se caracteriza pela liberação de vírions na circulação; e b) a forma latente, na qual o EBV se associa ao genoma das células $B$, assumindo a forma epissomal, sem produção viral. O genoma viral é constituído de aproximadamente 100 genes que são expressos durante a replicação, porém uma célula $B$ com infecção latente expressa um número limitado de genes: 6 proteínas nucleares (EBNA-1, EBNA-2, EBNA-3A, 3B, 3C e EBNA-LP), 3 proteínas latentes de membrana (LMP-1, LMP-2A e 2B), 
2 pequenos RNAs não codificadores (EBER1 e EBER2) e transcritos de RNA da região BamHI-A. De acordo com o perfil de expressão de proteínas virais, 3 tipos de programas de latência foram postulados, conhecidos como tipo I, II e III. O LB está classicamente associado à latência tipo I. A latência tipo II é observada nos linfomas de Hodgkin, PEL, linfoma de células T/NK e carcinomas indiferenciados de nasofaringe. Já a latência do tipo III é observada nos casos de doença linfoproliferativa pós-transplante. Esta redução de proteínas virais durante a latência viral dificulta o reconhecimento das células infectadas pelos mecanismos de defesa do sistema imunológico (Rezk e Weiss, 2007; Deyrup, 2008). A tabela 1 apresenta o perfil de expressão protéica viral do EBV em cada um dos programas de latência.

Tabela 1 - Perfil de expressão das proteínas virais do EBV nos diferentes programas de latência - Fonte: Deyrup, 2008

\begin{tabular}{ccc}
\hline LATÉNCIA TIPO I & LATÉNCIA TIPO II & LATÉNCIA TIPO III \\
\hline EBER1 & EBER1 & EBER1 \\
EBER2 & EBER2 & EBER2 \\
EBNA-1 & EBNA-1 & EBNA-1 \\
& & EBNA-2 \\
& & EBNA-3 \\
& LMP-1 & LMP-1 \\
& LMP-2 & LMP-2 \\
\hline
\end{tabular}

Dois tipos de EBV têm sido reconhecidos, de acordo com a organização dos genes EBNA-2, 3A, 3B e 3C: EBV do tipo A (ou tipo 1) e EBV do tipo B (ou tipo 2). Estes diferentes subtipos de EBV apresentam distribuições geográficas distintas. O EBV do tipo A é mais comum nas 
populações dos países desenvolvidos, correspondendo ao subtipo viral mais freqüentemente demonstrado no sangue periférico, sendo de $3 \%$ o percentual de indivíduos portadores de EBV do tipo B nessas regiões. Por sua vez, a prevalência de EBV do tipo B encontra-se aumentada em pacientes com SIDA e em regiões na qual a malária é endêmica. Estudos têm demonstrado alta prevalência dos dois tipos de EBV no LB endêmico (Young et al., 1987; Chen et al., 1996; Deyrup, 2008) e predomínio de EBV do tipo A em LB nos EUA (Goldschmidts et al., 1992).

Recentemente, Bellan et al. (2005), através da análise de $I G H$, demonstraram a existência de dois tipos de células distintos de origem para os LB EBV positivos e LB EBV negativos. Os casos de LB EBV negativos apresentaram uma menor freqüencia de mutações, indicando uma origem em centoblasto precoce para os casos de LB esporádicos. Por outro lado, os casos de LB associados ao EBV apresentaram uma freqüencia maior de mutações e sinais de seleção antigênica, indicando uma origem em célula B tardia intragerminal (zona clara do centro germinativo), que iniciou processo de diferenciação para células B de memória, para os casos de LB endêmicos e associados ao HIV. A figura 2 exemplifica os dois tipos celulares de origem dos LB EBV positivos e EBV negativos propostos por Bellan et al. 


\section{Centroblasto precoce Célula de memória}

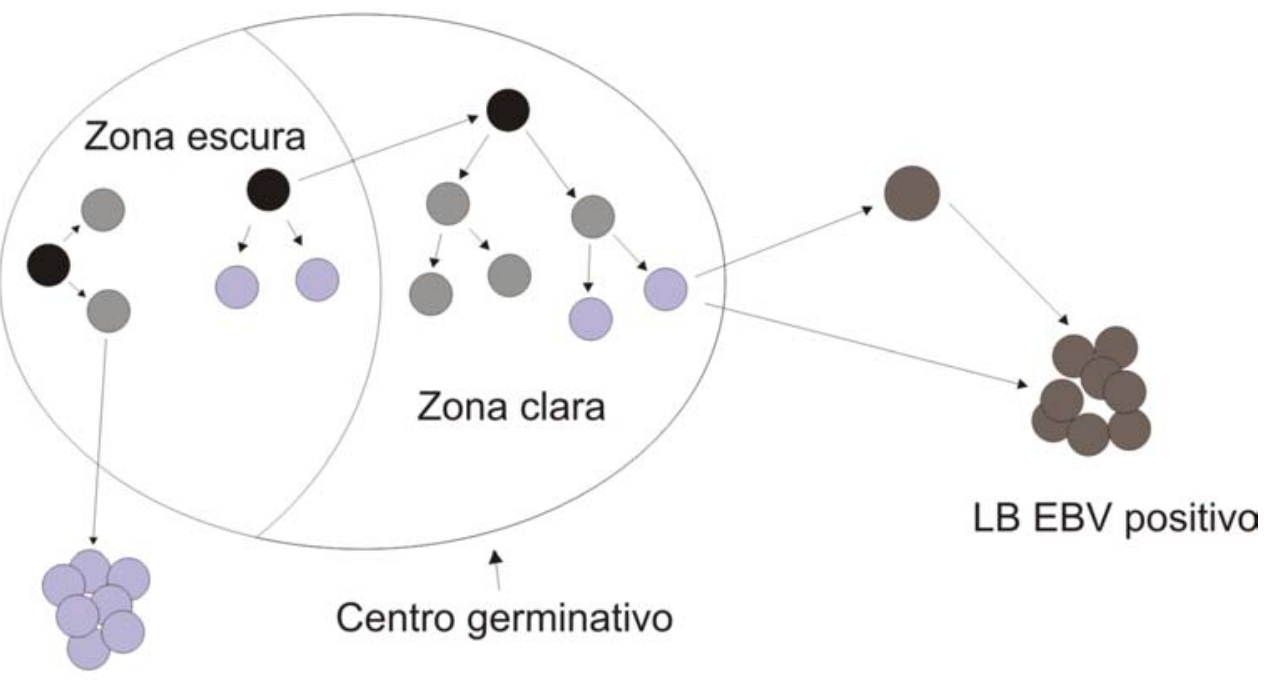

LB EBV negativo

Figura 2. Representação esquemática dos tipos celulares de origem dos LB EBV positivos e EBV negativos segundo Bellan et al. (2005)

\subsection{LB no Brasil}

Há poucos estudos sobre a incidência do LB no Brasil e a exata situação epidemiológica continua ainda pouco compreendida. Todavia, o país tem sido considerado como uma região de incidência intermediária entre o LB endêmico e o LB ocorrendo em regiões desenvolvidas como EUA e Europa (Diebold et al., 2001; Kelly e Rickinson, 2007; Hassan et al., 2008).

Em 1968, Fagundes et al. descreveram 20 casos de linfoma em crianças no Rio Grande do Sul com características morfológicas de LB, a maioria em localização abdominal. Marigo et al. (1969), estudando neoplasias infantis, estimaram que a incidência do LB no Brasil correspondia a $13 \%$ de todos os linfomas sólidos e a $2,5 \%$ de todos os tumores malignos encontrados em crianças brasileiras. 
Estudos mais recentes sobre o LB no Brasil analisam aspectos citogenéticos, clínicos e epidemiológicos do LB, bem como a associação com o EBV em regiões geográficas específicas do país e com ênfase em população pediátrica. Todavia, não há estudos envolvendo grande número de pacientes e englobando todas as regiões geográficas do Brasil. Além disso, a análise dos subtipos de EBV, através de PCR, revela maior prevalência de EBV do tipo A, variando de 74 a 93\% (Chen et al., 1996; Araujo et al., 1996; Klumb et al., 2004; Hassan et al., 2006; Hassan et al., 2008). A tabela 2 apresenta os trabalhos publicados sobre LB no Brasil, com número de casos avaliados, região geográfica e freqüencia de associação com o EBV.

Tabela 2 - Publicações sobre LB no Brasil

\begin{tabular}{cccc}
\hline REFERÉNCIA & $\begin{array}{c}\text { REGIÃO } \\
\text { GEOGRÁFICA }\end{array}$ & $\begin{array}{c}\text { NÚMERO DE } \\
\text { CASOS }\end{array}$ & $\begin{array}{c}\text { ASSOCIAÇÃO } \\
\text { COM EBV (\%) }\end{array}$ \\
\hline Araujo et al. (1996) & Nordeste & 54 & $87 \%$ \\
Sandlund et al. (1997) & Nordeste & 11 & $73 \%$ \\
Gutiérrez et al. (1992) & Sudeste & 12 & $58 \%$ \\
Bacchi et al. (1996) & Sudeste & 24 & $71 \%$ \\
Klumb et al. (2004) & Sudeste & 29 & $72 \%$ \\
Hassan et al. (2008) & Sudeste & 54 & $61 \%$ \\
Pizza et al. (2008) & Sudeste & 50 & $66 \%$ \\
Haralambieva et al. & Sul & 10 & $50 \%$ \\
(2004) & & & \\
\hline
\end{tabular}

${ }^{1}$ Refere-se ao número de casos analisados para detecção do EBV

Sandlund et al. (1997), apesar de realizarem a pesquisa de infecção pelo EBV em apenas 11 casos de LB, revisaram 98 casos de LNH 
em crianças e adolescentes do Recife, dos quais 92 eram LB, e concluíram que o LB é o linfoma mais freqüente em crianças do Nordeste do Brasil.

\subsection{Proteínas p53 e p63}

O gene TP53 é um gene supressor tumoral, está localizado no braço curto do cromossomo 17 (17p13) e codifica uma fosfoproteína de $53 \mathrm{Kd}$ que tem papel fundamental na manutenção da integridade do genoma após o dano do DNA, pois bloqueia a célula na fase G1 do ciclo celular, permitindo o reparo ou levando à morte celular por apoptose. Assim, mutações do gene TP53 podem ter conseqüencias importantes para sua função supressora tumoral, permitindo a replicação de células com alterações genéticas (Martinez-Delgado et al., 1997). Alterações do gene TP53 estão presentes em amplo espectro de neoplasias malignas humanas, incluindo neoplasias hematopoiéticas (Wada et al., 1993). Contudo estudos moleculares indicam que mutações do gene TP53 não estão associadas de maneira genérica com os linfomas, mas de forma peculiar com certas entidades, como o LB, síndrome de Richter no linfoma/leucemia linfocítica crônica, LDGCB, além de linfoma de células do manto (Gaidano et al., 1991; Koduru et al., 1997). Mutações do gene TP53 têm sido descritas em $30 \%$ dos LB endêmicos e em cerca de $70 \%$ das linhagens celulares derivadas de LB (Gaidano et al., 1991; Bhatia et al., 1992). A detecção da proteína p53, através de estudo imunoistoquímico, é freqüentemente observada em $\mathrm{LNH}$, 
especialmente nos de alto grau (Villuendas et al., 1992). Todavia, trabalhos têm demonstrado que em alguns LNH de alto grau a expressão imunoistoquímica da proteína p53 não reflete necessariamente a presença de mutação gênica e vice-versa (Klumb et al., 2004; Kocialkowski et al., 1995).

O gene TP63, homólogo aos genes TP53 e TP73, localizase no braço longo do cromossomo 3 (3q27-28), codifica múltiplas isoformas com várias atividades biológicas e, do ponto de vista funcional, apresenta similaridades e diferenças com o gene TP53. A isoforma TAp63 transativa genes alvos do TP53 e induz apoptose, apresentando atividade supressora tumoral. A isoforma $\Delta p 63$, de maneira oposta, apresenta atividades oncogênicas (Nylander et al., 2002; Flores, 2007). Em tecidos normais, a expressão da proteína p63, restrita ao núcleo, é observada no epitélio escamoso, no epitélio transicional, nas células basais da próstata, nas células mioepiteliais da mama, no epitélio reticular do timo e também em subpopulação de linfócitos do centro germinativo de linfonodos (Di Como et al., 2002; Park e Oh, 2005). Nas neoplasias linfóides, a expressão da proteína p63 tem sido descrita em $32 \%$ a $53 \%$ dos casos de LDGCB, em $22 \%$ a $29 \%$ dos linfomas foliculares, em até $44 \%$ dos linfomas anaplásicos de grandes células CD30 positivos, e em casos isolados de linfoma da zona marginal, linfoma/leucemia linfoblástica aguda e linfoma de células T/NK (Di Como et al., 2002; Park e Oh, 2005; Hedvat et al., 2005; Gualco et al., 2008). Há escassas informações na literatura sobre a expressão dessa proteína no 
LB. Park e Oh (2005) avaliaram 3 casos de LB e não observaram expressão para proteína p63.

1.7 Herpesvírus humano 8 (HHV-8)

O Herpesvírus humano 8 (HHV-8), também conhecido como Herpesvírus humano associado ao sarcoma de Kaposi (KSHV) foi identificado em 1994 por Chang et al. e, atualmente, já foi detectado em todas as formas do sarcoma de Kaposi, independente da associação com o HIV. O HHV-8 é um vírus de DNA e pertence à família Herpesviridae, subfamília Gammaherpesvirinae, da qual também fazem partes o EBV e o Herpesvírus saimiri. Os herpesvírus gama são linfotrópicos e promovem o aparecimento de células linfóides atípicas com elevada capacidade de proliferação celular (Cesarman et al., 1996). O genoma do HHV-8 possui 96 seqüencias abertas para leitura (ORF), das quais 13 codificam produtos homólogos a proteínas humanas envolvidas na regulação do ciclo celular, transdução de sinais e inibição da apoptose (Cesarman e Knowles, 1999; Jarviluoma e Ojala, 2006).

Além do sarcoma de Kaposi, o HHV-8 tem sido identificado na doença de Castleman multicêntrica (MCD) (Soulier et al., 1995), no linfoma plasmablástico associado à MCD (Du et al., 2001), na desordem germinotrópica linfoproliferativa (Du et al., 2002), no PEL (Cesarman et al., 1995; Carbone et al., 2000), além de PEL extracavitário (Chadburn et al., 
2004). É importante ressaltar que a co-infecção EBV/HHV-8 é comumente observada nos casos de PEL (Laurent et al., 2008).

Na literatura há poucos estudos analisando a associação do HHV-8 em LB. Em regiões da África nas quais o sarcoma de Kaposi é endêmico e onde são observadas altas taxas de seroprevalência para o HHV-8, Lazzi et al. $(1998,2006)$ estudaram, respectivamente, 29 e 16 casos de LB e Tao e Ambinder (1999) avaliaram 10 casos de LB e não detectaram infecção pelo HHV-8. Mais recentemente, Chuang et al. (2007) também não detectaram infecção por HHV-8 em 28 casos de LB. 


\section{OBJETIVOS}

O presente trabalho tem como objetivos:

1. Avaliar as características clínicas (sexo, idade, localização anatômica, infecção pelo HIV) e morfológicas de um grande número de casos bem caracterizados de LB em pacientes adultos e pediátricos provenientes das 5 regiões geográficas do Brasil;

2. Avaliar a freqüencia de associação com o EBV através de hibridização "in situ" (HIS), bem como realizar a subtipagem do EBV através de PCR;

3. Avaliar, através de estudo imunoistoquímico, a expressão das proteínas p53, p63 e de MUM1/IRF4;

4. Investigar a presença de infecção pelo HHV-8 (KSHV) em casos de linfoma de Burkitt através de estudo imunoistoquímico e de PCR. 


\section{MÉTODOS}

3.1 Seleção de casos e delineamento do estudo

O grupo de estudo incluiu casos consecutivos de LB diagnosticados através de avaliação histopatológica e imunoistoquímica entre junho de 1997 e dezembro de 2007 na Consultoria em Patologia. A Consultoria em Patologia é laboratório de referência em Anatomia Patológica com unidades em São Paulo e Botucatu, SP.

Foram levantados dos arquivos da Consultoria em Patologia 595 casos com diagnóstico de LB ou de LNH de células B de alto grau sendo LB um dos principais diagnósticos diferenciais. Noventa e nove casos foram eliminados devido à indisponibilidade dos blocos de parafina no arquivo. Inicialmente, foram confeccionados 6 blocos de "array" de tecido, com os casos selecionados até maio de 2007, totalizando-se 446 casos. Em seguida, foi realizado estudo imunoistoquímico e após avaliação dos resultados, os casos BCL-2 positivos e/ou CD10 negativos, num total de 135, foram excluídos. Aos 311 casos remanescentes foram acrescidos mais 50 casos, estes selecionados no período de junho a dezembro de 2007 , resultando em 2 blocos adicionais de "array" de tecido. Nestes 361 casos, analisamos o rearranjo do gene $C-M Y C$ através da técnica de FISH. Após a análise dos resultados de FISH foram excluídos outros 127 casos por apresentarem resultados inconclusivos ou inconsistentes com o diagnóstico 
de LB segundo os critérios relatados no item 3.8. Desta forma, a população final, avaliada nesse estudo, corresponde a 234 de LB. A figura 3 apresenta o fluxograma para seleção dos casos.

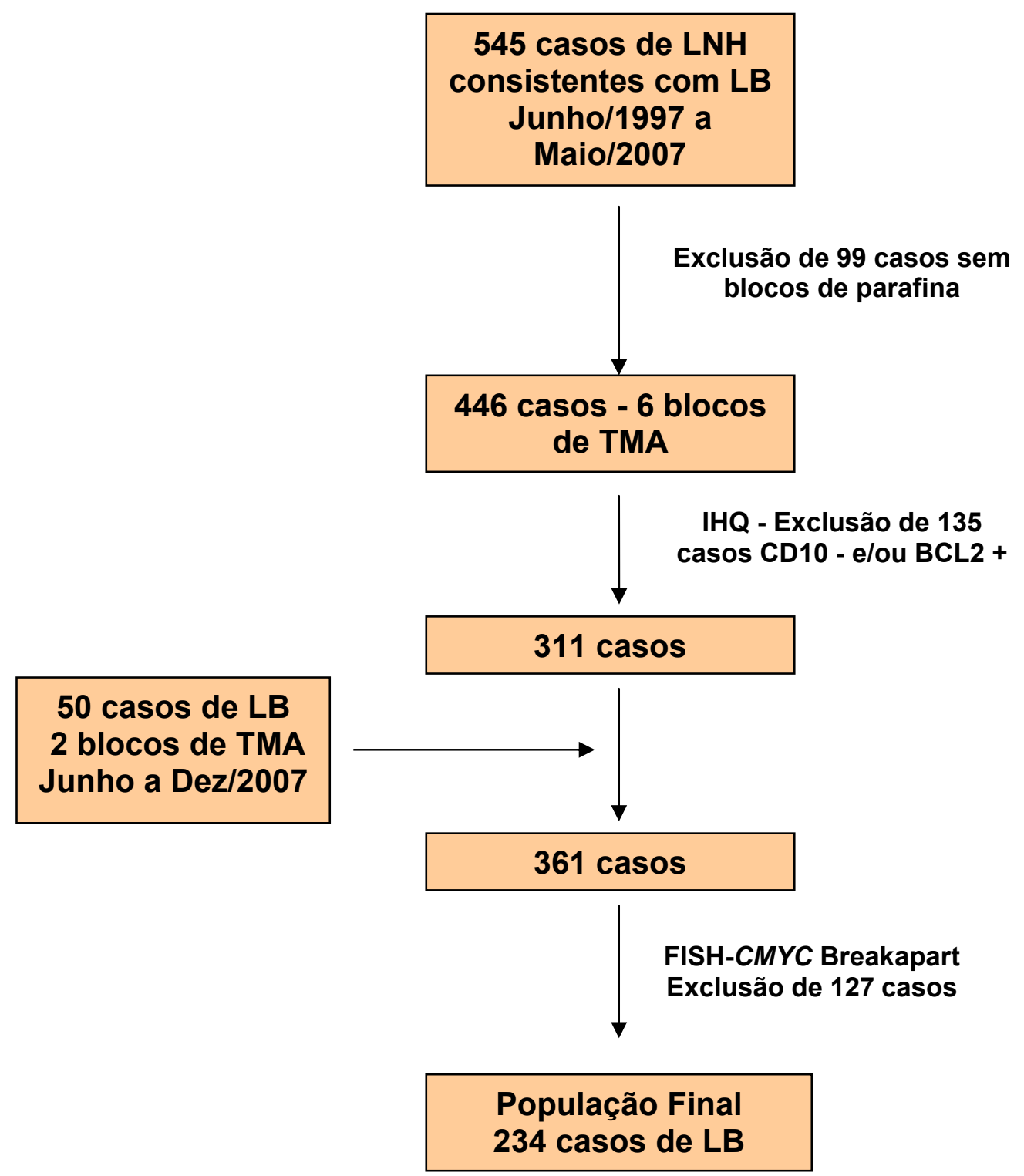

Figura 3. Fluxograma da seleção de casos $\mathrm{IHQ}$, imunoistoquímica 
O presente estudo teve seu Protocolo de Pesquisa (441/05) aprovado pela Comissão de Ética para análise de Projetos de Pesquisa (CAPPesq) em 22 de junho de 2005 (vide Apêndice).

\subsection{Levantamento de informações clínicas}

Informações como sexo, idade do paciente no momento do diagnóstico, localização anatômica da neoplasia, infecção pelo HIV e cidade/estado/região geográfica de procedência, foram obtidas dos relatórios anatomopatológicos, através de contato telefônico e correspondência com os médicos assistentes ou com o patologista consultante. Foram considerados pediátricos os casos com idade até 16 anos $(\leq 16)$ e adultos os casos com idade superior a 16 anos. Para a determinação da região geográfica, consideramos a localização do serviço responsável pelo envio do caso.

\subsection{Avaliação morfológica}

As lâminas histológicas de $3 \mu \mathrm{m}$ de espessura, disponíveis nos arquivos da Consultoria em Patologia, obtidas com micrótomo histológico e coradas em hematoxilina-eosina foram reavaliadas e tiveram áreas selecionadas para a confecção dos blocos de "array" de tecido. 
A subclassificação morfológica de cada um dos casos foi realizada segundo os critérios da OMS (Diebold et al., 2001) que, como descrito anteriormente, reconhece além da forma clássica, duas variantes morfológicas: a) LB atípico/Burkitt-símile; e b) LB com diferenciação plasmacitóide.

3.4 Construção dos blocos de "array" de tecido ("tissue microarray" - TMA)

No total foram construídos 8 blocos de parafina do tipo "array" de tecido (TMA) utilizando-se um "arrayer" de tecido biológico produzido pela Beecher Instruments, Sun Prairie, EUA (Figura 4). Essa técnica permite a inclusão de grande número de casos em um mesmo bloco de parafina, que ficam representados por cilindros de tecidos, cujo diâmetro pode variar de 0,6 a 2,0 mm, espaçados entre si a uma distância de 1,0 mm, tanto na horizontal quanto na vertical. No presente trabalho, cada caso foi representado por 3 cilindros de tecido consecutivos obtidos a partir dos blocos de parafina "doadores" (blocos originais contendo a neoplasia), com diâmetro de 0,6 $\mathrm{mm}$. A retirada dos cilindros do bloco de parafina "doador" e sua inclusão no bloco de parafina "receptor" (bloco de TMA) é realizada com a ajuda de agulhas especiais. Os cilindros ou amostras de todos os casos incluídos no estudo foram distribuídos num total de 8 blocos receptores (Figura 5), numerados de 1 a 8, obedecendo-se ao mapa de TMA (Figura 6). 
A quantidade de casos em cada um dos blocos variou de 19 a 84 . Esse mapa registra a disposição dos casos nos blocos, permitindo a identificação dos mesmos para a interpretação dos resultados. Além dos casos em estudo, cada bloco de TMA também apresentou tecidos-controle adequados para a avaliação dos anticorpos empregados no estudo imunoistoquímico, bem como para as reações de hibridização "in situ" (HIS) e FISH. Dois cilindros de tecido-controle estavam dispostos consecutivamente na linha 8 dos mapas e blocos de TMA. 


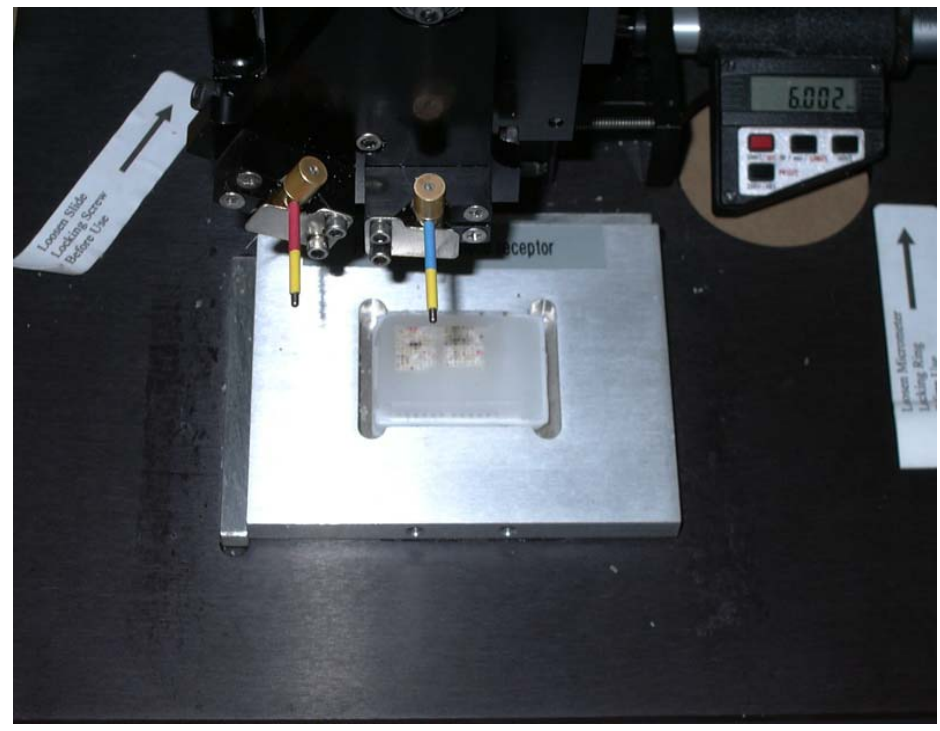

Figura 4. Fotografia do "array" de tecido utilizado na construção dos blocos de TMA

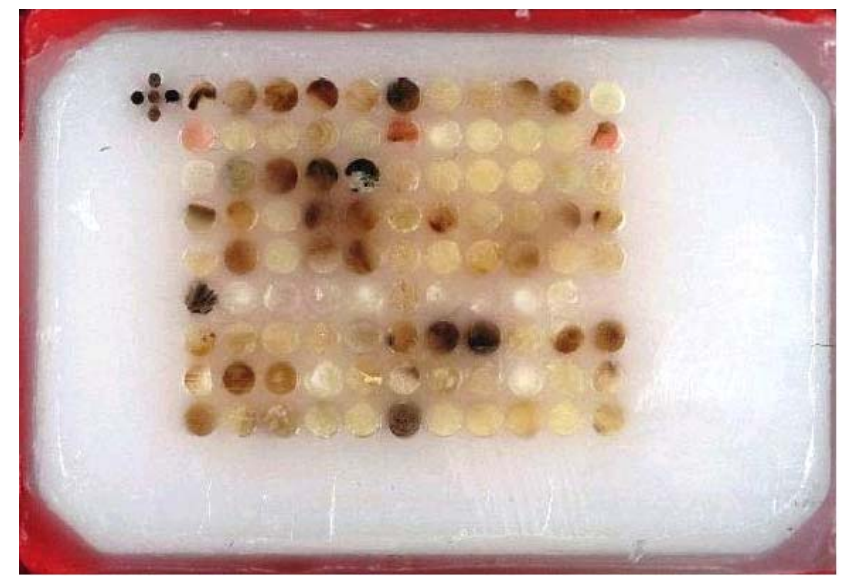

Figura 5. Exemplo de bloco de parafina "receptor" (bloco de TMA) 
Mapa para Tissue microarray (TMA)

\begin{tabular}{|c|c|c|c|c|c|c|c|c|c|c|c|c|c|c|c|c|c|c|c|c|}
\hline \multicolumn{9}{|c|}{ Responsável: } & \multicolumn{9}{|c|}{ Técnico: } & \multicolumn{3}{|c|}{ Data: 23 mair2008 (sex) } \\
\hline \multicolumn{21}{|c|}{ Descriçäo: } \\
\hline \multicolumn{21}{|c|}{ Densidade: } \\
\hline Linha (x) • & A & B & C & D & $\mathrm{E}$ & $F$ & G & H & 1 & $J$ & $\mathbf{K}$ & L & $M$ & $\mathbf{N}$ & 0 & \begin{tabular}{|l|}
$\mathbf{P}$ \\
\end{tabular} & $\mathbf{Q}$ & $\mathbf{R}$ & $\mathbf{s}$ & $\mathrm{T}$ \\
\hline - Columa $(y)$ & $(1,00)$ & $(2,00)$ & $(3,00)$ & $(4,00)$ & $(5,00)$ & $(6,00)$ & $(7,00)$ & $(8,00)$ & $(9,00)$ & $(10,00)$ & $(11,00)$ & $(12,00)$ & $(13,00)$ & $(14,00)$ & $(15,00)$ & $(16,00)$ & $(17,00)$ & $(18,00)$ & $(19,00)$ & $(20,00)$ \\
\hline $01(1,00)$ & - & - & - & $\square$ & - & - & ㅁ & - & - & $\square$ & $\square$ & $\square$ & $\square$ & +1 & $\square$ & $\square$ & $\square$ & $\square$ & $\square$ & $\square$ \\
\hline $02(2,00)$ & $\square$ & $\square$ & $\square$ & $\square$ & $\square$ & $\square$ & $\square$ & $\square$ & $\square$ & $\square$ & $\square$ & $\square$ & $\square$ & $\square$ & $\square$ & $\square$ & $\square$ & $\square$ & $\square$ & $\square$ \\
\hline $03(3,00)$ & $\square$ & $\square$ & $\square$ & $\square$ & $\square$ & $\square$ & $\square$ & $\square$ & $\square$ & $\square$ & $\square$ & $\square$ & $\square$ & $\square$ & $\square$ & $\square$ & $\square$ & E & $\square$ & E \\
\hline \begin{tabular}{|l|l|}
$04(4,00)$ \\
\end{tabular} & $\square$ & $\square$ & 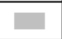 & $\square$ & 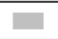 & $\square$ & $\square$ & $\square$ & 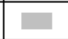 & 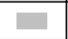 & $\square$ & $\square$ & 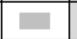 & $\square$ & 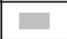 & 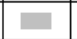 & $\square$ & $\square$ & $\square$ & $\square$ \\
\hline \begin{tabular}{|l|l|}
05 & $(5,00)$ \\
\end{tabular} & $\square$ & $\square$ & $\square$ & $\square$ & $\square$ & $\square$ & $\square$ & $\square$ & $\square$ & 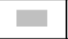 & $\square$ & $\square$ & $\square$ & +1 & $\square$ & $\square$ & 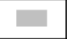 & $\square$ & $\square$ & $\square$ \\
\hline \begin{tabular}{|l|l|}
06 & $(6,00)$ \\
\end{tabular} & $\square$ & $\square$ & $\square$ & $\square$ & $\square$ & $\square$ & $\square$ & $\square$ & $\square$ & $\square$ & $\square$ & $\square$ & $\square$ & $\square$ & $\square$ & $\square$ & $\square$ & $\square$ & 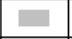 & $\square$ \\
\hline \begin{tabular}{|l|l|}
07 & $(7,00)$ \\
\end{tabular} & 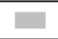 & $\square$ & $\square$ & $\square$ & $\square$ & $\square$ & + & $\square$ & $\square$ & $\square$ & $\square$ & $\square$ & $\square$ & + & $\square$ & 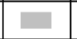 & $\square$ & $\square$ & $\square$ & $\square$ \\
\hline \begin{tabular}{|l|l|}
08 & $(8,00)$ \\
\end{tabular} & $\square$ & $\square$ & $\square$ & $\square$ & $\square$ & $\square$ & $\square$ & $\square$ & $\square$ & 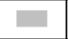 & $\square$ & $\square$ & $\square$ & $\square$ & $\square$ & $\square$ & $\square$ & $\square$ & $\square$ & $\square$ \\
\hline $09(9,00)$ & $\square$ & $\square$ & 1 & $\square$ & $\square$ & $\square$ & $\square$ & $\square$ & $\square$ & $\square$ & $\square$ & $\square$ & $\square$ & $\square$ & $\square$ & $\square$ & - & $\square$ & $\square$ & $\square$ \\
\hline $10(10,00)$ & $\square$ & $\square$ & $\square$ & $\square$ & $\square$ & $\square$ & $\square$ & $\square$ & $\square$ & $\square$ & $\square$ & $\square$ & 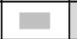 & $\square$ & $\square$ & $\square$ & $\square$ & $\square$ & $\square$ & 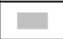 \\
\hline $11(11,00)$ & $\square$ & $\square$ & $\square$ & $\square$ & $\square$ & $\square$ & $\square$ & $\square$ & $\square$ & $\square$ & $\square$ & $\square$ & $\square$ & $\square$ & $\square$ & $\square$ & $\square$ & $\square$ & $\square$ & $\square$ \\
\hline $12(12,00)$ & $\square$ & $\square$ & $\square$ & $\square$ & $\square$ & $\square$ & $\square$ & $\square$ & $\square$ & $\square$ & $\square$ & $\square$ & $\square$ & +1 & $\square$ & $\square$ & + & $\square$ & $\square$ & 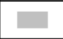 \\
\hline $13(13,00)$ & $\square$ & $\square$ & $\square$ & $\square$ & $\square$ & $\square$ & + & $\square$ & $\square$ & $\square$ & $\square$ & $\square$ & $\square$ & $\square$ & $\square$ & $\square$ & $\square$ & $\square$ & $\square$ & $\square$ \\
\hline $14(14,00)$ & $\square$ & $\square$ & $\square$ & $\square$ & $\square$ & $\square$ & $\square$ & $\square$ & $\square$ & $\square$ & $\square$ & $\square$ & $\square$ & $\square$ & $\square$ & $\square$ & $\square$ & $\square$ & $\square$ & $\square$ \\
\hline $15(15,00)$ & $\square$ & $\square$ & 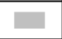 & $\square$ & $\square$ & $\square$ & $\square$ & $\square$ & $\square$ & $\square$ & $\square$ & $\square$ & $\square$ & $\square$ & $\square$ & $\square$ & $\square$ & $\square$ & $\square$ & $\square$ \\
\hline $16(16,00)$ & $\square$ & $\square$ & 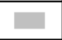 & $\square$ & $\square$ & $\square$ & $\square$ & $\square$ & $\square$ & 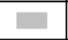 & $\square$ & $\square$ & $\square$ & $\square$ & 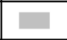 & 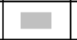 & $\square$ & $\square$ & 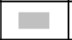 & $\square$ \\
\hline $17(17,00)$ & $\square$ & $\square$ & $\square$ & $\square$ & $\square$ & $\square$ & $\square$ & $\square$ & $\square$ & $\square$ & $\square$ & $\square$ & $\square$ & $\square$ & $\square$ & $\square$ & $\square$ & $\square$ & $\square$ & 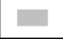 \\
\hline $18(18,00)$ & $\square$ & $\square$ & $\square$ & $\square$ & $\square$ & $\square$ & $\square$ & $\square$ & $\square$ & $\square$ & $\square$ & $\square$ & $\square$ & $\square$ & $\square$ & $\square$ & $\square$ & $\square$ & $\square$ & $\square$ \\
\hline $19(19,00)$ & $\square$ & $\square$ & $\square$ & $\square$ & $\square$ & $\square$ & $\square$ & $\square$ & $\square$ & $\square$ & $\square$ & $\square$ & $\square$ & $\square$ & $\square$ & $\square$ & $\square$ & $\square$ & $\square$ & 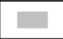 \\
\hline $20(20,00)$ & $\square$ & $\square$ & $\square$ & $\square$ & $\square$ & a & $\square$ & $\square$ & $\square$ & $\square$ & $\square$ & $\square$ & $\square$ & $\square$ & $\square$ & $\square$ & $\square$ & $\square$ & $\square$ & $\square$ \\
\hline
\end{tabular}

Figura 6. Mapa de TMA. Exemplo de mapa utilizado para a orientação da inclusão dos casos nos blocos de TMA e, posteriormente, a identificação dos casos para a interpretação dos resultados obtidos

\subsection{HIS para EBV}

Para a realização da HIS foi utilizada sonda DNA de oligonucleotídeo biotinilado de 30 bases, complementar ao segmento do gene EBER1. Essa região do genoma do EBV é ativamente transcrita (até $10^{7}$ cópias por célula) em células com infecção latente (Glickman et al., 1988). A sonda foi obtida comercialmente da Invitrogen (São Paulo, Brasil) e apresenta a seguinte sequência: 5' AGA CAC CGT CCT CAC CAC CCG GGA CTT GTA 3'. 
Os cortes histológicos de $3 \mu \mathrm{m}$ de todos os blocos de TMA foram colocados sobre lâminas com adesivo poli-D-lisina (Sigma, St. Louis, EUA, Cód. P7886) e mantidos em estufa a $60^{\circ} \mathrm{C}$ por período noturno de aproximadamente 12-18 horas. A seguir, as lâminas foram desparafinadas e hidratadas de maneira rotineira. Seguiu-se a disgestão enzimática com Pronase (Sigma, St. Louis, EUA). Após acréscimo da sonda para detecção do EBV (concentração final: $0,25 \mathrm{ng} / \mu \mathrm{l}$ ), os cortes foram mantidos em câmara úmida a $37^{\circ} \mathrm{C}$ em período noturno de aproximadamente 12-18 horas. A revelação da reação foi realizada utilizando-se solução de $3,3^{\prime}$ diaminobenzidina (DAB, Sigma, St. Louis, EUA, Cód. D5637 1 mg/mL + Tris$\mathrm{HCl} 1 \mathrm{M} \mathrm{pH} 7,4)$, a contracoloração com hematoxilina de Mayer e montagem com resina histológica Permount ${ }^{\circledR}$ (Fischer Scientific, Pittsburgh, EUA, Cód. SP15-500). A leitura das reações foi realizada ao microscópio óptico comum. Células revelando positividade quanto à presença do EBV apresentam marcação nuclear, resultado da precipitação do cromógeno nos sítios de ligação da sonda ao RNA viral. Os controles positivos para a reação foram incluídos nos blocos de TMA e foram representados por um caso de linfoma de Hodgkin clássico e um caso de LB.

3.6 Imunoistoquímica

Para a realização do estudo imunoistoquímico foram obtidos, de cada um dos blocos de TMA, cortes histológicos seriados com espessura 
de $3 \mu \mathrm{m}$, utilizando-se micrótomo histológico. Foi avaliada a expressão imunoistoquímica de CD20, CD3, CD10, CD5, CD23, TdT, do antígeno de proliferação celular Ki-67, PAX-5, LMP-1, MUM1/IRF4, das proteínas BCL-2, BCL-6, p53 e p63 e do antígeno nuclear associado à latência (LANA-1) do HHV-8.

Os cortes histológicos foram dispostos em lâminas de vidro previamente tratadas com o adesivo poli-D-lisina (Sigma, St. Louis, EUA, Cód. P7886) e mantidos a $60^{\circ} \mathrm{C}$ em estufa por 4 horas. A seguir, foi realizada a desparafinação com banhos sucessivos de xilol, passagem em álcool etílico absoluto e lavagem com solução salina tamponada (PBS), com bloqueio da atividade endógena com solução de $\mathrm{H}_{2} \mathrm{O}_{2}$ à $3 \%$. Os métodos de recuperação de epítopos utilizados variaram de acordo com o antígeno em investigação: pelo calor em panela de pressão (proteínas p53 e p63, antígeno de proliferação celular Ki-67, LANA-1 e TdT), forno de microondas caseiro (CD20, CD5, CD23 e BCL-2), vaporizador (CD3, CD10, PAX-5, LMP1 e MUM1/IRF4) ou por método enzimático (tripsina $0,1 \%$ para proteína BCL-6). Para os marcadores CD20, CD3, CD10, CD5, CD23, LMP-1, antígeno Ki-67, BCL-2, proteínas p53 e p63, LANA-1 e MUM1/IRF4, as lâminas foram incubadas em solução de citrato $0,01 \mathrm{M}$ pH 6,0 e para TdT as lâminas foram incubadas em solução de EDTA $0,001 \mathrm{M}$ pH 8,0. Após a recuperação dos epítopos, as lâminas foram incubadas com os anticorpos primários em período noturno de aproximadamente $12-18$ horas à $4^{\circ} \mathrm{C}$ na diluição apropriada. Após nova lavagem em PBS, foram incubadas por 60 minutos com os respectivos anticorpos secundários. Seguiu-se a utilização 
dos sistemas de detecção conforme instruções do fabricante (Novolink Polímero, Novocastra, Newcastle upon Tyne, Reino Unido, Cód. 7161, para CD10, antígeno de proliferação celular Ki-67, PAX-5, LMP-1, MUM1/IRF4, BCL-6 e proteína LANA-1 do HHV-8; ABC Elite, Vector, Burklingame, EUA, Cód. PK-6100, para CD20, CD3, CD5, CD23 e BCL-2; Envision Rabbit, DAKO, Carpinteria, EUA, Cód. K4003 para TdT; e Envision Mouse, DAKO, Carpinteria, EUA, Cód. K4001, para proteínas p53 e p63). A finalização foi feita com tratamento por solução de 3,3' diaminobenzidina (DAB, Sigma, St. Louis, EUA, Cód. D5637 $1 \mathrm{mg} / \mathrm{mL}$ + Tris-HCl 1M pH 7,4) acrescida de $\mathrm{H}_{2} \mathrm{O}_{2}$ (concentração final $0,2 \%$ ), contracoloração com hematoxilina de Mayer e montagem com resina histológica Permount ${ }^{\circledR}$ (Fischer Scientific, Pittsburgh, EUA, Cód. SP15-500). Os detalhes sobre estes antígenos/anticorpos secundários, diluição e fabricantes estão especificados na Tabela 3.

Os resultados foram avaliados em microscópio óptico comum. Todas as imunocolorações empregadas, com exceção da proteína p63, MUM1/IRF4 e LANA-1, foram interpretadas como positivas ou negativas (positiva se $>10 \%$ das células neoplásicas apresentassem imunocoloração acastanhada na localização antigênica esperada para o anticorpo utilizado). Em relação à proteína p63, um caso foi considerado positivo quando $>5 \%$ das células neoplásicas expressaram o marcador. Os casos foram divididos em quatro grupos de acordo com a quantidade de células positivas: escore 0 (negativo; $<5 \%$ ), escore $1+(>5$ até $10 \%)$, escore $2(>10$ até $50 \%)$ e escore $3+(>50 \%)$, de acordo com Gualco et al. (2008). A avaliação do índice de proliferação celular pelo antígeno Ki-67 foi 
determinada pela semiquantificação em porcentagem (\%) de núcleos de células neoplásicas imunocoradas, variando de 0 a 100\%. Para o marcador LANA-1, consideramos positivo o padrão nuclear granular (puntiforme) característico. Em relação ao MUM1/IRF4, um caso foi considerado positivo quando >20\% das células neoplásicas apresentaram marcação nuclear.

Os tecidos-controle incluídos nos blocos de TMA foram: tonsilas palatinas com hiperplasia linfóide folicular reativa, para os marcadores CD20, CD3, CD10, CD5, CD23, BCL-6, BCL-2, antígeno Ki-67, PAX-5, MUM1/IRF4 e proteína p63 (epitélio escamoso da tonsila); um caso de linfoma linfoblástico, para TdT; um caso de linfoma de Hodgkin clássico (EBV positivo), para LMP-1 e um caso de LB (EBV positivo). Para a avaliação das proteínas p53 e LANA-1 foram utilizados como controle, respectivamente, um caso de carcinoma ductal invasivo da mama positivo para p53 e um caso de sarcoma de Kaposi, estes não incluídos nos blocos de TMA. 
Tabela 3 - Especificações dos antígenos, clones dos anticorpos primários, suas diluições e respectivos fabricantes empregados no estudo imunoistoquímico

\begin{tabular}{|c|c|c|c|}
\hline ANTÍGENO & CLONE & DILUIÇÃO & FABRICANTE \\
\hline CD20 & L26 & $1: 1.200$ & DAKO \\
\hline CD3 & SP7 & $1: 200$ & Neomarkers \\
\hline CD10 & $56 \mathrm{C} 6$ & $1: 100$ & Novocastra \\
\hline BCL-6 & PG-B6P & $1: 100$ & DAKO \\
\hline BCL-2 & 124 & $1: 400$ & DAKO \\
\hline Ki-67 & MIB-1 & $1: 4.800$ & DAKO \\
\hline TdT & Polyclonal & $1: 1.600$ & DAKO \\
\hline PAX-5 & 24 & $1: 400$ & Neomarkers \\
\hline LMP-1 & CS1-4 & $1: 500$ & DAKO \\
\hline CD5 & $4 C 7$ & $1: 150$ & Novocastra \\
\hline CD23 & SP23 & $1: 400$ & Neomarkers \\
\hline MUM1/IRF4 & MUM1P & $1: 1.200$ & DAKO \\
\hline Proteína p53 & DO-7 & $1: 2.000$ & DAKO \\
\hline Proteína p63 & $4 \mathrm{~A} 4$ & $1: 300$ & Neomarkers \\
\hline LANA-1 & LN-53 & $1: 30.000$ & Ad. Biotechnologies \\
\hline
\end{tabular}

Ad: advanced

DAKO (Carpinteria, EUA); Neomarkers/Lab Vision (Fremont, EUA); Novocastra (Newcastle upon Tyne, Reino Unido); Advanced Biotechnologies (Columbia, EUA). 


\subsection{PCR}

\subsubsection{Extração do DNA}

Foram obtidos cortes do tecido fixado em formalina e incluído em parafina, utilizando-se micrótomo histológico (exclusivo para processamento de amostras para PCR), tomando-se todos os cuidados necessários para se evitar contaminação cruzada. Os cortes foram acondicionados em tubos de microcentrífuga devidamente identificados, sendo então submetidos à desparafinação em banhos repetidos com xilol, desidratação com etanol $100 \%$ e secagem do material em banho seco. A digestão do material e purificação do DNA foi realizada conforme Howe et al. (1997).

A qualidade do DNA extraído foi avaliada através de PCR, utilizando-se um conjunto de iniciadores-controles que amplificam produtos de 100, 200,300, 400 e até 600 pares de bases (bp), dependendo da integridade do DNA obtido, segundo van Dongen et al. (2003). 


\subsubsection{Detecção do HHV-8}

A pesquisa de infecção pelo HHV-8, através de $P C R$, foi realizada em 32 casos de LB, sendo 9 HIV positivos e 23 HIV negativos. Dos 32 casos estudados, 13 foram EBV positivos.

Para a detecção do HHV-8 utilizou-se iniciador KS330 (sense AGCCGAAAGGATTCCACCAT e anti-sense TCCGTGTTGTCTACGTCCAG), previamente descrito na literatura (Chang et al., 1994), cujo "amplicon" corresponde a um segmento de 233 pb da seqüência aberta para leitura 26 (ORF26). Para cada reação foi considerado um volume de $25 \mu \mathrm{L}$ contendo uma mistura de $100 \mathrm{ng}$ de DNA do caso em estudo, $0,3 \mu \mathrm{mol} / \mathrm{L}$ do iniciador $\mathrm{KS} 330,0,2 \mathrm{mmol} / \mathrm{L}$ de $\mathrm{dNTP}, 2,5 \mu \mathrm{L}$ de tampão, 1,25 U de Platinum Taq DNA polimerase (Invitrogen, Carlsbad, EUA) e $3,0 \mathrm{mmol} / \mathrm{L}$ de $\mathrm{MgCl}_{2}$. A PCR foi iniciada em termociclador $\mathrm{MJ}$ Research PTC-200 (Global Medical Instruments, Ramsey, EUA), com desnaturação inicial a $95^{\circ} \mathrm{C}$ por 2 minutos, 35 ciclos de 30 segundos a $93^{\circ} \mathrm{C}$, anelamento a $60^{\circ} \mathrm{C}$ por 25 segundos, extensão a $72{ }^{\circ} \mathrm{C}$ por 30 segundos, com extensão final a $72{ }^{\circ} \mathrm{C}$ por 5 minutos, conforme Pak et al. (2005).

Os controles positivos utilizados foram: caso de sarcoma de Kaposi e caso de LNH de imunofenótipo B (não Burkitt) associado ao HIV. 


\subsubsection{Subtipagem do EBV}

A subtipagem do EBV, através da amplificação da região EBNA2 do genoma viral, foi realizada nos 123 casos de LB-EBV positivos pela ISH. Foram utilizados dois iniciadores na região EBNA2 (E2 "up" 5'AGGCTGCCCACCCTGAGGAT-3" e "low" E2 5'GCCACCTGGCAGCCCTAAAG-3'), permitindo a amplificação de produto de 170 pb para o EBV do tipo A e de 186 pb para o EBV do tipo B. Alguns casos foram submetidos à reação de PCR "semi-aninhado" (seminested PCR) utilizando-se os iniciadores E2 "up" e E2R “low" (5'GCTGCCACCTGGCGGAAT-3') permitindo a amplificação de produtos de $111 \mathrm{pb}$ e de 127 pb para os tipos A e B de EBV, respectivamente. Para cada reação foi considerado um volume de $25 \mu \mathrm{L}$ contendo uma mistura de 100 ng de DNA do caso em estudo, 0,2 $\mu \mathrm{mol} / \mathrm{L}$ dos iniciadores, $0,2 \mathrm{mmol} / \mathrm{L}$ de dNTP, 2,5 $\mu \mathrm{L}$ de tampão, 1,25 U de Platinum Taq DNA polimerase (Invitrogen, Carlsbad, EUA) e 1,5 mmol/L de $\mathrm{MgCl}_{2}$. A PCR foi iniciada em termociclador MJ Research PTC-200 (Global Medical Instruments, Ramsey, EUA), com desnaturação inicial a $96^{\circ} \mathrm{C}$ por 2 minutos, seguidos de 35 ciclos de amplificação (30 segundos a $96^{\circ} \mathrm{C}, 30$ segundos a $60^{\circ} \mathrm{C}$ e 1 minuto a $72^{\circ} \mathrm{C}$ ), com extensão final a $72^{\circ} \mathrm{C}$ por 10 minutos, conforme Araujo et al. (1996).

Todas as reações foram analisadas em corrida eletroforética em gel de poliacrilamida $7 \%$ corado pelo método de impregnação pela prata. 


\subsection{FISH}

A técnica de FISH foi empregada para a detecção de rearranjo no gene C-MYC (8q24) em cada um dos blocos de TMA utilizandose o sistema de detecção LSI ${ }^{\circledR}$ MYC Dual Color Break Apart Rearrangement Probe, Cód. 32-191096 (Vysis, Abbott Molecular, EUA), que é constituído por 2 sondas separadas ( $5^{\prime}$ SpectrumOrange ${ }^{\mathrm{TM}}$ e $3^{\prime}$ SpectrumGreen $^{\mathrm{TM}}$ ) que abrangem as regiões de quebra comuns no LB (Figura 7).

Cortes de $3 \mu \mathrm{m}$ de espessura, obtidos por micrótomo histológico a partir de blocos de TMA, foram dispostos em lâminas de vidro e submetidos, nessa ordem, à desparafinação em xilol, hidratação em álcool etílico absoluto, tratamento ácido em $0,2 \mathrm{~N} \mathrm{HCl}$, lavagem em água, prétratamento com tiocionato de sódio $8,1 \%$, lavagem em água e solução de cloreto de sódio $3 \mathrm{M}+$ citrato de sódio $0,3 \mathrm{M}(\mathrm{pH} 5,3)$, digestão enzimática em pepsina $0,8 \%$ e lavagem em água e solução de cloreto de sódio $3 \mathrm{M}+$ citrato de sódio $0,3 \mathrm{M}(\mathrm{pH} \mathrm{5,3)}$. A seguir, adicionou-se a sonda de forma a cobrir toda a superfície do corte histológico de TMA representado na lâmina, com colocação posterior da lamínula. As lâminas foram submetidas, então, ao processo de desnaturação e hibridização pelo calor por período noturno de aproximadamente 12-18 horas após a incubação com a sonda. No dia seguinte, as lâminas foram lavadas em solução de cloreto de sódio $3 \mathrm{M}+$ citrato de sódio 0,3 M (pH 5,3) e as lamínulas retiradas. A seguir, as lâminas foram lavadas em solução pós-hibridização pré-aquecida, constituída por cloreto de sódio $3 \mathrm{M}+$ citrato de sódio 0,3 M (pH 5,3) e NP-40 0,3\% (Cód. 
30-804820, Vysis, Abbott Molecular, Des Plaines, EUA), contracoradas com DAPI em "Fluorguard Anfitade" (Cód. F201/F202 e Cód. F001, Insitus, Albuquerque, EUA) e montadas com lamínula.

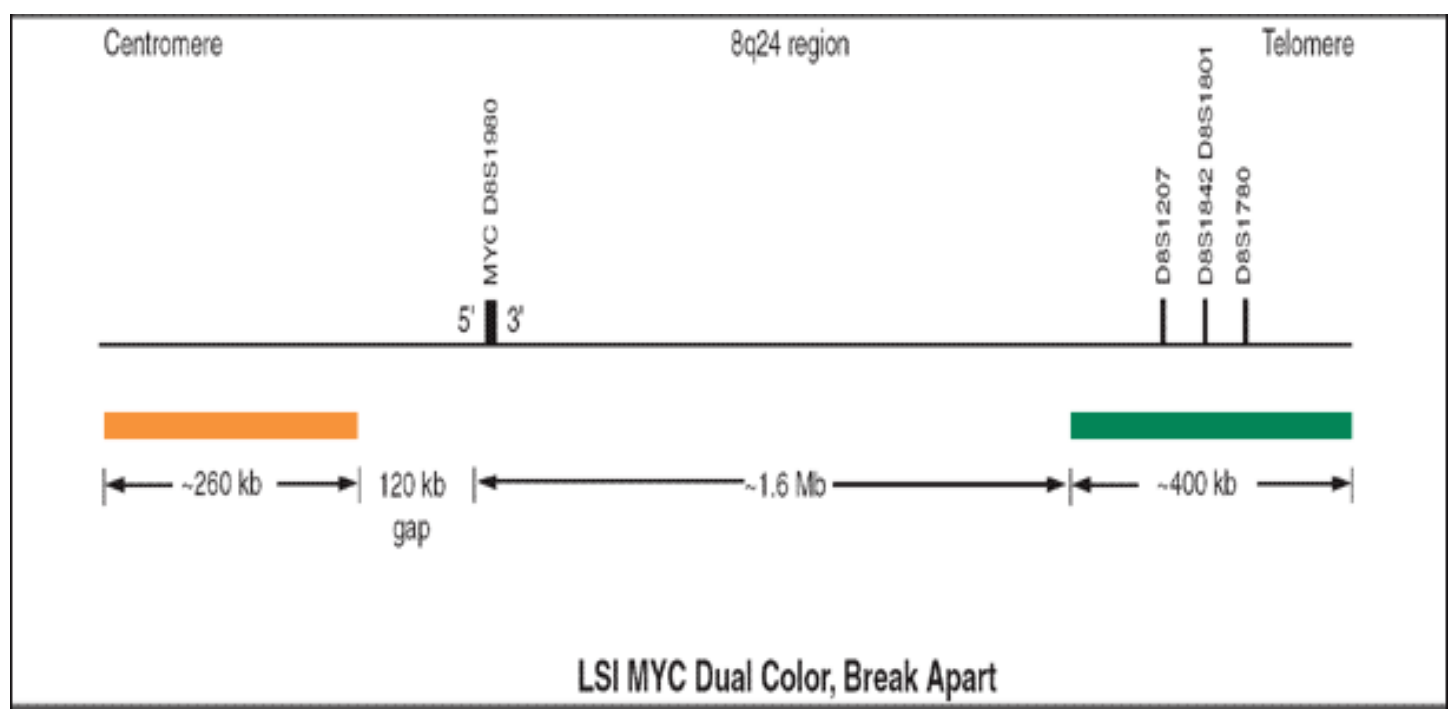

Figura 7. Mapa da sonda LSI ${ }^{\circledR}$ MYC Dual Color Break Apart Rearrangement Probe (Vysis, Abbott Molecular) utilizada no FISH. Fonte: http://www.abbottmolecular.com/LSIMYCDualColorBreakApartRearrangeme ntProbe_5405.aspx

A análise morfométrica quantitativa foi realizada em um microscópio de fluorescência Zeiss Axio Imager M1 (Carl Zeiss AG, Alemanha) com filtros apropriados para o espectro dos sinais observados (Chroma Technology $\mathrm{GmbH}$, Alemanha), acoplado a um computador PC (Dell Optiplex, EUA) com os programas Isis e Metafer 4 (Metasystems, Altlussheim, Alemanha) (Figuras 8 e 9). Dessa forma, uma célula normal, sem rearranjo envolvendo o gene $C-M Y C$, apresenta dois sinais verdes e dois sinais laranjas fusionados (Figuras 10A). Por sua vez, uma célula com ponto de quebra no gene $C-M Y C$, como no LB, caracteriza-se por apresentar 
um sinal verde separado de um sinal laranja e um sinal verde e um sinal laranja unidos (figura 10B). O sistema Metasystems tem a habilidade de analisar a distância 3D entre estes sinais e os quadrados ("tiles") que apresentam a separação entre um sinal verde e laranja com distância maior do que 10 pixels são considerados positivos e a porcentagem desses quadrados ("tiles") é calculada e comparada com o grupo controle. Neste estudo, foram utilizadas como controles tonsilas palatinas sem o rearranjo em questão. Assim, um caso é considerado positivo para a presença do rearranjo do gene C-MYC quando a porcentagem de quadrados ("tiles") positivos calculada é 3 vezes superior à média do grupo controle negativo. A média do grupo controle negativo foi de $0,73 \%$. Portanto, o ponto de corte estabelecido no estudo foi de $2,19 \%$.

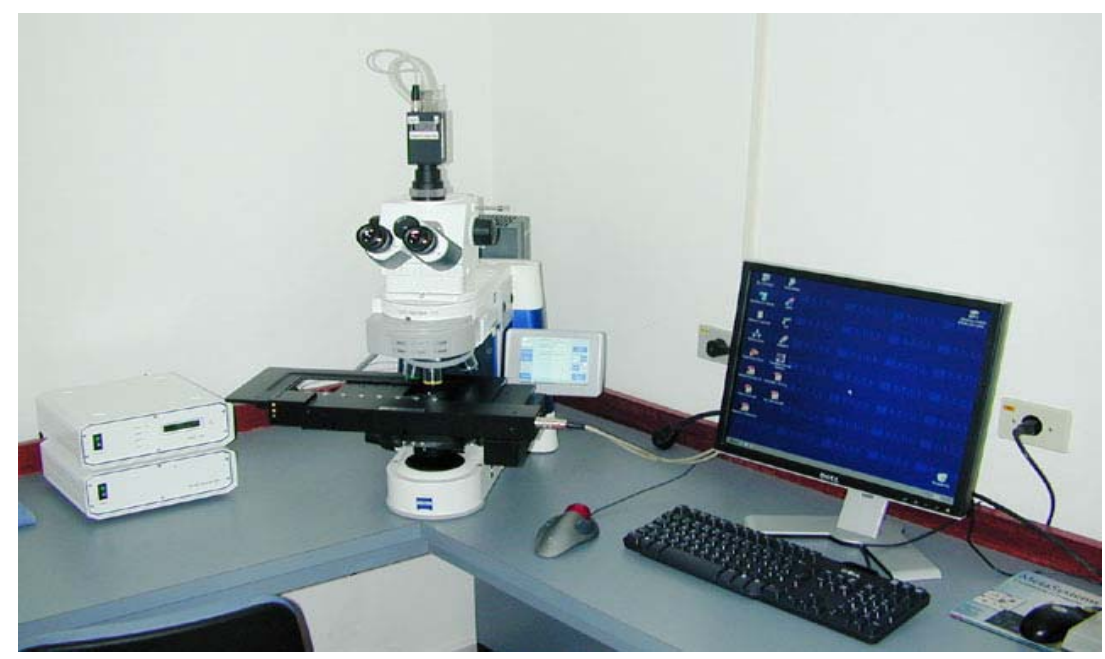

Figura 8. Fotografia do sistema Zeiss-Metasystems utilizado para a análise dos resultados do FISH 


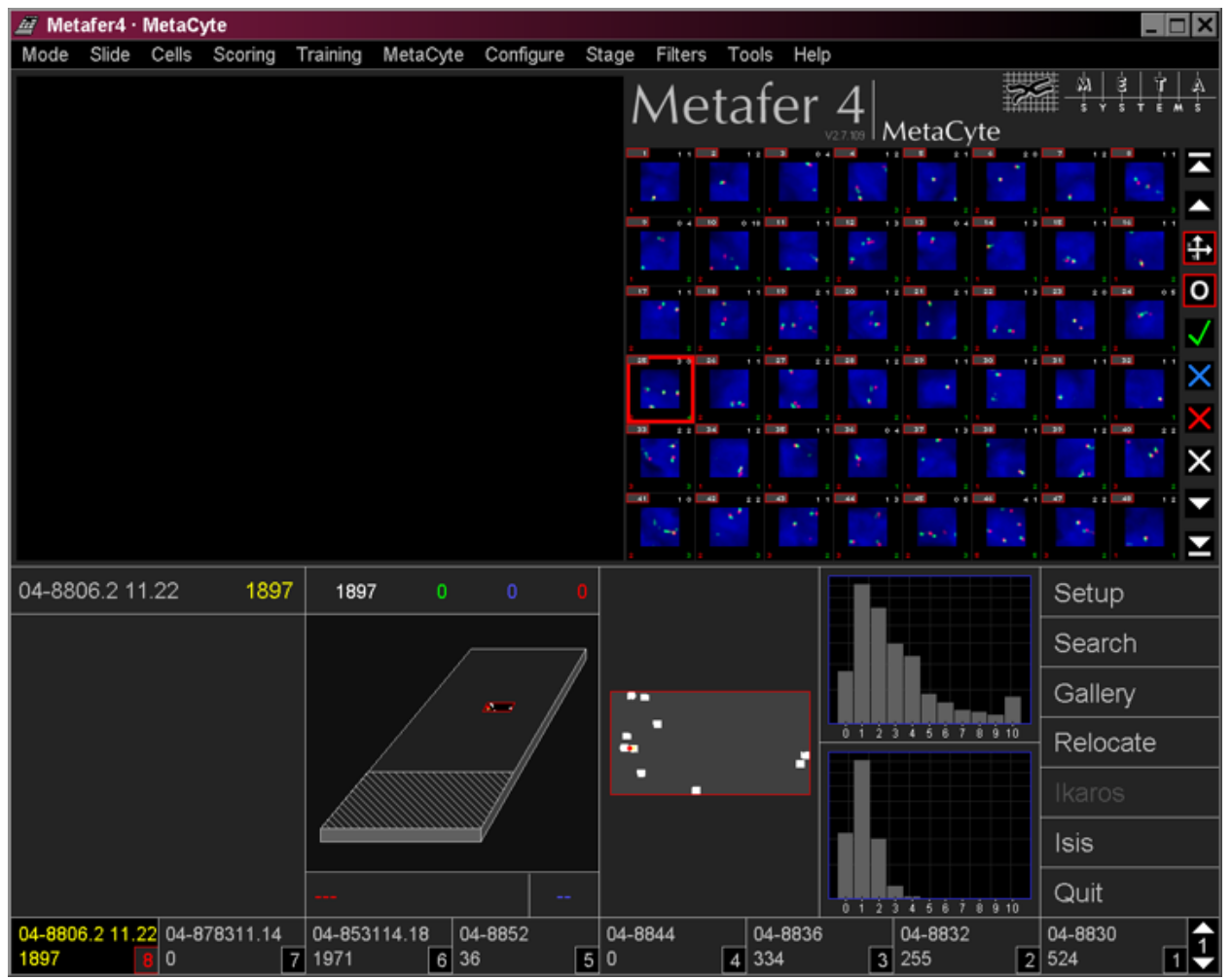

Figura 9. Fotografia da tela do programa Metafer 4, utilizado para quantificação dos sinais fluorescentes na técnica de FISH
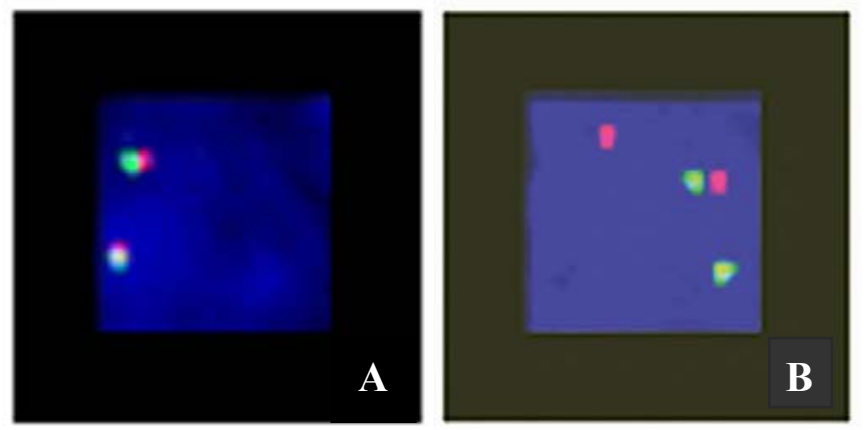

Figura 10. Fotomicrografias de casos avaliados com a sonda $\mathrm{LSI}^{\circledR} \mathrm{MYC}$ Dual Color Break Apart Rearrangement Probe. A: controle negativo (tonsila palatina) apresentando sinais verdes e laranjas unidos. B: caso de LB apresentado um sinal verde e um sinal laranja separados e fusão de sinal verde com sinal laranja, indicando a presença de rearranjo do gene $C-M Y C$ 
3.9 Análise dos resultados

As médias de idade em cada uma das regiões geográficas foram comparadas utilizando a técnica de Análise de Variância, com estatística F-Fischer. Quando foi detectada diferença significativa, intervalos simultâneos de Bonferroni foram ajustados para identificação de diferenças significativas entre as médias. O coeficiente utilizado foi de 95\%.

A associação entre duas variáveis foi avaliada através da estatística Qui-quadrado de Pearson. O nível de significância adotado nesse estudo foi de $5 \%$. Para todos os testes, o nível descritivo foi calculado e apresentado, possibilitando identificar os casos onde há forte indício de associação (Sankoh et al., 1997).

Um modelo de regressão logística multinomial (MRLM) foi ajustado para avaliação dos casos de LB associados ao HIV, considerando o estado de portador do HIV como variável resposta, a idade como co-variada e o sexo e infecção pelo EBV como fatores fixos. 


\section{RESULTADOS}

\subsection{Características clínicas}

Dos 234 casos de LB selecionados para o estudo, 173 $(73,9 \%)$ foram do sexo masculino e $61(26,1 \%)$ foram do sexo feminino. $A$ razão entre sexo masculino/feminino foi de 2,8:1. A idade ao diagnóstico variou de 7 meses até 81 anos, com idade média de 19,1 e mediana de 11 anos. Em 3 casos $(1,3 \%)$ a idade foi desconhecida. Não foi observada diferença significante nas médias das idades com relação ao sexo. A distribuição dos casos segundo a idade é apresentada na figura 11. Em relação à faixa etária, 143 casos $(61,1 \%)$ foram classificados como pertencentes ao grupo pediátrico (com idade até 16 anos) e 88 casos $(37,6 \%)$ foram classificados como adultos (idade superior a 16 anos). 


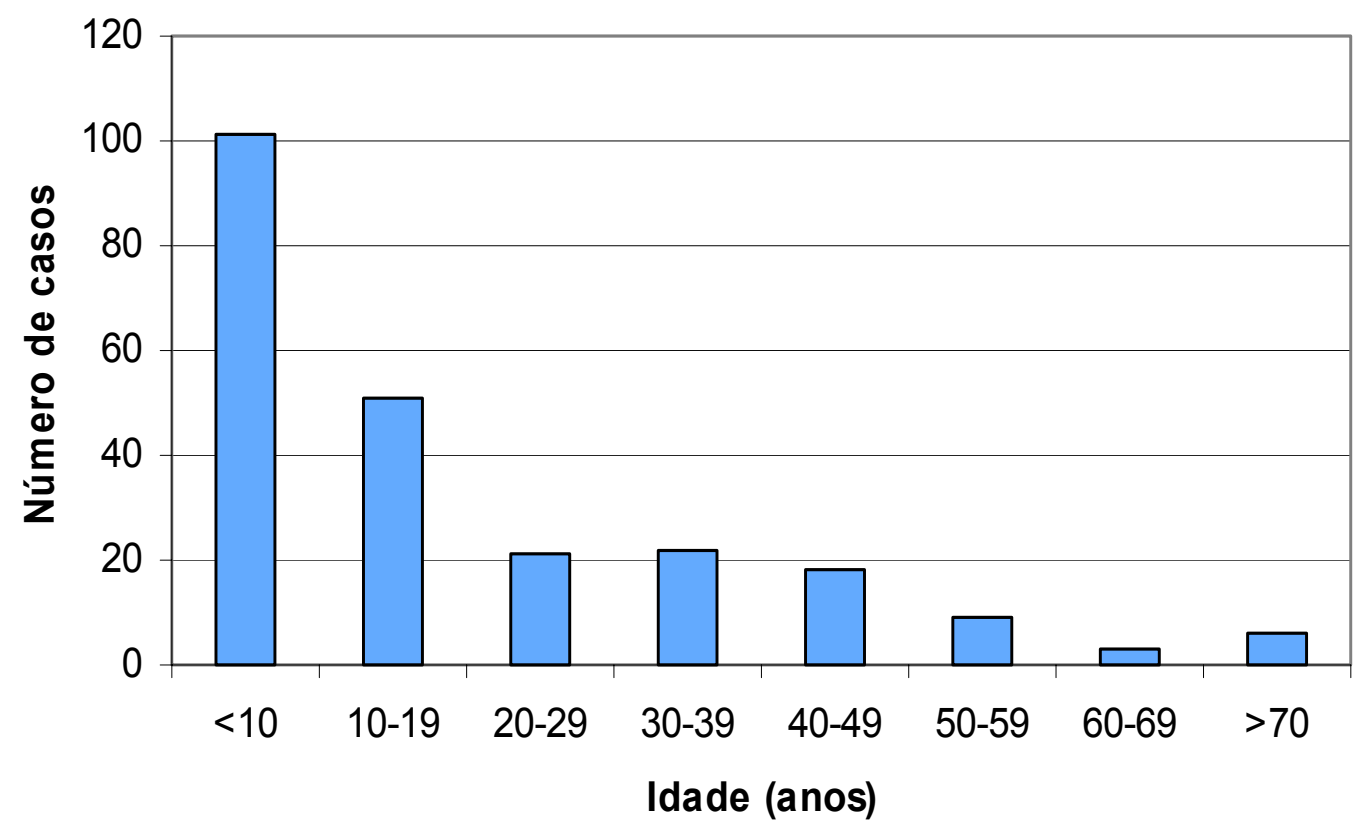

Figura 11. Distribuição dos casos segundo a idade

Em relação à localização anatômica, apresentação extranodal foi observada em 159 casos (68\%), enquanto que envolvimento linfonodal como manifestação inicial foi verificado em 67 casos (28,6\%); a localização anatômica não esteve disponível em 8 casos (3,4\%). Nos casos com topografia extranodal, a localização mais freqüente foi o trato gastrintestinal (59 casos), sendo 54 casos intestinais e 5 casos com acometimento gástrico. Quarenta e nove casos foram referidos como tumor abdominal extranodal sem outra especificação (SOE). Envolvimento hepático, de orofaringe/nasofaringe, ossos da face (maxila/mandíbula), ovários e do sistema nervoso central foi observado em 7, 6, 5, 4 e 2 casos, respectivamente. Nos casos com apresentação nodal, os sítios mais comuns 
de envolvimento foram linfonodos cervicais (32 casos) e da região axilar (15 casos). As figuras 12 e 13 ilustram as freqüencias de LB em relação às localizações anatômicas extranodal e nodal, respectivamente.

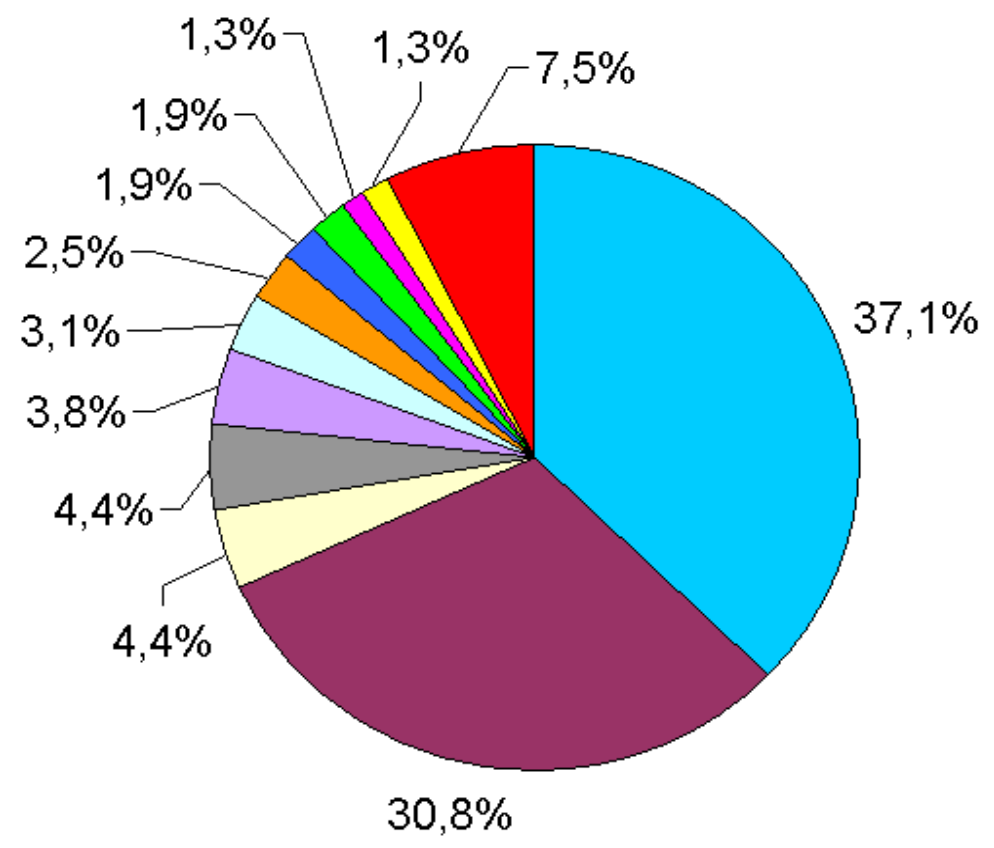

- Trato gastrintestinal

- Tumor abdominal SOE Fígado

- Mesentério

- Orofaringe/nasofaringe Maxila/mandíbula
- Ovário

- Tonsila palatina

- Glândula tireóide

- Sistema nervoso central Região pélvica

- Outras localizações*

*Refere-se a locais com apenas 1 ocorrência: mama, região escrotal, couro cabeludo, glândula salivar, vértebra, parede torácica, palato, omento, pâncreas, bochecha, região para-ovariana e fossa ilíaca

Figura 12. Distribuição das diferentes localizações anatômicas dos casos de LB com apresentação extranodal 


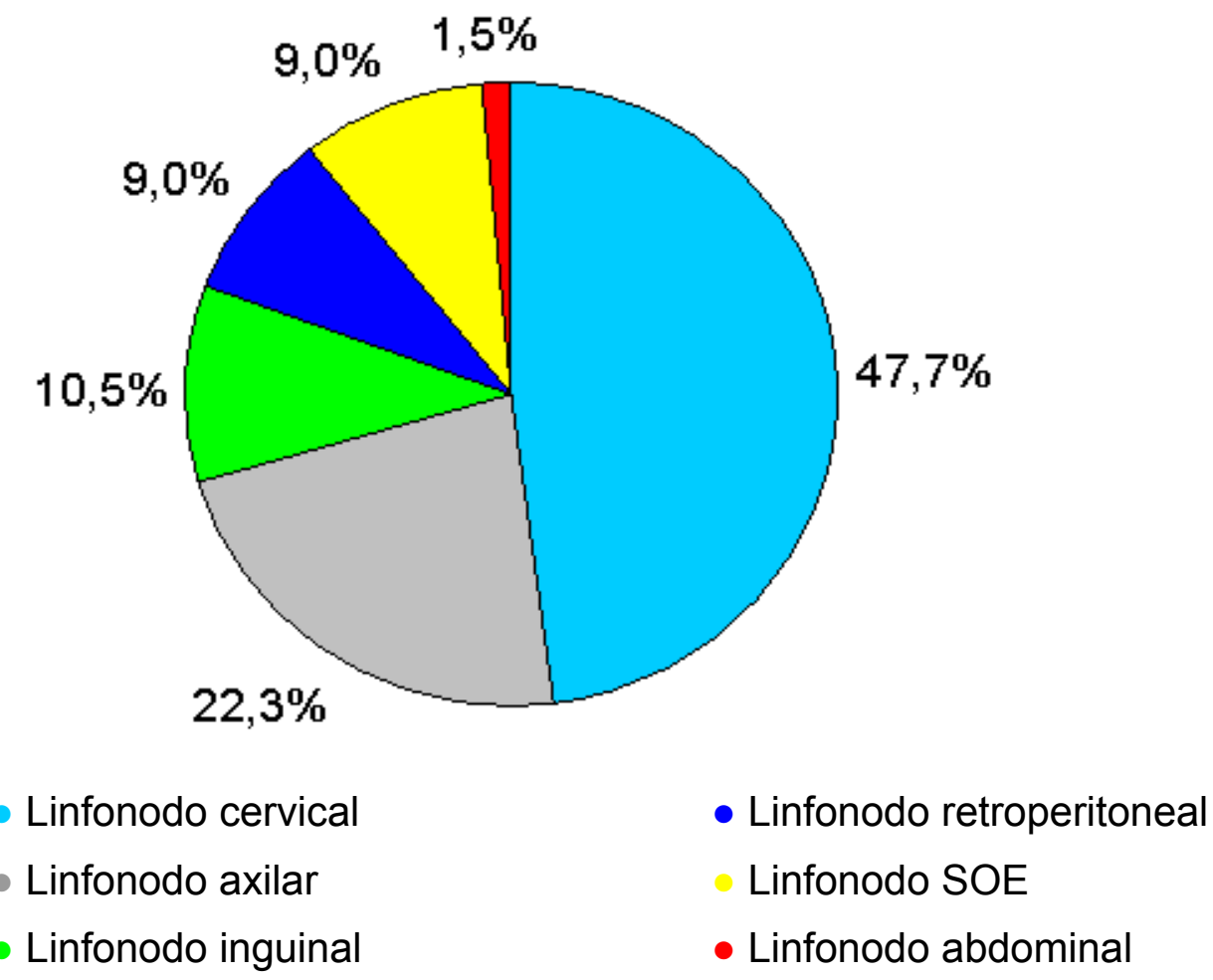

Figura 13. Distribuição das diferentes localizações anatômicas dos casos de LB com apresentação nodal

Na população pediátrica a localização extranodal foi a mais freqüentemente encontrada, enquanto que na população adulta houve tendência de comprometimento nodal. A Tabela 4 mostra a distribuição das localizações anatômicas dos LB nos grupos pediátrico e adulto.

Tabela 4 - Distribuição das localizações anatômicas dos LB nos grupos pediátrico e adulto

\begin{tabular}{lcc}
\hline TOPOGRAFIA & LB PEDIÁTRICO & LB ADULTO \\
\hline Extranodal & $113(79 \%)$ & $43(48,9 \%)$ \\
Nodal & $23(16,1 \%)$ & $44(50 \%)$ \\
Desconhecida & $7(4,9 \%)$ & $1(1,1 \%)$ \\
TOTAL & $143(100 \%)$ & $88(100 \%)$ \\
\hline
\end{tabular}


4.1.1 Características clínicas nas diferentes regiões geográficas do Brasil

Foram analisados casos de LB provenientes das 5 regiões geográficas do Brasil, assim distribuídos: 17 da região Centro-Oeste, 17 da região Norte, 42 da região Sul, 72 da região Sudeste e 86 da região Nordeste.

As características clínicas, incluindo distribuição por sexo, faixa etária (adulto/pediátrico), idade média, mediana de idade e localização anatômica, nas diferentes regiões geográficas, estão resumidas na tabela 5 e na figura 15. A figura 15 apresenta ainda a distribuição dos casos com relação à localização anatômica (nodal/extranodal) nos grupos de pacientes adultos e pediátricos em cada uma das regiões geográficas. Nas regiões Sul e Centro-Oeste o número de pacientes adultos foi superior ao número de casos pediátricos e essas duas regiões apresentaram, conseqüentemente, as maiores média e mediana da idade. Além disso, somente nestas duas regiões geográficas, a localização extranodal, na população adulta, foi superior ao número de casos com envolvimento nodal.

O teste comparativo das médias de idade das 5 regiões geográficas apresentou estatística igual a $\mathrm{F}_{(4,230)}=6,012$ com $p<0,001$. Os intervalos simultâneos de Bonferroni nos permitem inferir que a média de idade para a região Norte foi significativamente inferior às observadas nas regiões Sul e Centro-Oeste. A região Sul apresentou média de idade 
superior às das regiões Norte, Nordeste e Sudeste, podendo ser considerada equivalente à região Centro-Oeste. A figura 14 apresenta as médias de idade por região e respectivos intervalos de confiança de Bonferroni elaborados com coeficiente de $95 \%$.

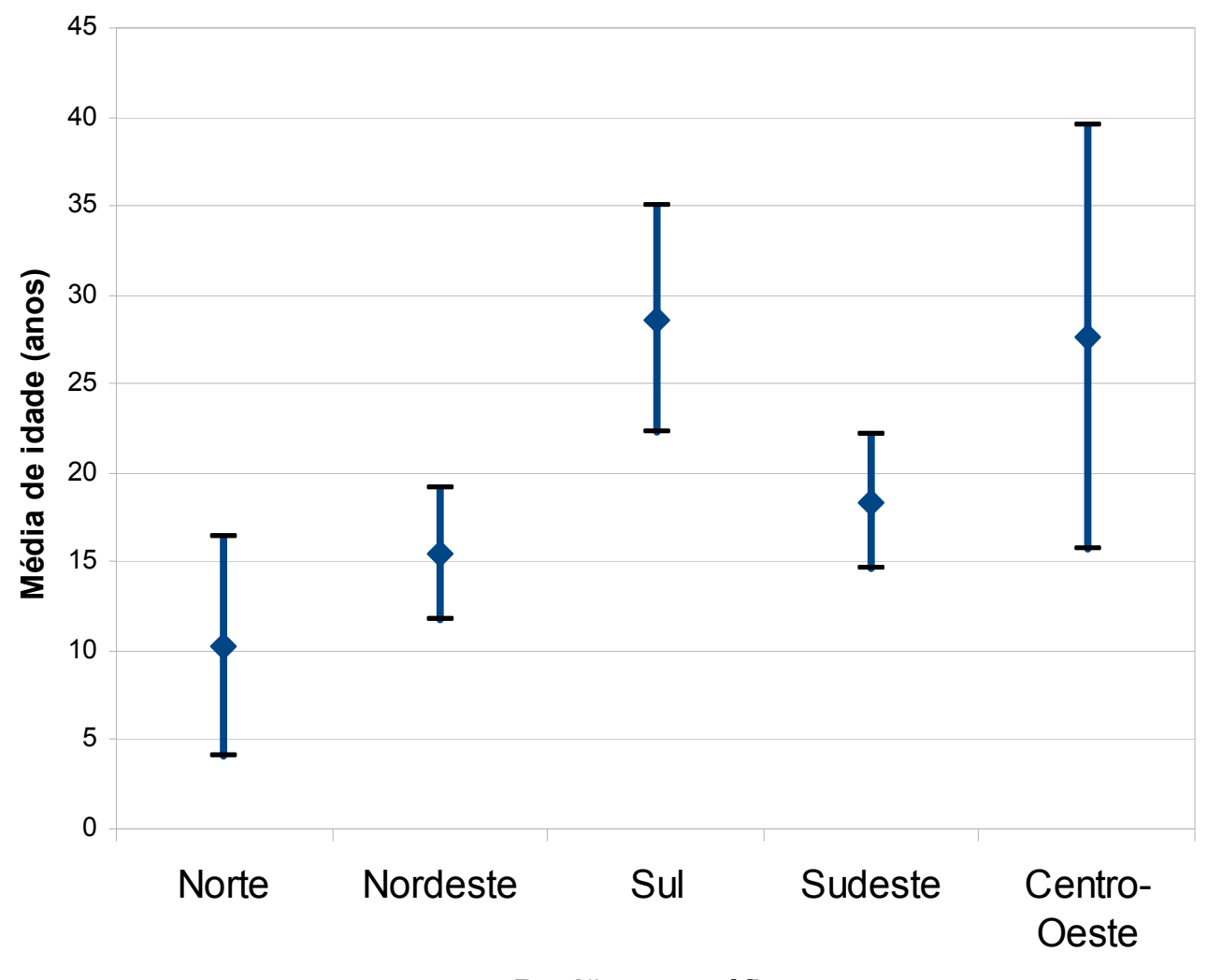

Figura 14. Média das idades segundo região geográfica com intervalo de confiança de $95 \%$

A distribuição dos casos segundo o sexo pode ser considerada homogênea nas 5 regiões. A estatística Qui-quadrado de Pearson teve valor igual a $\chi^{2}=1,297$, com $p=0,862$.

Não foi significativa a associação entre topografia da lesão e região geográfica. A estatística do teste foi igual a $\chi^{2}=1,205$, com $p=0,877$. 
Tabela 5. - Características clínicas dos casos de LB nas diferentes regiões geográficas do Brasil

\begin{tabular}{|c|c|c|c|c|c|c|c|}
\hline \multirow{2}{*}{\multicolumn{2}{|c|}{ Características clínicas }} & \multicolumn{5}{|c|}{ REGIÃO GEOGRÁFICA } & \multirow{2}{*}{$\begin{array}{c}\text { População } \\
\text { geral }\end{array}$} \\
\hline & & \multirow{2}{*}{$\begin{array}{c}\text { Nordeste } \\
86(36,7 \%)\end{array}$} & \multirow{2}{*}{$\begin{array}{c}\text { Centro- } \\
\text { Oeste } \\
17(7,3 \%)\end{array}$} & \multirow{2}{*}{$\begin{array}{c}\text { Sul } \\
42(17,9 \%)\end{array}$} & \multirow{2}{*}{$\begin{array}{c}\text { Sudeste } \\
72(30,8 \%)\end{array}$} & \multirow{2}{*}{$\begin{array}{c}\text { Norte } \\
17(7,3 \%)\end{array}$} & \\
\hline & & & & & & & $234(100 \%)$ \\
\hline \multirow{3}{*}{ Idade } & $\begin{array}{c}\text { Média } \\
\text { Mediana }\end{array}$ & $\begin{array}{c}15,4 a \\
7 a\end{array}$ & $\begin{array}{c}27,5 a \\
20 a\end{array}$ & $\begin{array}{c}28,6 a \\
24 a\end{array}$ & $\begin{array}{c}18,3 a \\
11 a\end{array}$ & $\begin{array}{c}10,3 a \\
5 a\end{array}$ & $\begin{array}{c}19,1 \mathrm{a} \\
11 \mathrm{a}\end{array}$ \\
\hline & Variação & $7 m-79 a$ & $3-75 a$ & $3-81 a$ & $2-80 a$ & $3-51 a$ & $7 m-81 a$ \\
\hline & $\mathbf{M}$ & $64(74,4 \%)$ & $12(70,6 \%)$ & $29(69 \%)$ & $54(75 \%)$ & $14(82,4 \%)$ & $173(73,9 \%)$ \\
\hline \multirow[t]{3}{*}{ Sexo } & $\mathbf{F}$ & $22(25,6 \%)$ & $5(29,4 \%)$ & $13(31 \%)$ & $18(25 \%)$ & $3(17,6 \%)$ & $61(26,1 \%)$ \\
\hline & $M / F$ & 2,78 & 2,4 & 2,2 & 3 & 4,6 & 2,83 \\
\hline & Adulto & $23(26,7 \%)$ & $9(53 \%)$ & $26(61,9 \%)$ & $27(37,5 \%)$ & $3(17,6 \%)$ & $88(37,6 \%)$ \\
\hline \multirow[t]{3}{*}{ Faixa etária } & Pediátrico & $63(73,3 \%)$ & $8(47 \%)$ & $14(33,3 \%)$ & $44(61,1 \%)$ & $14(82,4 \%)$ & $143(61,1 \%)$ \\
\hline & NR & 0 & 0 & $2(4.8 \%)$ & $1(1,4 \%)$ & 0 & $3(1.3 \%)$ \\
\hline & Nodal & $23(26,7 \%)$ & $5(29,4 \%)$ & $15(35,7 \%)$ & $21(29,2 \%)$ & $3(17,6 \%)$ & $67(28,6 \%)$ \\
\hline \multirow[t]{2}{*}{ Topografia } & Extranodal & $57(66,3 \%)$ & $12(70,6 \%)$ & $27(64,3 \%)$ & $50(69,4 \%)$ & $13(76,5 \%)$ & $159(68 \%)$ \\
\hline & NR & $6(7 \%)$ & 0 & 0 & $1(1,4 \%)$ & $1(5,9 \%)$ & $8(3,4 \%)$ \\
\hline
\end{tabular}

m: meses; a: anos; M: masculino; F: feminino; NR: não referido 


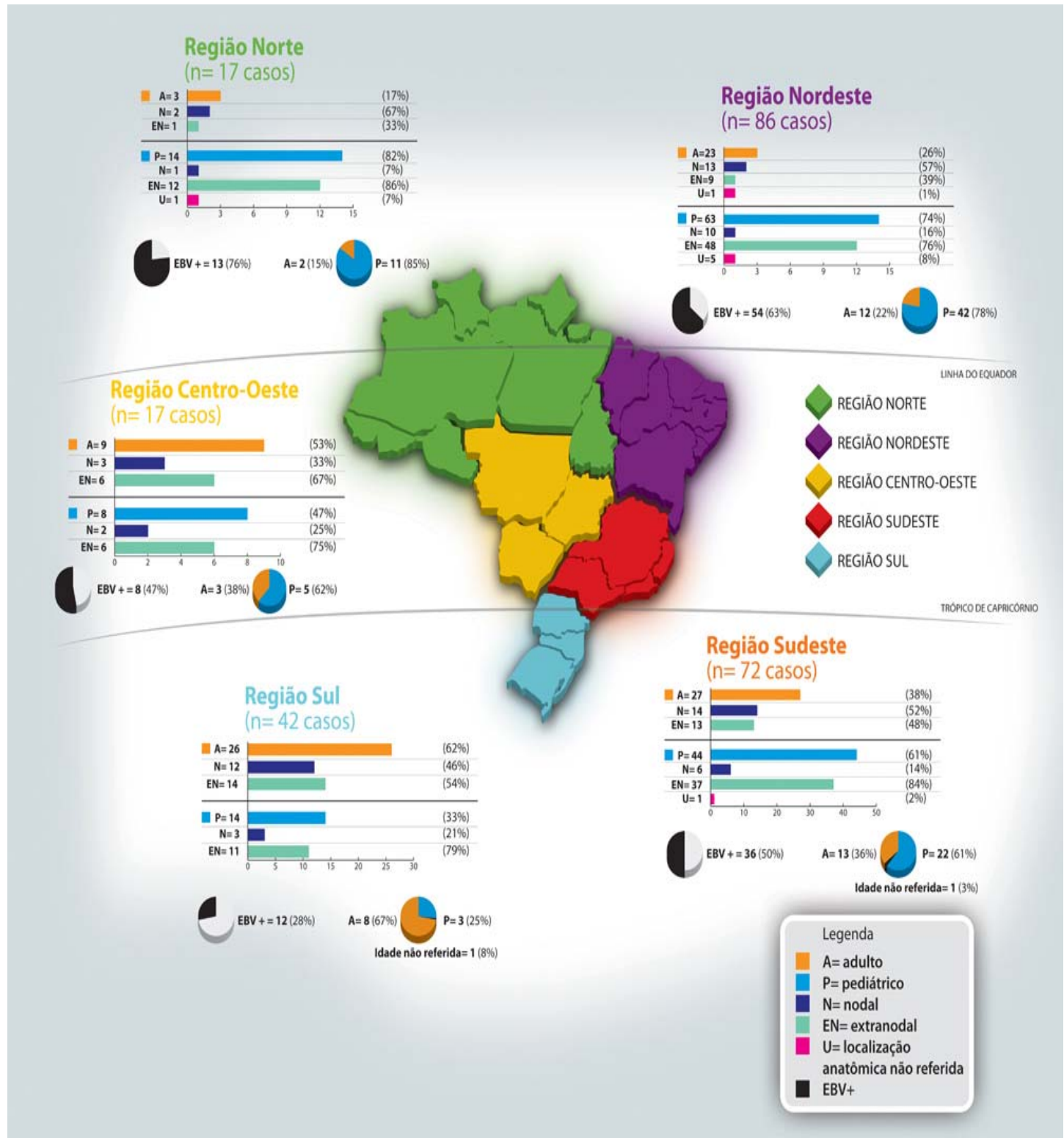

Figura 15. Mapa do Brasil com divisão em regiões geográficas mostrando a distribuição de casos de LB, localização anatômica em relação às faixas etárias e proporção de casos EBV positivos

\subsection{Características morfológicas}

A grande maioria dos casos (99\%) apresentou arquitetura difusa e somente 2 casos apresentaram padrão nodular. A forma clássica do 
LB, caracterizada pela proliferação monomórifca de células de médio tamanho, com núcleos redondos, múltiplos nucléolos, citoplasma escasso e basofílico, freqüentes figuras de mitoses e padrão em "céu-estrelado" devido à presença de histiócitos fagocitando células neoplásicas apoptóticas (Figura 16), foi observada em 213 casos (91\%). Por sua vez, 14 casos $(6 \%)$ foram classificados como LB atípico/Burkitt-símile (Figura 17A) e 7 casos (3\%) como LB com diferenciação plasmacitóide (Figura 17B).

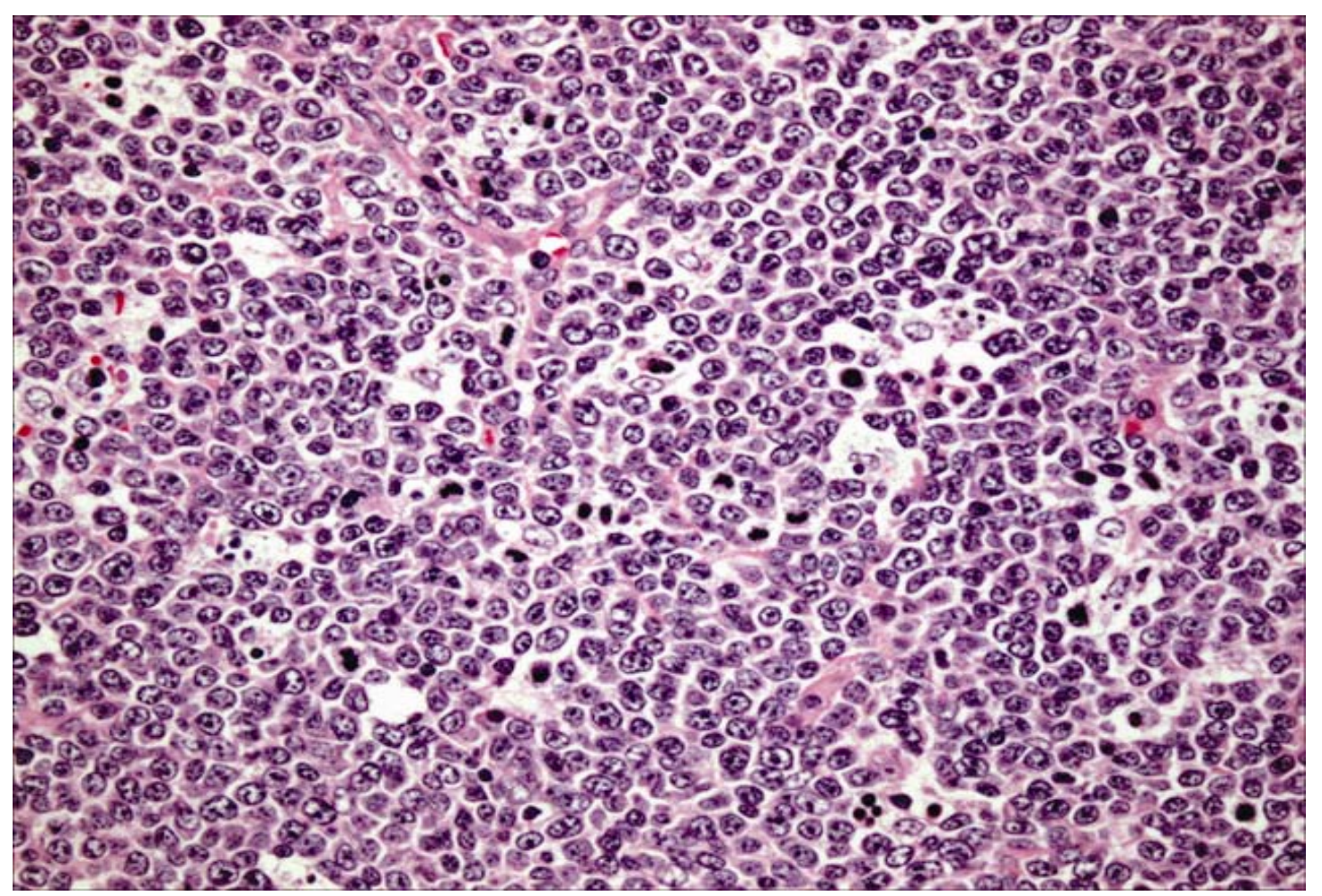

Figura 16. Corte histológico corado pela hematoxilina-eosina de LB clássico, com típico padrão em "céu-estrelado" (X200) 


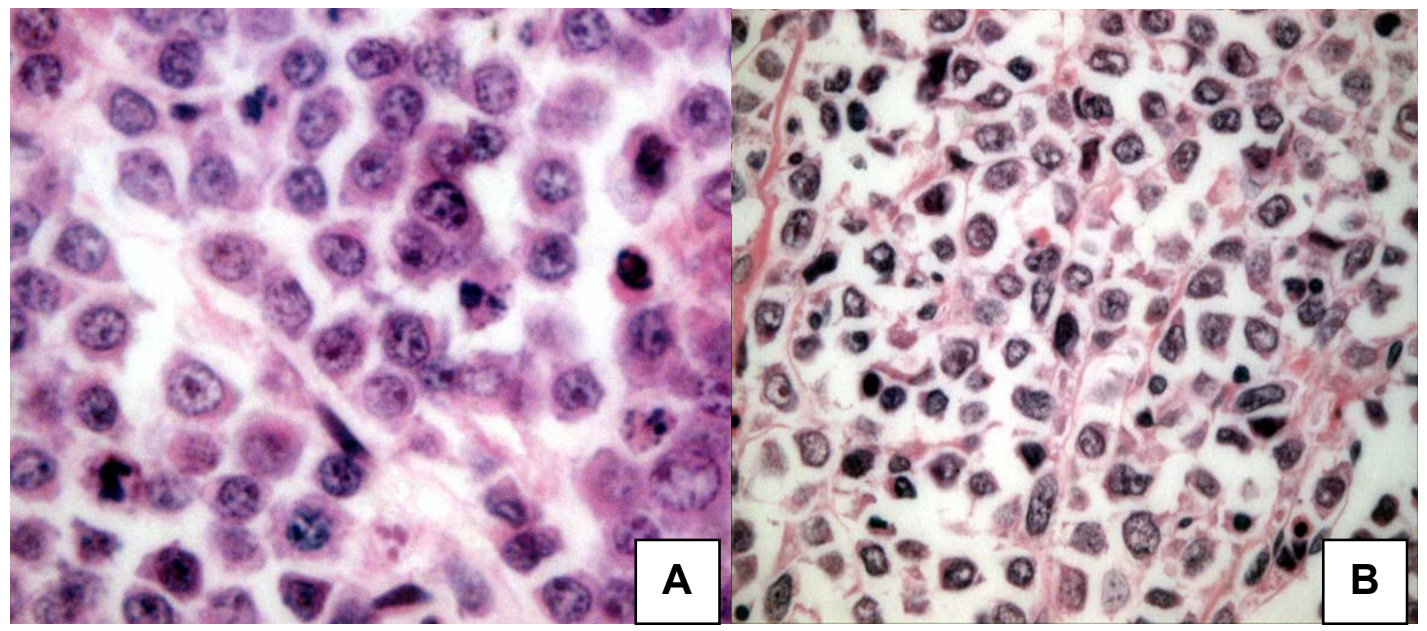

Figura 17. Cortes histológicos corados pela hematoxilina-eosina das variantes morfológicas do LB: A: LB com diferenciação plasmacítóide caracterizado por células com citoplasma excêntrico e basofílico (X400). B: LB atípico/Burkitt-símile apresentando maior variação do tamanho nuclear (X400)

\subsection{HIS para EBV}

O EBV foi detectado em 123 casos $(52,5 \%)$ de LB. Em cada um dos casos positivos, virtualmente, todas as células neoplásicas exibiram marcação nuclear com a sonda biotinilada dirigida ao transcrito viral EBER1 (Figura 18). Em apenas 1 caso, a HIS mostrou resultado inconclusivo $(0,5 \%)$. 


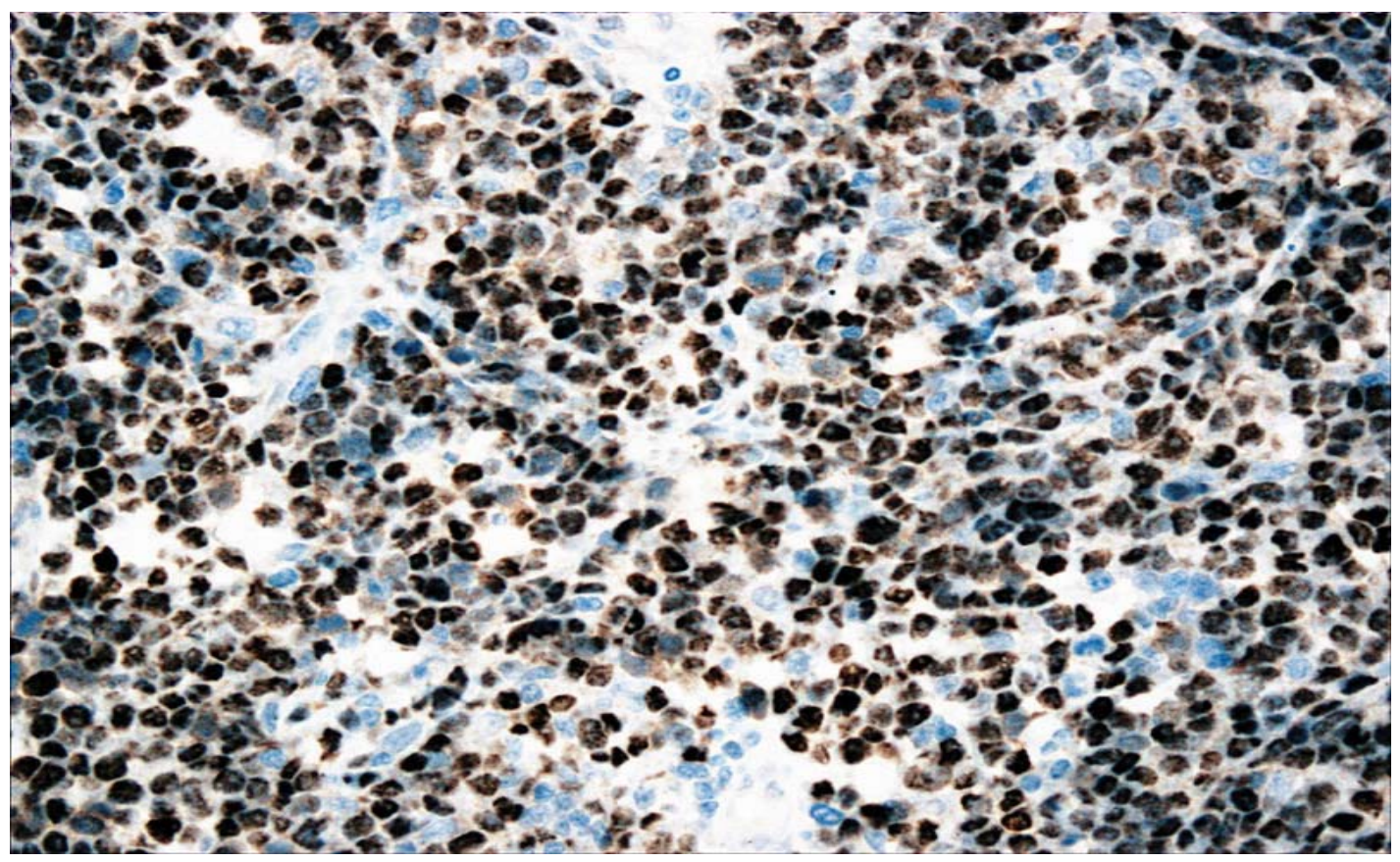

Figura 18. HIS para EBV (contracoloração pela hematoxilina de Mayer) de um caso de LB revelando marcação nuclear em virtualmente todas as células neoplásicas (X200)

A média e a mediana de idade dos casos EBV positivos foram, respectivamente, 16 e 7 anos, ou seja, significativamente menores quando comparadas aos casos EBV negativos, os quais apresentaram idade média e mediana de 23 e 14 anos, respectivamente. A figura 19 apresenta a distribuição dos casos EBV positivos e EBV negativos em relação à idade. A tabela 6 apresenta as características clínicas (faixa etária e topografia) dos casos de LB EBV positivos e EBV negativos. Podemos observar que 43,6\% (38 casos) dos LB em pacientes adultos apresentaram infecção pelo EBV, enquanto que na população pediátrica a freqüencia de infecção pelo EBV foi de $58 \%$ (83 casos). A estatística Qui-quadrado de Pearson teve valor igual a ${ }^{2}=4,476$ com $p=0,034$, indicando que é significante a diferença entre infecção por EBV nos grupos pediátricos e adultos. 


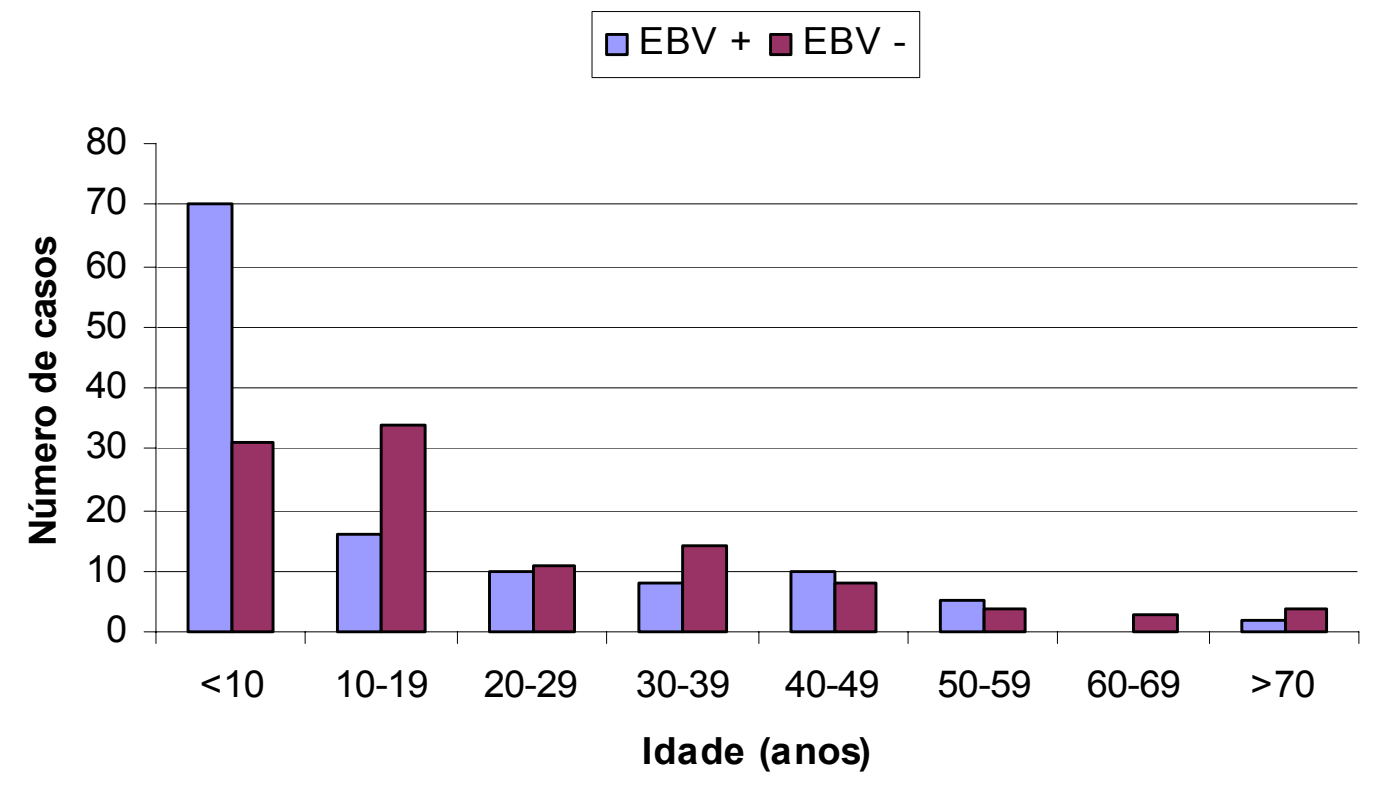

Figura 19. Distribuição por faixa etária dos casos de LB EBV positivos e EBV negativos

Tabela 6 - Características clínicas (faixa etária e topografia) dos casos de LB EBV positivos e EBV negativos

\section{HIS-EBV}

\begin{tabular}{cccc} 
CARACTERÍSTICAS CLÍNICAS & $\begin{array}{c}\text { EBV POSITIVO } \\
\mathbf{n = 1 2 3}\end{array}$ & $\begin{array}{c}\text { EBV NEGATIVO } \\
\mathbf{n = 1 1 0}\end{array}$ \\
\hline \multirow{3}{*}{ Faixa etária } & Adulto & $38(30,9 \%)$ & $49(44,5 \%)$ \\
& Pediátrico & $83(67,5 \%)$ & $60(54,6 \%)$ \\
Topografia & NR & $2(1,6 \%)$ & $1(0,9 \%)$ \\
& Nodal & $30(24,4 \%)$ & $36(32,7 \%)$ \\
& Extranodal & $87(70,7 \%)$ & $72(65,4 \%)$ \\
& NR & $6(4,9 \%)$ & $2(1,9 \%)$
\end{tabular}

NR, não referido

Quando consideramos apenas os casos pediátricos de LB (143 casos), observamos que os pacientes EBV positivos apresentaram idade média e mediana de 6 e 5 anos, respectivamente, enquanto que os 
casos EBV negativos apresentaram idade média e mediana de 9,1 e 8,5 anos, respectivamente. A figura 20 apresenta a distribuição de idade dos casos pediátricos de LB EBV positivos e EBV negativos.

$\square E B V+\square E B V$ -

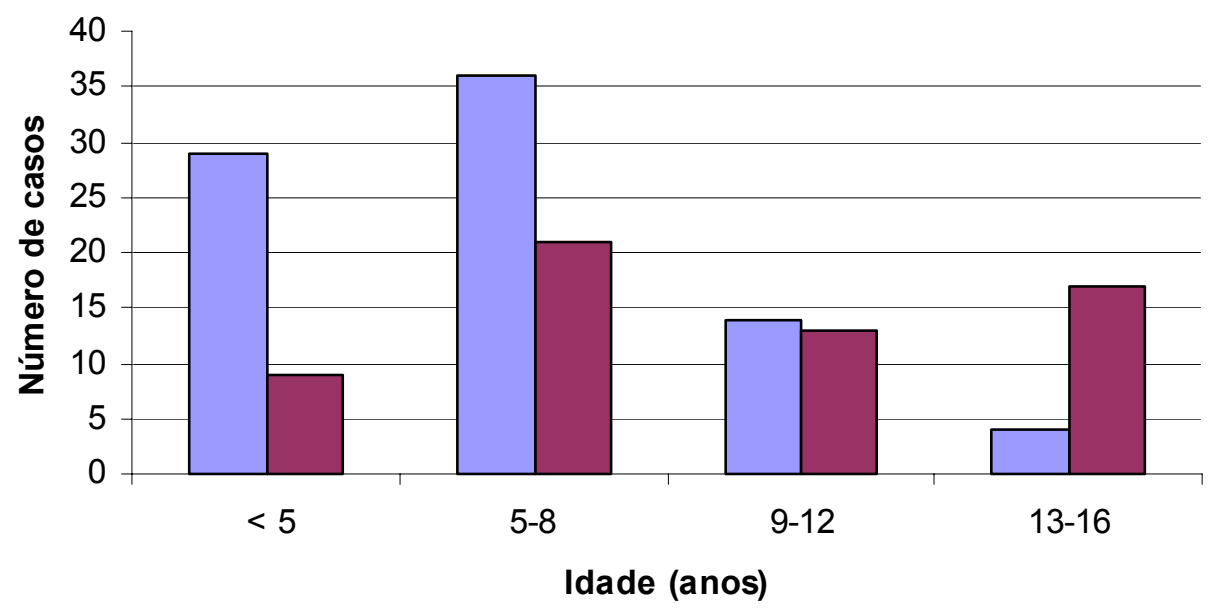

Figura 20. Distribuição por faixa etária dos casos pediátricos de LB EBV positivos e EBV negativos

\subsubsection{HIS nas regiões geográficas}

As regiões Norte e Nordeste do Brasil apresentaram as maiores freqüências de infecção pelo EBV, respectivamente, $76,4 \%$ e $62,8 \%$. Por sua vez, a menor associação entre EBV e LB foi observada na região Sul, na qual $28,6 \%$ apresentaram resultado positivo pela ISH. A tabela 7 apresenta os resultados da ISH nas 5 regiões geográficas. 
Tabela 7- Distribuição dos casos EBV positivos e EBV negativos nas 5 regiões geográficas

\begin{tabular}{lcccccc}
\hline & \multicolumn{5}{c}{ REGIÃO GEOGRÁFICA } & \multirow{2}{*}{ HISEBV } \\
\cline { 2 - 6 } & Nordeste & C.Oeste & Norte & Sul & Sudeste & P. Geral \\
\hline EBV + & $54(62,8 \%)$ & $8(47,1 \%)$ & $13(76,4 \%)$ & $12(28,6 \%)$ & $36(50 \%)$ & $123(52,5 \%)$ \\
EBV - & $32(37,2 \%)$ & $9(52,9 \%)$ & $3(17,4 \%)$ & $30(71,4 \%)$ & $36(50 \%)$ & $110(47 \%)$ \\
Inconc & - & - & $1(5,9 \%)$ & - & - & $1(0,5 \%)$ \\
\hline C:centro; P:população; Inconc: inconclusivo & & &
\end{tabular}

A freqüência de infecção pelo vírus EBV correlacionou-se com as regiões geográficas do país. A associação entre EBV e LB nas regiões Norte, Nordeste e Sul diferiu significativamente da freqüência de infecção por EBV nas regiões Sudeste e Centro-Oeste (estatística Quiquadrado de Pearson teve valor igual a $\chi^{2}=18,985$, com $\left.p<0,001\right)$.

A figura 15 mostra também a distribuição segundo faixa etária (adulto e pediátrico) nos casos EBV positivos. Verificou-se que, em todas as regiões geográficas, com exceção da região Sul, houve predomínio de pacientes pediátricos entre os casos de LB associados ao EBV.

\subsection{Caracterização imunoistoquímica}

Todos os 234 casos revelaram expressão para CD20, CD10, com índice de proliferação celular > 95\%, determinado pela expressão do antígeno Ki-67, e negatividade para CD3, TdT e BCL-2. Nenhum dos 44 casos avaliados com os anticorpos anti CD5 e CD23 revelou resultado 
positivo. A figura 21 apresenta exemplos de casos de LB com expressão para CD20, CD10, Ki-67 e negatividade para BCL-2.

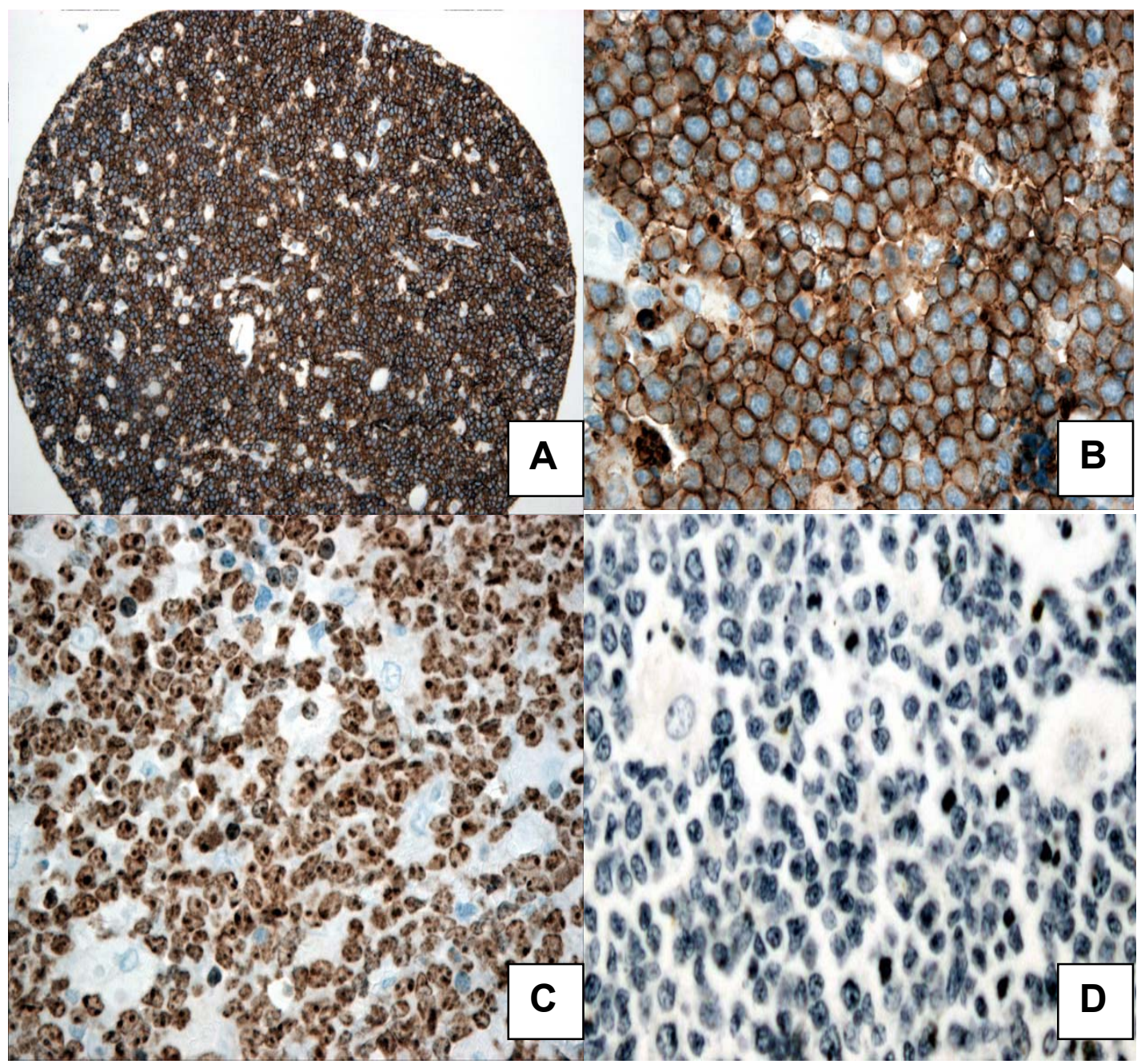

Figura 21. Resultado imunoistoquímico (contracoloração pela hematoxilina de Mayer) de casos de LB. A: expressão para CD20 (X100). B: expressão para CD10 (X200). C: expressão de Ki-67 em virtualmente todas as células neoplásicas (X200). D: negatividade para BCL-2 (X200)

A pesquisa de infecção pelo HHV-8 através da avaliação da proteína viral LANA-1 revelou negatividade em todos os casos. A figura 22 ilustra um caso de LB com ausência de expressão para proteína LANA-1. 


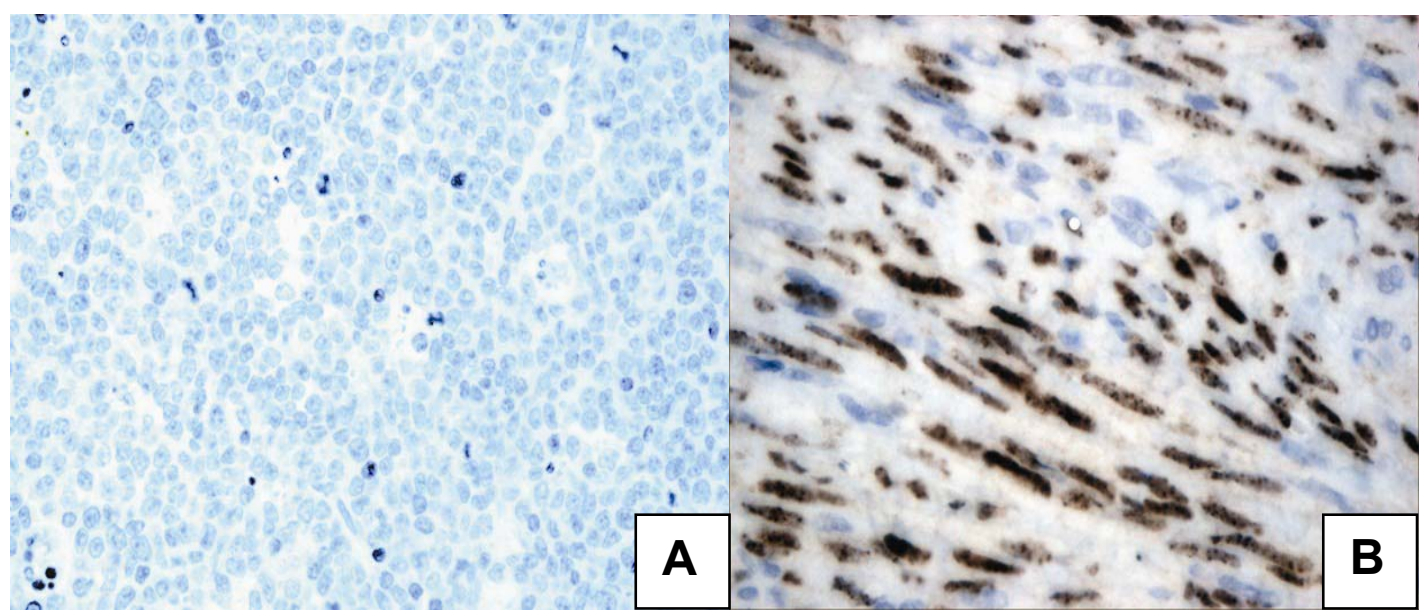

Figura 22. Resultado imunoistoquímico (contracoloração pela hematoxilina de Mayer) da pesquisa de infecção pelo HHV-8. A: ausência de expressão da proteína viral LANA-1 em caso de LB (X200). B: controle positivo (sarcoma de Kaposi) apresentando positividade nuclear em padrão granular (X400)

A tabela 8 apresenta os resultados obtidos empregando-se os marcadores BCL-6, MUM1/IRF4, PAX-5, LMP-1 e proteínas p53 e p63 e a figura 23 exemplifica a expressão dos marcadores acima mencionados.

Tabela 8 - Resultados obtidos para os marcadores BCL-6, MUM1/IRF4, PAX-5, LMP-1 e proteínas p53 e p63 nos 234 casos de LB

\begin{tabular}{cccc}
\hline \multirow{2}{*}{ ANTígENO } & \multicolumn{3}{c}{ RESULTADO } \\
\cline { 2 - 4 } & POSITIVO(\%) & NEGATIVO(\%) & INCONCLUSIVO(\%) \\
\hline BCL-6 & $203(86,7 \%)$ & $28(12 \%)$ & $3(1,3 \%)$ \\
MUM1/IRF4 & $91(38,9 \%)$ & $141(60,2 \%)$ & $2(0,9 \%)$ \\
PAX-5 & $225(96,1 \%)$ & $6(2,6 \%)$ & $3(1,3 \%)$ \\
LMP-1 & $1(0,4 \%)$ & $230(98,3 \%)$ & $3(1,3 \%)$ \\
Proteína p53 & $38(16,2 \%)$ & $194(82,9 \%)$ & $2(0,9 \%)$ \\
Proteína p63 & $9(3,8 \%){ }^{1}$ & $223(95,3 \%)$ & $2(0,9 \%)$ \\
\hline
\end{tabular}




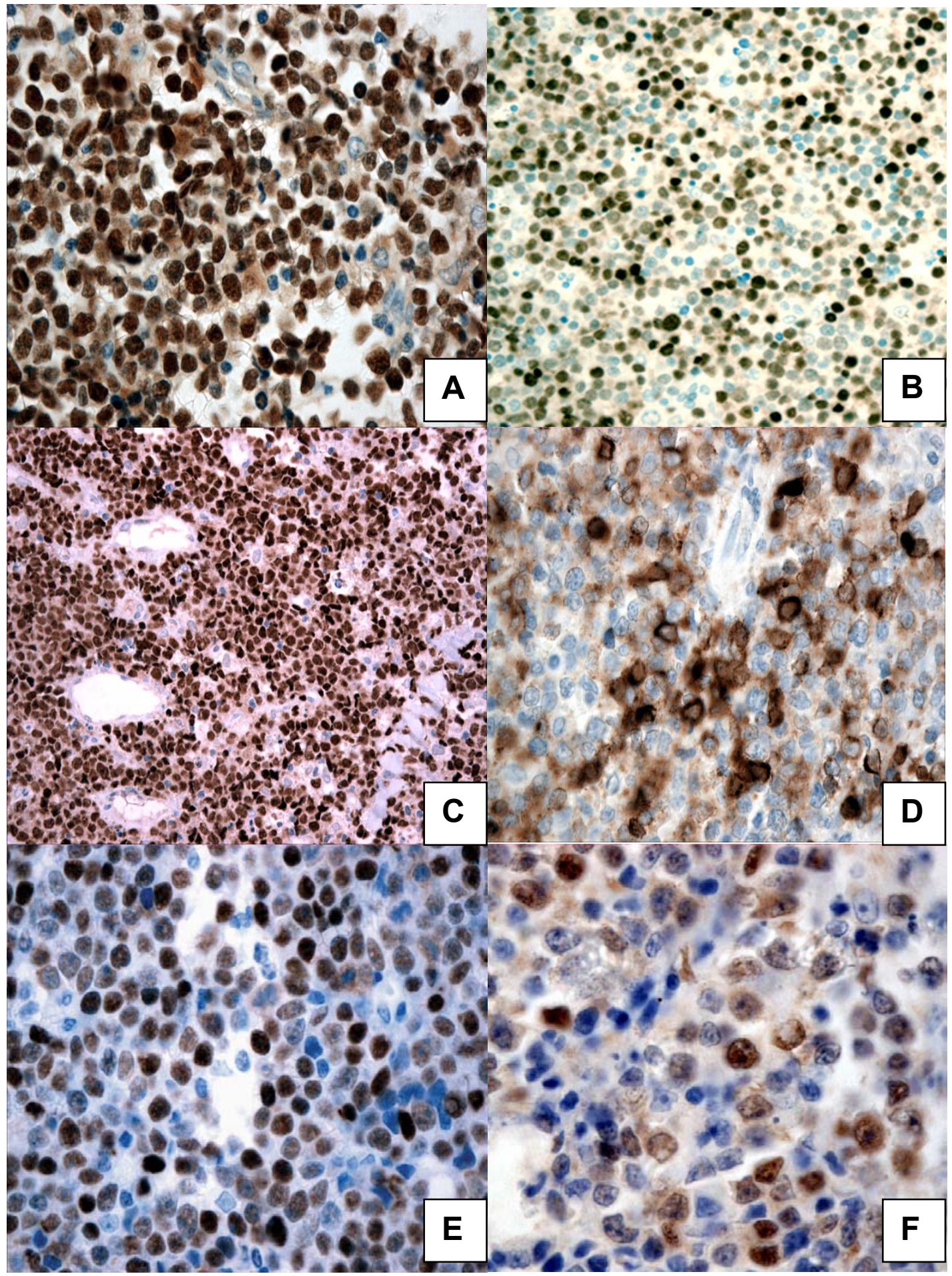

Figura 23. Resultado imunoistoquímico (contracoloração pela hematoxilina de Mayer). A: expressão para BCL-6 (X200). B: expressão nuclear para MUM1/IRF4 (X200). C: expressão para PAX-5 (X200). D: expressão citoplasmática de LMP-1 (X200). E: expressão para proteína p53. F: expressão para proteína p63 (X400) 
A coexpressão das proteínas p53 e p63 foi observada em apenas 1 caso.

4.4.1 Associação entre expressão da proteína p53 e HISEBV

A tabela 9 mostra a freqüência de expressão do EBER1 através de HIS nos casos p53 positivos e p53 negativos. Podemos observar que a expressão para proteína p53 correlacionou-se de maneira inversa com infecção pelo EBV. A estatística Qui-quadrado de Pearson teve valor igual a $\chi^{2}=4,773$ com $p=0,029$.

Tabela 9 - Freqüencia de infecção pelo EBV pesquisada através de ISH nos casos p53 positivos e p53 negativos

\begin{tabular}{ccc}
\hline & \multicolumn{2}{c}{ ISH-EBV } \\
\cline { 2 - 3 } IHQ-p53 & EBV POSITIVO & EBV NEGATIVO \\
\hline p53 + (38 casos) & $14(36,8 \%)$ & $24(63,2 \%)$ \\
p53 - (194 casos) & $109(56,2 \%)$ & $85(43,8 \%)$ \\
\hline
\end{tabular}

$\mathrm{IHQ}$, imunoistoquímica 
4.4.2 Associação entre MUM1/IRF4, BCL-6 e infecção pelo EBV

Dos 232 casos com resultado conclusivo para MUM1/IRF4, $91(39,2 \%)$ apresentaram resultado positivo, caracterizado pela expressão nuclear de moderada à forte intensidade na maioria das células neoplásicas (figura 23B).

A tabela 10 apresenta a correlação entre BCL-6 e MUM1/IRF4. A coexpressão BCL6 e MUM1/IRF4, caracterizando fenótipo centro germinativo tardio, foi observada em 76 (32,9\%). Por sua vez, 127 casos (55\%) apresentaram fenótipo centro germinativo, isto é, BCL6 positivo e MUM1/IRF4 negativo. É importante ressaltar que somente 15 casos $(6,5 \%)$ apresentaram fenótipo pós-centro germinativo (BCL6 negativo e MUM1/IRF4 positivo) e 13 casos (5,6\%) mostraram negatividade para BCL6 e MUM1/IRF4 (fenótipo de células do manto). A estatística do teste para a correlação entre MUM1/IRF4 e expressão de BCL6 foi igual a $\chi^{2}=2,682$ com $p=0,101$, indicando haver forte indício de associação.

Tabela 10 - Correlação entre expressão para BCL6 e MUM1/IRF4

\begin{tabular}{lll}
\hline \multirow{2}{*}{ IHQ-MUM1/IRF4 } & \multicolumn{2}{c}{ IHQ-BCL6 } \\
\cline { 2 - 3 } & BCL6 POSITIVO & BCL6 NEGATIVO \\
\hline MUM1 +(n=91) & $76(83,5 \%)$ & $15(16,5 \%)$ \\
MUM1 -(n=140) & $127(90,7 \%)$ & $13(9,3 \%)$ \\
\hline
\end{tabular}

$\mathrm{IHQ}$, imunoistoquímica

${ }^{1} 1$ caso MUM/IRF4 negativo apresentou resultado inconclusivo para BCL6. 
A correlação entre ISH-EBV e expressão de MUM1/IRF4 é apresentada na tabela 11. A associação entre a expressão de proteína MUM1/IRF4 e EBV foi significativa e teve sentido oposto, ou seja, $72,9 \%$ dos casos com infecção pelo EBV foram MUM1 negativo; por sua vez, 52,7\% dos casos negativos para EBV apresentaram positividade para MUM1/IRF4. A estatística Qui-quadrado de Pearson teve valor igual a $\chi^{2}=15,999$ com $p<0,001$

Tabela 11 - Correlação entre MUM1/IRF4 e infecção pelo EBV

\begin{tabular}{llc}
\hline & & HIS-EBV \\
IHQ-MUM1/IRF4 & EBV POSITIVO & EBV NEGATIVO \\
\hline MUM1 +(n=91) & $33(36,3 \%)$ & $58(63,7 \%)$ \\
MUM1 -(n=141) & $89(63,1 \%)$ & $52(36,9 \%)$ \\
\hline
\end{tabular}

$\mathrm{IHQ}$, imunoistoquímica

A tabela 12 apresenta a distribuição dos casos de LB EBV positivos e EBV negativos em relação ao fenótipo. A expressão para MUM1/IRF4 foi observada em 33 casos de LB EBV positivos, sendo 26 BCL6 positivos e 7 BCL6 negativos. A maioria dos LB associados ao EBV enquadra-se no fenótipo centro germinativo, enquanto que nos LB negativos para EBV foi mais freqüente o fenótipo de centro germinativo tardio. 
Tabela 12 - Distribuição dos casos EBV positivos e EBV negativos segundo o fenótipo

\begin{tabular}{ccccc}
\hline & \multicolumn{4}{c}{ FENÓTIPO } \\
\cline { 2 - 5 } HIS-EBV & $\begin{array}{c}\text { BCL6+/MUM1- } \\
\text { Centro } \\
\text { germinativo }\end{array}$ & $\begin{array}{c}\text { BCL6+/MUM1+ } \\
\text { Centro } \\
\text { germinativo } \\
\text { tardio }\end{array}$ & $\begin{array}{c}\text { BCL6-/MUM1+ } \\
\text { Pós-centro } \\
\text { germinativo }\end{array}$ & $\begin{array}{c}\text { BCL6-/MUM1- } \\
\text { Células do } \\
\text { manto }\end{array}$ \\
\hline EBV +(n=122) & $86(67,7 \%)$ & $26(34,2 \%)$ & $7(46,6 \%)$ & $3(23 \%)$ \\
EBV -(n=109) & $41(32,3 \%)$ & $50(65,8 \%)$ & $8(53,4 \%)$ & $10(77 \%)$ \\
TOTAL & $127(100 \%)$ & $76(100 \%)$ & $15(100 \%)$ & $13(100 \%)$ \\
\hline $\begin{array}{c}1 \\
\text { 1 caso EBV }\end{array}$ & negativo, MUM1/IRF4 negativo apresentou & resultado \\
inconclusivo para BCL6 & & &
\end{tabular}

\subsection{PCR}

\subsubsection{Detecção do HHV-8}

Empregando-se os iniciadores KS330 não se detectou infecção pelo HHV-8 em nenhum dos 32 casos analisados. A figura 24 exemplifica a PCR em 4 casos de LB. 


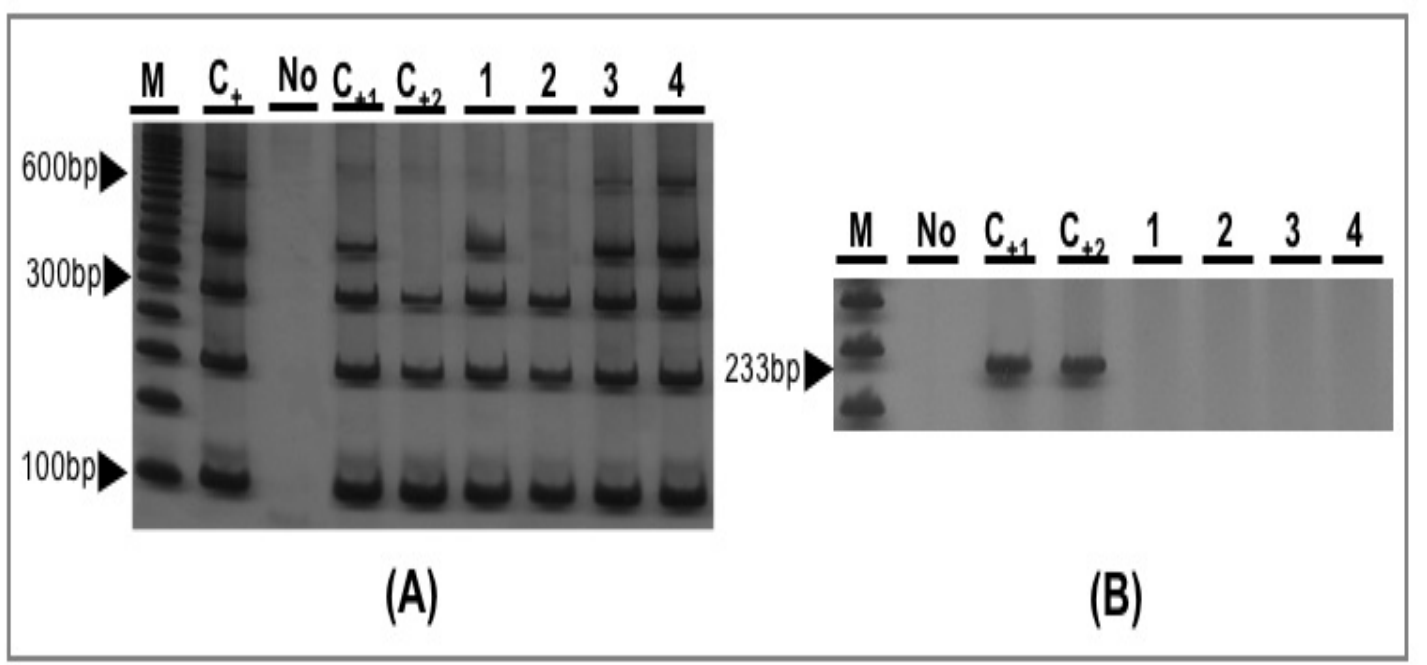

Figura 24. Detecção do HHV-8 em LB através de PCR: A: controle de tamanho da PCR. B: PCR específica para HHV-8. M, marcador de peso molecular; C+, DNA extraído do sangue periférico; No, controle negativo da reação (ausência de DNA); $\mathrm{C}+1$ e $\mathrm{C}+2$, controles positivos (caso de sarcoma de Kaposi e caso de LNH de imunofenótipo B - não Burkitt - associado ao HIV, respectivamente) mostrando amplificação de segmento de $233 \mathrm{pb}$ do capsídeo viral (ORF26); 1 e 2, casos de LB associados ao HIV; 3 e 4, casos de LB HIV negativos, demonstrando ausência de infecção pelo HHV-8

\subsubsection{Subtipagem do EBV}

A análise molecular para subtipagem do EBV nos 123 casos de LB positivos pela ISH demonstrou que 95 casos $(77,2 \%)$ foram EBV do tipo A e $24(19,5 \%)$ foram EBV do tipo B. Em apenas 4 casos $(3,3 \%)$ o resultado mostrou-se inconclusivo devido à má qualidade do DNA obtido. Os dois subtipos de EBV numa mesma amostra não foram observados em nenhum dos casos. A figura 25 apresenta PCR para subtipagem do EBV em 5 casos de LB. 


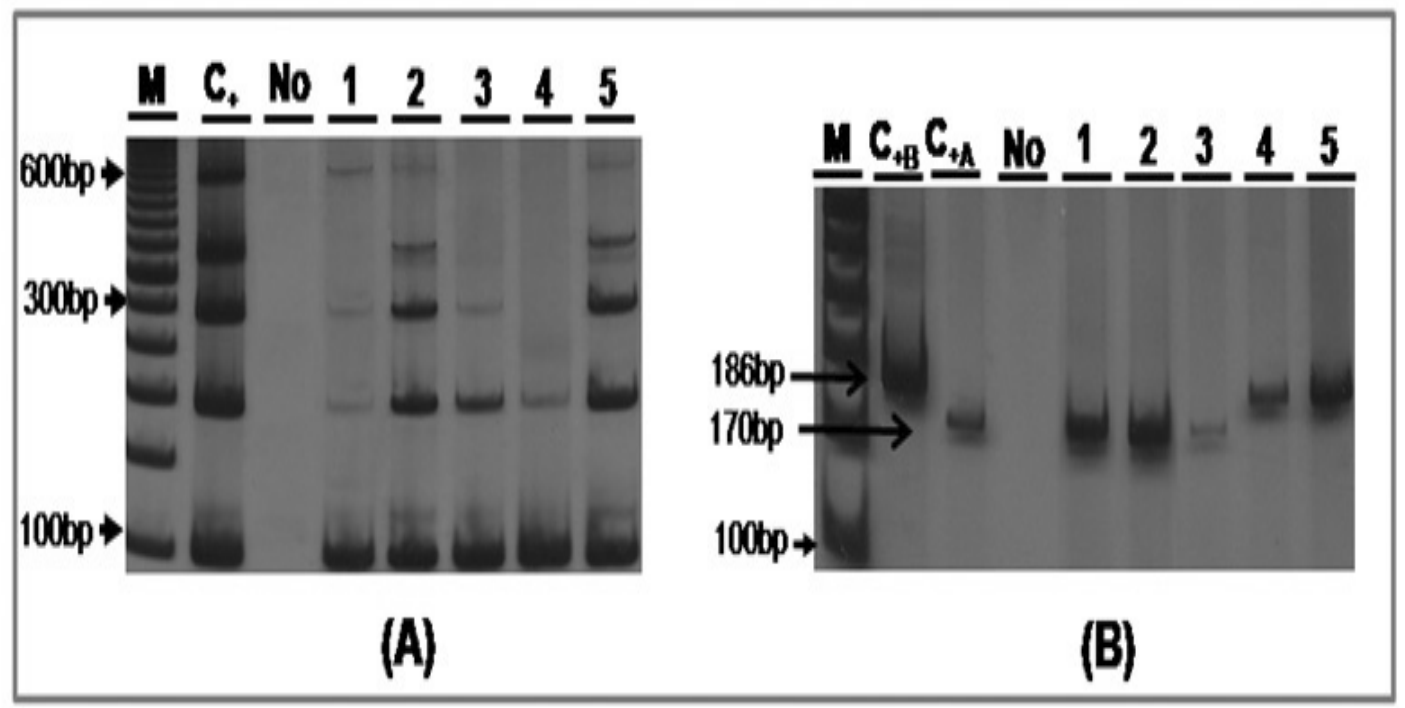

Figura 25. Subtipagem do EBV em LB através de PCR: $A$ : controle de tamanho da PCR. B: PCR específica para EBV. M, marcador de peso molecular; $\mathrm{C}+$, DNA extraído do sangue periférico; No, controle negativo da reação (ausência de DNA); $C+A$, controle positivo (caso de LB com EBV do tipo A) mostrando amplificação de segmento de 170 pb; C+B; controle positivo (caso de LB com EBV do tipo B) mostrando amplificação de segmento de 186 pb; 1,2 e 3, casos de LB com infecção por EBV do tipo A; 4 e5, casos de LB com infecção por EBV do tipo B

4.5.2.1 Distribuição dos tipos de EBV nas regiões geográficas

Houve predomínio de EBV do tipo A em 4 das 5 regiões geográficas. A única exceção foi observada na região Centro-Oeste, na qual observou-se distribuição equivalente de EBV tipos A e B. A tabela 13 apresenta a distribuição dos subtipos de EBV em cada uma das regiões geográficas. 
Tabela 13.- Distribuição dos subtipos de EBV nas 5 regiões geográficas

\begin{tabular}{lcccccc}
\hline \multirow{2}{*}{$\begin{array}{l}\text { TIPO } \\
\text { EBV }\end{array}$} & Nordeste & C.Oeste & Norte & Sul & Sudeste & \multirow{2}{*}{ P. Geral } \\
\cline { 2 - 6 } TIPO A & $40(74 \%)$ & $4(50 \%)$ & $9(69,2 \%)$ & $11(91,7 \%)$ & $31(86,1 \%)$ & $95(77,2 \%)$ \\
TIPO B & $10(18,5 \%)$ & $4(50 \%)$ & $4(30,8 \%)$ & $1(8,3 \%)$ & $5(13,9 \%)$ & $24(19,5 \%)$ \\
Inconc. & $4(7,5 \%)$ & - & - & - & - & $4(3,3 \%)$ \\
\hline
\end{tabular}

C:centro; P:população; Inconc: inconclusivo

A estatística comparativa Qui-quadrado de Pearson demonstrou valor igual a $\chi^{2}=7,256$ com $p=0,123$. Dessa forma, não foi possível evidenciar comportamento diferente na distribuição dos subtipos de EBV na região Centro-Oeste.

4.6 Características clínicas e patológicas dos casos HIV positivos

Segundo informações obtidas a partir dos relatórios anatomopatológicos, 14 (5,9\%) dos 234 casos foram HIV positivos. A idade deste grupo de pacientes, na época do diagnóstico, variou de 2 a 55 anos (idade média de 34 e mediana de 35,5), sendo $12(85,7 \%)$ adultos e 2 $(14,3 \%)$ pediátricos. Em relação ao sexo, 11 (78,6\%) foram do sexo masculino e $3(21,4 \%)$ foram do sexo feminino. A apresentação nodal (8 casos; $57,1 \%$ ) foi mais freqüente que envolvimento extranodal (6 casos; 42,9\%). Todos os casos de LB associados ao HIV apresentaram padrão 
morfológico clássico. A infecção pelo EBV através de HIS foi observada em $10(71,4 \%)$ dos 14 casos, sendo 8 do tipo A e 2 do tipo B.

Os resultados do ajuste do MRLM para os casos de LB associados ao HIV são apresentados na tabela 14.

.Tabela 14 - Resultado do ajuste do MRLM - teste das variáveis

\begin{tabular}{ccc}
\hline VARIÁVEL & QUI-QUADRADO & SIGNIFICÂNCIA (p) \\
\hline Idade & 9,961 & 0,002 \\
Sexo & 0,543 & 0,461 \\
EBV-ISH & 3,612 & 0,057 \\
\hline
\end{tabular}

\subsection{FISH}

Dos 361 casos analisados para detecção do rearranjo do gene C-MYC, 89 foram excluídos do estudo por apresentarem resultado inconclusivo devido às más condições de fixação do material. Outros 38 casos foram também eliminados por apresentarem resultados inconsistentes com LB, ou seja, nesses casos a porcentagem de quadrados ("tiles") positivos calculada pelos "softwares" foi inferior a 2,19\%. Nos 234 casos positivos para o rearranjo em questão, a porcentagem de quadrados ("tiles") positivos variou de $2,20 \%$ a $43,2 \%$ (média de $12,5 \%$ ). A figura $10 \mathrm{~B}$ ilustra um caso de LB apresentando rearranjo do gene $C-M Y C$. 


\section{DISCUSSÃO}

O LB é linfoma de células $B$ agressivo com incidência variável dependendo da região geográfica. Em áreas endêmicas, como na África Equatorial, as taxas de incidência são da ordem de 5 a 10 casos novos/100.000 crianças com idade inferior a 15 anos, por ano. Já em regiões desenvolvidas, como EUA, Europa e Japão, essas taxas são até 100 vezes inferiores às observadas nas áreas endêmicas. $O$ Brasil tem sido considerado como região de risco intermediário entre as formas endêmica e esporádica, esta última ocorrendo em regiões desenvolvidas (Klumb et al., 2004; Kelly e Rickinson, 2007; Hassan et al., 2008). Por outro lado, existem ainda inúmeras lacunas de informações sobre a real situação epidemiológica do LB no Brasil que necessitam ser elucidadas. São poucos os estudos sobre LB no Brasil e, de acordo com as publicações da literatura, nosso estudo é o primeiro em larga escala, bem como é o único na análise de casos provenientes das cinco regiões geográficas, incluindo tanto pacientes adultos quanto pediátricos. Os trabalhos prévios analisam casos de regiões geográficas isoladas (regiões Nordeste, Sudeste e Sul), com ênfase em população pediátrica (Araujo et al., 1996; Sandlund et al., 1997; Bacchi et al., 1996; Klumb et al., 2004; Haralambieva et al., 2004; Hassan et al., 2008; Pizza et al., 2008).

Em relação às características clínicas da população como um todo, observamos em nossos casos, predomínio de indivíduos do sexo masculino (masculino/feminino: 2,8:1), sendo o número de casos pediátricos 
superior ao de adultos. Em relação à topografia, a apresentação extranodal foi mais freqüente que a apresentação nodal. Nos casos com localização extranodal, o envolvimento abdominal foi observado em aproximadamente $77 \%$ dos casos. O acometimento de ossos da face foi infreqüente (apenas 5 dos 234 casos), diferentemente do que costuma ocorrer no LB endêmico. $\mathrm{Na}$ população adulta, com exceção das regiões Centro-Oeste e Sul, a apresentação nodal foi a mais freqüente. Dessa forma, as características clínicas (sexo, idade e localização anatômica) do LB no Brasil, de um modo geral, se assemelham às da forma esporádica de LB que ocorre em áreas desenvolvidas como EUA e Europa (Diebold et al., 2001; Boerma et al., 2004; Ferry, 2006).

O Brasil é um país de grandes dimensões territoriais e entre as regiões geográficas observam-se diferenças sócio-econômicas importantes, além de climáticas. Como exemplos dessas diferenças regionais citam-se as taxas de mortalidade infantil observadas em algumas regiões geográficas. As regiões Sul e Sudeste apresentam taxas similares a alguns países desenvolvidos, enquanto que a região Nordeste apresenta um padrão distante do desejável devido a fatores como falta de saneamento básico, carência de assistência em saúde e desnutrição (Fischer et al., 2007). Além disso, algumas doenças infecciosas/parasitárias são mais comuns em algumas regiões, como a malária na região Norte e a esquistossomose na região Nordeste (Braga et al, 2006; Coura et al., 2004).

É bem estabelecido o fato de que há uma significante associação entre o LB e a infecção pelo EBV, numa freqüencia variável de 
acordo com a forma clinicopatológica. No presente estudo, encontramos infecção pelo EBV, através de ISH, em 52,5\% dos 234 casos. Deve-se ressalatar que esta análise incluiu pacientes adultos e pediátricos. Este resultado coloca o Brasil como um país no qual a associação entre LB e infecção pelo EBV é intermediária entre as formas endêmica e esporádica de LB. Todavia, essa freqüencia de associação entre LB e EBV não se apresentou uniformemente nas 5 regiões, pois, como previamente mencionado, houve diferença estatística significante entre as regiões geográficas. As maiores freqüências de associação com EBV foram observadas nas regiões Norte e Nordeste $(76,4 \%$ e $62,8 \%$, respectivamente), enquanto que a menor foi verificada na região Sul $(28,6 \%)$. O resultado observado na região Sul é superponível àquele observado nos casos de LB esporádicos em países desenvolvidos (Diebold et al., 2001; Kelly e Rickinson, 2007). As regiões Sudeste e Centro-Oeste apresentaram resultados homogêneos entre si, com $50 \%$ e $47 \%$, respectivamente. Com esses dados, é possível verificar que as maiores freqüencias de infecção pelo EBV ocorreram justamente nas regiões menos desenvolvidas economicamente e que apresentam piores indicadores sociais. Esta associação pode indicar que aspectos sócio-econômicos podem contribuir com a frequência de infecção pelo EBV nessas áreas. De fato, a seroconversão para EBV em regiões pouco desenvolvidas ocorre muito mais precocemente quando comparadas com países industrializados (Klumb et al., 2004). Figueira-Silva e Pereira (2004), estudando seroprevalência para EBV em crianças e adolescentes de Vitória, Estado do 
Espírito Santo, demonstraram que a seroconversão para EBV em grupos menos favorecidos economicamente, e com menor escolaridade materna, ocorreu precocemente.

Ainda em relação à associação com o EBV, observamos que o grupo de pacientes EBV positivos apresentou média e mediana de idade menores do que o grupo de pacientes sem infecção pelo EBV. De fato, verificamos ser significativa a associação entre EBV e faixa etária. Vale salientar que estudos prévios sobre a associação entre EBV e LB no Brasil analisaram pacientes pediátricos (com idade variando de 1 até 15 anos). Dessa forma, quando comparamos a mediana de idade dos casos EBV positivos e EBV negativos no nosso grupo pediátrico de pacientes (com idade até 16 anos) verificamos resultados semelhantes aos obtidos por Araujo et al. (1996), Klumb et al., (2004) e Hassan et al. (2008). Esta é a primeira série sobre LB no Brasil que inclui a análise de número significativo de pacientes adultos. Neste grupo etário observamos que a associação com a infecção pelo EBV foi maior do que a relatada em casos adultos de LB esporádico ocorrendo em regiões desenvolvidas (Spina et al., 1998).

A análise dos subtipos de EBV, através de PCR, demonstrou, na população geral do estudo, maior frequência de EBV do tipo A $(77,2 \%)$, refletindo, provavelmente, o predomínio desse subtipo de EBV em nosso país. Essa distribuição pode ser considerada intermediária entre o LB endêmico (Young et al., 1987) e o LB ocorrendo nos EUA (Goldschmidts et al., 1992). Todavia, essa distribuição não foi homogênea entre as regiões geográficas do país. Os resultados obtidos nas regiões Nordeste e Sudeste 
foram semelhantes entre si, e estão de acordo com estudos prévios (Araujo et al., 1996, Chen et al., 1996; Klumb et al., 2004; Hassan et al., 2006; Hassan et al., 2008). Saliente-se que a região Norte apresentou freqüencia superponível às regiões Nordeste e Sudeste em relação à associação do LB com o subtipo A do EBV. A menor proporção de EBV do tipo B foi verificada na região Sul $(8,3 \%)$, um padrão de distribuição semelhante ao obtido por Goldschmidts et al. (1992) em LB nos EUA. Já na região Centro-Oeste, observou-se alta freqüencia de EBV do tipo B ( $50 \%$ dos casos), padrão esse semelhante ao descrito em áreas endêmicas (Young et al., 1987). A quantidade de casos analisados nesta área é pequena (apenas 8 casos) e, dessa forma, estudos adicionais envolvendo maior número de pacientes estão indicados para verificar a real distribuição dos subtipos de EBV nos casos de LB dessa região geográfica.

A grande maioria dos casos de LB associados ao EBV, endêmico, esporádico ou associado ao HIV, apresenta um padrão restritivo de expressão das proteínas virais, caracterizando o padrão de latência do tipo I, com ausência de expressão para LMP-1 (Rezk e Weiss, 2007; Kelly e Rickinson, 2007; Deyrup, 2008). No nosso estudo, a expressão imunoistoquímica para LMP-1 foi observada em apenas 1 caso $(0,5 \%)$, em em padrão focal de distribuição. Resultados semelhantes têm sido descritos na literatura. Niedobitek et al. (1995) observaram a expressão de LMP-1 em uma proporção variável de células tumorais em 2 de 17 casos endêmicos de LB. No Brasil, Chen et al. (1996) demonstraram imunomarcação para LMP-1 em 1 de 17 casos e Araujo et al. (1996) em 2 de 54 casos estudados. 
No nosso estudo, foi freqüente a expressão de MUM1/IRF4, observada em 91 casos $(39,2 \%)$, utilizando-se anticorpo monoclonal de camundongo (DAKO, clone MUM1P). Os primeiros estudos na literatura analisando a expressão dessa proteína em LB avaliaram número reduzido de casos, com resultados negativos (Tsuboi et al., 2000; Carbone et al., 2000; Natkunam et al., 2001). Falini et al. (2000), usando anticorpo monoclonal por ele desenvolvido, demonstrou expressão para MUM1/IRF4 em linhagem celular de LB denominada Ramos, com ausência de expressão na linhagem denominada Daudi e em 3 amostras teciduais de LB. Carbone et al. (2001) estudaram 19 casos de LB associado ao HIV e demonstraram a expressão de MUM1/IRF4 em ocasionais células $(<20 \%)$ em apenas 2 casos. Recentemente, Tumwine et al. (2008) não evidenciaram expressão para MUM1/IRF4 em 95 casos de LB. A diferença entre o nosso resultado e os resultados acima relatados, provavelmente, está relacionada aos diferentes tipos de anticorpos empregados. Tsuboi et al. (2000) e Carbone et al. (2000) empregaram anticorpo policlonal (ICSAT/M-17, Santa Cruz Biotechnology), enquanto que Natkunam et al. (2001) e Tumwine et al. (2008) utilizaram anticorpo desenvolvido por Falini. Por outro lado, Chuang et al. (2007, 2008) e Garcia et al. (2008), usando o mesmo anticorpo do nosso estudo (DAKO, clone MUM1P), demonstraram expressão para MUM1/IRF4 em, respectivamente, $18 \%, 23 \%$ e $39 \%$ dos casos de LB analisados. Após os estudos que analisaram o perfil de expressão gênica para estabelecer uma assinatura molecular do LB, realizados por Hummel et al. (2006) e Dave et al. (2006), a avaliação imunoistoquímica da proteína 
MUM1/IRF4 tem sido sugerida como marcador útil na distinção entre LB (ausência de expressão no LB) e LDGCB (Harris e Horning, 2006). Porém, frente à alta freqüencia de expressão dessa proteína observada em nosso estudo e também por outros autores (Chuang et al. e Garcia et al.), podemos concluir que esse marcador não deve ser usado isoladamente com essa finalidade.

Através da análise molecular do IGH, Bellan et al. (2005) postularam a existência de dois tipos de células candidatas a se transformarem em LB. Para os LB EBV negativos, a origem postulada seria o centroblasto precoce (zona escura do centro germinativo). Para os casos de LB EBV positivos, a origem postulada seria em célula B tardia intragerminal (zona clara do centro germinativo), que iniciou o processo de diferenciação para células $B$ de memória. Dessa forma, baseando-se na hipótese de Bellan et al. (2005) e considerando-se o fato de que MUM1/IRF4 é considerado marcador histogenético de célula B tardia intragerminal e de célula B pós-germinal, seria esperada, portanto, uma freqüente expressão para MUM1/IRF4 nos casos de LB EBV positivos. Além disso, a freqüente expressão de MUM1/IRF4 observada neste estudo poderia ser explicada pela alta associação com infecção por EBV nos casos de LB no Brasil. Todavia, no presente estudo, a associação entre a expressão de proteína MUM1/IRF4 e infecção pelo EBV foi significativa $(p<0,001)$ e teve sentido oposto, ou seja, um caso aleatório de LB EBV positivo terá maior probabilidade de ser MUM1/IRF4 negativo. Ainda, analisando a combinação BCL-6 e MUM1/IRF4 e classificando os casos segundo o fenótipo, conforme 
demonstrado na tabela 12, observamos que $86(70,5 \%)$ dos 122 casos de LB EBV positivos, apresentaram fenótipo centro germinativo (BCL-6+/MUM). Por sua vez, no fenótipo centro germinativo tardio (BCL-6+/MUM1+) houve predomínio de casos EBV negativos. Diante do exposto, podemos concluir que a infecção pelo EBV não explica a alta freqüencia de expressão de MUM1/IRF4 verificada neste estudo.

A relação entre imunodeficiência e desenvolvimento de neoplasia é bem estabelecida e foi verificada, antes mesmo do surgimento da epidemia da SIDA. A infecção pelo HIV está associada a uma alta incidência de LNH (100 a 400 vezes superior quando comparada à população geral), sendo LDGCB e LB os dois tipos histológicos mais freqüentemente observados (Navarro e Kaplan, 2006; Stewart, 2006). O LB foi o primeiro LNH descrito em associação com infecção pelo HIV (Ferry, 2006). As características clínicas do nosso grupo de pacientes HIV positivos tais como, predomínio de indivíduos adultos, do sexo masculino e freqüente envolvimento nodal, são concordantes com a literatura (Diebold et al. 2001). Nos LB associados ao HIV a infecção pelo EBV tem sido observada em 30 a 40\% dos casos (Diebold et al., 2001; Kelly e Rickinson, 2007). Em 1996, Bacchi et al. realizaram estudo sobre linfomas associados à SIDA no Brasil. Dos 24 casos por eles analisados, 5 foram representados por LB, 2 (40\%) dos quais associados à infecção pelo EBV. No presente estudo foi alta a freqüência de infecção pelo EBV nos casos de LB associados ao HIV, observada em $10(71,4 \%)$ dos 14 casos. Esta alta freqüencia de associação com EBV é semelhante à descrita por Lazzi et al. (1999), que demonstraram 
infecção por EBV em $6(75 \%)$ de 8 casos de LB na África. Conforme previamente mencionado, a prevalência de EBV do tipo B encontra-se aumentada em pacientes com SIDA (Goldschmidts et al., 1992; Chen et al., 1996; Deyrup, 2008), todavia esse subtipo de EBV só foi identificado em 2 (20\%) dos 10 casos de LB associados ao HIV e EBV positivos, percentual semelhante ao demonstrado na população geral do estudo.

Através de estudo imunoistoquímco, demonstramos a expressão para proteína p53 em $38(16,2 \%)$ dos casos de LB, que se correlacionou de maneira inversa com a infecção pelo EBV. Villuendas et al. (1992) e Klumb et al. (2004), utilizando ponto de corte de 5\%, demonstraram expressão para essa proteína em $63 \%$ e $46 \%$ dos casos de LB por eles estudados, respectivamente. Essa menor porcentagem de expressão para proteína p53 no nosso estudo pode ser explicada, pelo menos em parte, pelo ponto de corte utilizado (10\%). É importante ressaltar que neste estudo avaliamos uma quantidade significativa de casos, o que pode representar uma medida mais significativa da expressão dessa proteína em LB. A detecção da proteína p53 através de estudo imunoistoquímico é freqüentemente observada em $\mathrm{LNH}$, especialmente nos de alto grau, todavia esse não é o método de escolha para a detecção da mutação do gene TP53, pois estudos têm demonstrado que a expressão da proteína p53 não reflete necessariamente a presença de mutação gênica e vice-versa (Kocialkowski et al., 1995; Klumb et al., 2004). Tem sido demonstrado que alguns tipos de mutações do gene TP53 têm valor prognóstico determinando vantagem seletiva às células tumorais e induzindo menor resposta à quimioterapia 
(Klumb et al., 2001). Em relação à expressão imunoistoquímica da proteína os resultados são controversos. Koduru et al. (1997) concluíram que mutação de TP53 e/ou expressão de p53 influenciaram negativamente a sobrevida dos LNH avaliados, podendo ser usado como indicador prognóstico. Por outro lado, Spina et al. (1998) não verificaram diferença na sobrevida e no intervalo livre de doença em casos de LB com e sem expressão para a proteína p53.

Há poucos estudos na literatura analisando a expressão imunoistoquímica da proteína p63 em LNH, especialmente no LB. Este trabalho é, certamente, o primeiro a avaliar a expressão deste fator de transcrição em uma grande número de casos de LB. A expressão da proteína p63 foi detectada em apenas $9(3,8 \%)$ dos 234 casos de LB avaliados, não representando, portanto, marcador útil no diagnóstico ou mesmo prognóstico desta neoplasia.

A melhor maneira de se detectar o HHV-8 em tecido é através de estudo imunoistoquímico, utilizando-se anticorpo contra a proteína LANA-1. A detecção através de PCR é muito sensível e sujeita a resultado falso-positivo, sendo, provavelmente, a razão pela qual vários estudos têm descrito a presença desse vírus em casos de sarcoidose e mieloma múltiplo (Laurent et al., 2008). O espectro de neoplasias ao qual o HHV-8 tem sido associado é diferente e mais restrito que o espectro de neoplasias associadas ao EBV (Laurent et al., 2008). Em neoplasias linfóides a co-infecção EBV/HHV-8 tem sido demonstrada na maioria dos casos de PEL (Diebold et al., 2001; Carbone et al., 2000; Chadburn et al., 
2004), porém não tem sido demonstrada em casos de LB. No presente estudo, não encontramos evidências de infecção por HHV-8, através de estudo imunoistoquímico e PCR, em nenhum dos casos de LB analisados, incluindo pacientes HIV positivos. Este resultado, agora em número mais expressivo de casos, é concordante com trabalhos anteriores estudando a mesma associação (Lazzi et al., 1998; Tao e Ambider, 1999; Carbone et al., 2001; Lazzi et al., 2006; Chuang et al., 2007).

Portanto, este estudo apresentou características clinicopatológicas, imunoistoquímicas e moleculares de 234 casos de LB no Brasil. Esta série representa a maior casuística de LB estudada no país até o momento e o primeiro a analisar casos provenientes das 5 regiões geográficas, em pacientes pediátricos e adultos. 


\section{CONCLUSÕES}

Os resultados obtidos permitem as seguintes conclusões:

1. As características clínicas e morfológicas na população geral do estudo, indicam predomínio de casos pediátricos, de pacientes do sexo masculino e de apresentação extranodal (especialmente em topografia abdominal), com raro envolvimento de ossos da face e são semelhantes às observadas na forma esporádica do LB ocorrendo nos EUA e Europa; há certa variação em algumas regiões geográficas, como predomínio de população adulta nas regiões Centro-Oeste e Sul; os casos de LB associados ao HIV apresentaram características clínicas semelhantes às referidas em outros estudos;

2. A associação entre LB e infecção pelo EBV no Brasil é intermediária entre o LB endêmico e a forma esporádica; maior associação com infecção por EBV foi observada nas regiões Norte e Nordeste; a região Sul apresentou freqüencia de associação com EBV semelhante à observada em LB esporádico em países desenvolvidos; houve predomínio de EBV do tipo A na população geral do estudo, incluindo os casos de LB associados ao HIV, porém com certa variação entre as regiões geográficas;

3. Com relação ao estudo imunoistoquímico, foi freqüente a expressão para MUM1/IRF4; este marcador não deve ser usado isoladamente para o diagnóstico diferencial entre LB e LDGCB; a associação 
entre a expressão de proteína MUM1/IRF4 e EBV foi significativa e teve sentido oposto; a expressão da proteína p53 correlacionou-se de maneira inversa com a infecção pelo EBV; foi infreqüente a expressão da proteína p63, não sendo marcador útil para o diagnóstico ou efeito prognóstico no LB;

4. Não se observou infecção pelo HHV-8 em qualquer um dos casos analisados através de estudo imunoistoquímico e PCR. 
ANEXO 
Anexo: Resultados gerais dos casos de Linfoma de Burkitt

\begin{tabular}{|c|c|c|c|c|c|c|c|c|c|c|c|c|c|c|}
\hline CASO & DIAGNÓSTICO & IDADE & SEXO & TOPOGRAFIA & REGIÃO & BCL-6 & ISH-EBV/TIPO & LMP-1 & PAX-5 & MUM1 & FISH MYC & p53 & p63 & HIV \\
\hline ;B 454/98 & L. Burkitt atípico & 29 & $\mathrm{~F}$ & Ovário & Sudeste & NEG & NEG & NEG & POS & POS & $18 \%$ & NEG & NEG & NEG \\
\hline ;B 514/98 & L. Burkitt & 19 & M & Linf. axilar & Nordeste & NEG & NEG & NEG & NEG & POS & $11 \%$ & NEG & NEG & NEG \\
\hline :B 1454/98 & L. Burkitt & 75 & M & Linf. axilar & Centro-Oeste & NEG & NEG & NEG & POS & NEG & $5 \%$ & NEG & NEG & NEG \\
\hline ;B 1557/99 & L. Burkitt & 5 & M & Intestino & Nordeste & POS & NEG & NEG & POS & POS & $3,30 \%$ & NEG & NEG & NEG \\
\hline ;B 2838/99 & L. Burkitt & 15 & $\mathrm{~F}$ & Bochecha & Sudeste & POS & POS A & NEG & POS & NEG & $9 \%$ & NEG & NEG & NEG \\
\hline ;B 5222/99 & L. Burkitt & 5 & $\mathrm{~F}$ & Intestino SOE & Sudeste & NEG & POS B & NEG & POS & POS & $16,70 \%$ & NEG & NEG & NEG \\
\hline ;B 5704/99 & L. Burkitt & 3 & M & Mandíbula & Sul & POS & NEG & NEG & POS & NEG & $13,20 \%$ & NEG & NEG & NEG \\
\hline ;B 6130/99 & L. Burkitt atípico & 19 & M & Abdominal EN SOE & Sul & POS & POS A & NEG & POS & NEG & $28,60 \%$ & NEG & NEG & NEG \\
\hline ;B 2367/00 & L. Burkitt & 38 & M & Fossa temporal & Sudeste & POS & POS A & NEG & POS & NEG & $5,20 \%$ & NEG & NEG & NEG \\
\hline ;B 3142/00 & L. Burkitt & 9 & M & Intestino delgado & Sudeste & POS & POS A & NEG & POS & NEG & $19,90 \%$ & NEG & NEG & NEG \\
\hline ;B 4708/00 & L. Burkitt atípico & 13 & M & Ceco & Sul & NEG & NEG & NEG & POS & NEG & $7,90 \%$ & NEG & NEG & NEG \\
\hline ;B 5375/00 & L. Burkitt & NR & M & Intestino SOE & Sul & POS & NEG & NEG & POS & POS & $23,50 \%$ & NEG & NEG & NEG \\
\hline ;B 7791/00 & L. Burkitt & 66 & $\mathrm{~F}$ & Intestino delgado & Centro-Oeste & POS & NEG & NEG & POS & NEG & $6,30 \%$ & POS & NEG & NEG \\
\hline ;B 8884/00 & L. Burkitt & 19 & M & Abdominal EN SOE & Sul & NEG & NEG & NEG & POS & POS & $15,40 \%$ & NEG & NEG & NEG \\
\hline ;B 698/01 & L. Burkitt & NR & $\mathrm{F}$ & Intestino delgado & Sul & POS & POS A & NEG & POS & NEG & $3,30 \%$ & NEG & NEG & NEG \\
\hline ;B 1458/01 & L. Burkitt & 5 & M & NR & Nordeste & POS & POS A & NEG & POS & NEG & $19,90 \%$ & NEG & NEG & NEG \\
\hline ;B 1846/01 & L. Burkitt atípico & 33 & M & Linf. inguinal & Sudeste & POS & NEG & NEG & POS & NEG & $11,60 \%$ & NEG & NEG & NEG \\
\hline ;B 1972/01 & L. Burkitt & 34 & M & Linf. cervical & Nordeste & POS & NEG & NEG & POS & NEG & $16,50 \%$ & POS & NEG & POS \\
\hline ;B 2882/01 & L. Burkitt & 25 & M & Linf. retroperitoneal & Sul & POS & NEG & NEG & POS & NEG & $2,20 \%$ & NEG & NEG & NEG \\
\hline ;B 8472/01 & L. Burkitt & 53 & M & Fígado & Sudeste & POS & POS A & NEG & POS & NEG & $19,60 \%$ & NEG & NEG & NEG \\
\hline ;B 8701/01 & L. Burkitt & 7 & M & Linf. cervical & Nordeste & POS & NEG & NEG & POS & NEG & $4,30 \%$ & NEG & NEG & NEG \\
\hline ;B 8956/01 & L. Burkitt atípico & 14 & M & Linf. SOE & Sudeste & POS & NEG & NEG & POS & NEG & $2,40 \%$ & NEG & NEG & NEG \\
\hline ;B 8999/01 & L. Burkitt & 10 & $\mathrm{~F}$ & NR & Nordeste & POS & POS I & NEG & POS & POS & $5,10 \%$ & NEG & NEG & NEG \\
\hline ;B 10760/01 & L. Burkitt plasm. & 46 & M & Epíplon/mesentério & Sudeste & POS & NEG & NEG & POS & NEG & $9,20 \%$ & NEG & NEG & NEG \\
\hline :B 10805/01 & L. Burkitt & 3 & M & Íleo terminal & Sudeste & POS & NEG & NEG & POS & POS & $4,70 \%$ & NEG & NEG & NEG \\
\hline ;B 328/02 & L. Burkitt & 5 & M & Abdominal EN SOE & Nordeste & POS & NEG & NEG & POS & POS & $4 \%$ & NEG & NEG & NEG \\
\hline ;B 1332/02 & L. Burkitt & 52 & $\mathrm{~F}$ & Tireóide & Sul & POS & NEG & NEG & POS & NEG & $6,60 \%$ & NEG & NEG & NEG \\
\hline ;B 2956/02 & L. Burkitt plasm. & 2 & M & Linf. cervical & Nordeste & POS & POS B & NEG & POS & POS & $19,10 \%$ & NEG & NEG & NEG \\
\hline ;B 4080/02 & L. Burkitt & 11 & M & Linf. cervical & Sudeste & POS & NEG & NEG & POS & NEG & $2,60 \%$ & NEG & NEG & NEG \\
\hline ;B 4140/02 & L. Burkitt & 5 & M & Mesentério & Norte & POS & POS B & NEG & POS & POS & $14 \%$ & NEG & NEG & NEG \\
\hline ;B 4725/02 & L. Burkitt & 11 & M & Linf. retroperitoneal & Nordeste & POS & NEG & NEG & POS & POS & $21,40 \%$ & NEG & NEG & NEG \\
\hline ;B 5434/02 & L. Burkitt atípico & 80 & M & Estômago & Sudeste & POS & NEG & NEG & POS & POS & $2,60 \%$ & NEG & NEG & NEG \\
\hline ;B 6937/02 & L. Burkitt atípico & 28 & $\mathrm{M}$ & Sigmóide & Nordeste & POS & NEG & NEG & POS & POS & $18 \%$ & POS & NEG & NEG \\
\hline ;B 7675/02 & L. Burkitt & 18 & $\mathrm{~F}$ & Linf. cervical & Sudeste & POS & POS A & NEG & POS & NEG & $4,50 \%$ & NEG & NEG & NEG \\
\hline ;B 8317/02 & L. Burkitt & 17 & M & Válvula íleo-cecal & Sul & POS & NEG & NEG & POS & NEG & $19 \%$ & NEG & NEG & NEG \\
\hline ;B 8375/02 & L. Burkitt & 3 & M & Mesentério & Nordeste & POS & POS I & NEG & POS & NEG & $3,50 \%$ & NEG & NEG & NEG \\
\hline ;B 8736/02 & L. Burkitt & 5 & M & Íleo & Norte & POS & POS B & NEG & POS & NEG & $5,50 \%$ & NEG & NEG & NEG \\
\hline ;B 8807/02 & L. Burkitt & 4 & M & Íleo & Nordeste & NEG & POS B & NEG & POS & POS & $9,90 \%$ & NEG & NEG & NEG \\
\hline :B 8894/02 & L. Burkitt & 5 & $\mathrm{M}$ & Abdominal EN SOE & Nordeste & POS & POS B & NEG & POS & POS & $13,10 \%$ & NEG & POS & NEG \\
\hline
\end{tabular}

L.,linfoma; F, feminino; M, masculino; NEG, negativo; POS, positivo; I, inconclusivo; linf.; linfonodo; EN, extranodal; SOE, sem outra especificação; NR, não referido; m, meses; plasm, plasmacitóide. 
Continuação - Anexo: Resultados gerais dos casos de Linfoma de Burkitt

\begin{tabular}{|c|c|c|c|c|c|c|c|c|c|c|c|c|c|c|}
\hline CASO & D. ORIGINAL & IDADE & SEXO & L. LESÃO & REGIÃO & BCL-6 & ISH-EBV & LMP-1 & PAX-5 & MUM1 & FISH MYC & p53 & p63 & HIV \\
\hline CB 9192/02 & L. Burkitt & 19 & $M$ & Intestino delgado & Sudeste & POS & NEG & NEG & POS & NEG & $24,50 \%$ & NEG & NEG & NEG \\
\hline CB 10477/02 & L. Burkitt & 20 & M & Linf. cervical & Sudeste & POS & NEG & NEG & POS & POS & $14,40 \%$ & NEG & NEG & NEG \\
\hline CB 11439/02 & L. Burkitt & 40 & $M$ & Linf. retroperitoneal & Nordeste & POS & POS A & NEG & POS & NEG & $7,80 \%$ & NEG & NEG & POS \\
\hline CB 1309/03 & L. Burkitt & 5 & $M$ & Abdominal EN SOE & Sudeste & POS & POS A & NEG & POS & NEG & $2,50 \%$ & NEG & NEG & NEG \\
\hline CB 1414/03 & L. Burkitt & 10 & $\mathrm{M}$ & Mandíbula & Centro-Oeste & POS & POS B & NEG & POS & NEG & $15,30 \%$ & NEG & NEG & NEG \\
\hline CB 1639/03 & L. Burkitt atípico & 65 & $\mathrm{~F}$ & Estômago & Sul & POS & NEG & NEG & POS & POS & $2,40 \%$ & NEG & NEG & NEG \\
\hline CВ 4354/03 & L. Burkitt & 7 & M & Abdominal EN SOE & Sudeste & POS & NEG & NEG & POS & POS & $5 \%$ & NEG & NEG & NEG \\
\hline CB 4385/03 & L. Burkitt & 41 & M & Linf. axilar & Sul & POS & POS A & NEG & POS & POS & $14,30 \%$ & NEG & NEG & NEG \\
\hline CB 4547/03 & L. Burkitt & 34 & $\mathrm{~F}$ & Maxila & Centro-Oeste & POS & NEG & NEG & POS & POS & $2,50 \%$ & NEG & NEG & NEG \\
\hline CB 6491/03 & L. Burkitt & 8 & $\mathrm{~F}$ & Orofaringe & Sudeste & POS & NEG & NEG & POS & POS & $20 \%$ & NEG & NEG & NEG \\
\hline CB 7353/03 & L. Burkitt & 33 & M & Linf. cervical & Centro-Oeste & POS & NEG & NEG & POS & POS & $15,10 \%$ & POS & NEG & NEG \\
\hline CB 7983/03 & L. Burkitt & 6 & M & Abdominal EN SOE & Nordeste & POS & POS I & NEG & POS & NEG & $2,40 \%$ & NEG & NEG & NEG \\
\hline CB 8153/03 & L. Burkitt & 30 & M & Abdominal EN SOE & Centro-Oeste & POS & NEG & NEG & POS & POS & $17,20 \%$ & NEG & NEG & NEG \\
\hline CB 8873/03 & L. Burkitt & 43 & M & Linf. inguinal & Sudeste & POS & NEG & NEG & POS & NEG & $8,90 \%$ & NEG & NEG & NEG \\
\hline CВ 9541/03 & L. Burkitt & 31 & M & Linf. SOE & Sul & POS & NEG & NEG & POS & POS & $16 \%$ & POS & NEG & NEG \\
\hline CB 10020/03 & L. Burkitt & 25 & $\mathrm{~F}$ & Linf. axilar & Sudeste & POS & POS B & NEG & POS & POS & $25,20 \%$ & NEG & NEG & POS \\
\hline CB 12123/03 & L. Burkitt & 12 & $\mathrm{~F}$ & Linf. SOE & Nordeste & POS & NEG & NEG & POS & POS & $15,60 \%$ & POS & NEG & NEG \\
\hline CB $12267 / 03$ & L. Burkitt & 8 & M & Região escrotal SOE & Sudeste & POS & POS A & NEG & POS & POS & $15,30 \%$ & NEG & NEG & NEG \\
\hline CB $12296 / 03$ & L. Burkitt & 49 & M & Cólon & Sul & POS & NEG & NEG & POS & NEG & $18,20 \%$ & NEG & NEG & NEG \\
\hline CB 12622/03 & L. Burkitt & 8 & $\mathrm{~F}$ & Abdominal EN SOE & Sudeste & POS & POS A & NEG & POS & POS & $10,60 \%$ & NEG & NEG & NEG \\
\hline CB $13267 / 03$ & L. Burkitt & 7 & $\mathrm{~F}$ & Ceco & Sudeste & NEG & NEG & NEG & POS & POS & $13,30 \%$ & POS & NEG & NEG \\
\hline CB14599/03 & L. Burkitt & 8 & M & Linf. cervical & Sul & POS & NEG & NEG & POS & NEG & $11,20 \%$ & NEG & NEG & NEG \\
\hline CB 77/04 & L. Burkitt & 45 & M & Linf. axilar & Sudeste & POS & POS A & NEG & POS & NEG & $11,60 \%$ & NEG & NEG & NEG \\
\hline СВ 904/04 & L. Burkitt & NR & $\mathrm{F}$ & Linf. axilar & Sudeste & POS & POS A & NEG & POS & NEG & $8,40 \%$ & NEG & NEG & NEG \\
\hline CB 1149/04 & L. Burkitt & 18 & M & Quiasma óptico & Sul & NEG & POS A & NEG & POS & POS & $8,50 \%$ & NEG & NEG & NEG \\
\hline CB 1675/04 & L. Burkitt & 38 & $\mathrm{~F}$ & Estômago & Sudeste & POS & POS A & NEG & POS & NEG & $7,90 \%$ & NEG & NEG & NEG \\
\hline CB 2292/04 & L. Burkitt & 5 & M & Estômago & Nordeste & POS & POS A & NEG & POS & NEG & $7,80 \%$ & NEG & NEG & NEG \\
\hline CB 3713/04 & L. Burkitt & 19 & M & Linf. cervical & Norte & I & I & I & 1 & I & $3,20 \%$ & I & 1 & NEG \\
\hline CВ 3741/04 & L. Burkitt & 5 & M & NR & Norte & POS & NEG & NEG & POS & POS & $6,90 \%$ & NEG & NEG & NEG \\
\hline CB 5036/04 & L. Burkitt & 3 & M & NR & Sudeste & POS & POS A & NEG & POS & NEG & $6,80 \%$ & NEG & NEG & NEG \\
\hline CB 5192/04 & L. Burkitt & 10 & M & Íleo & Norte & POS & POS A & NEG & POS & NEG & $9,40 \%$ & NEG & NEG & NEG \\
\hline CB 5282/04 & L. Burkitt & 15 & $\mathrm{M}$ & Abdominal EN SOE & Sul & POS & NEG & NEG & POS & POS & $20,50 \%$ & NEG & NEG & NEG \\
\hline CB 6181/04 & L. Burkitt & 42 & $\mathrm{M}$ & Intestino SOE & Centro-Oeste & POS & POS B & NEG & POS & NEG & $16 \%$ & NEG & NEG & NEG \\
\hline CB 6565/04 & L. Burkitt & 28 & $\mathrm{~F}$ & Intestino SOE & Sudeste & NEG & NEG & NEG & POS & POS & $19 \%$ & POS & NEG & NEG \\
\hline CB 6759/04 & L. Burkitt & 13 & $\mathrm{~F}$ & Intestino SOE & Sudeste & POS & NEG & NEG & POS & NEG & $14,40 \%$ & NEG & NEG & NEG \\
\hline CB 6777/04 & L. Burkitt & 37 & $\mathrm{M}$ & Linf. axilar & Nordeste & POS & POS A & NEG & POS & NEG & $7,70 \%$ & NEG & NEG & NEG \\
\hline CB 7280/04 & L. Burkitt & 6 & M & Abdominal EN SOE & Nordeste & POS & POS B & NEG & POS & NEG & $8,90 \%$ & POS & NEG & NEG \\
\hline CB 7442/04 & L. Burkitt & 13 & $\mathrm{~F}$ & Linf. cervical & Nordeste & POS & NEG & NEG & POS & NEG & $3,50 \%$ & NEG & NEG & NEG \\
\hline CB 7467/04 & L. Burkitt & 7 & M & Abdominal EN SOE & Nordeste & NEG & NEG & NEG & NEG & NEG & $4 \%$ & NEG & NEG & NEG \\
\hline
\end{tabular}

L.,linfoma; F, feminino; M, masculino; NEG, negativo; POS, positivo; I, inconclusivo; linf.; linfonodo; EN, extranodal; SOE, sem outra especificação; NR, não referido; m, meses; plasm, plasmacitóide. 
Continuação - Anexo: Resultados gerais dos casos de Linfoma de Burkitt

\begin{tabular}{|c|c|c|c|c|c|c|c|c|c|c|c|c|c|c|}
\hline ASO & D. ORIGINAL & IDADE & SEXO & L. LESÃO & REGIÃO & BCL-6 & ISH-EBV & LMP-1 & PAX-5 & MUM1 & FISH MYC & p53 & p63 & HIV \\
\hline ;B 7995/04 & L. Burkitt & 8 & $\mathrm{M}$ & Amígdala & Nordeste & POS & NEG & NEG & POS & POS & $16,70 \%$ & NEG & NEG & NEG \\
\hline ;B 8267/04 & L. Burkitt & 11 & $\mathrm{~F}$ & Amígdala & Nordeste & POS & POS I & NEG & POS & POS & $12,20 \%$ & NEG & NEG & NEG \\
\hline ;B 9831/04 & L. Burkitt atípico & 4 & M & Abdominal EN SOE & Nordeste & POS & POS B & NEG & POS & NEG & $11,40 \%$ & NEG & NEG & NEG \\
\hline :B 11938/04 & L. Burkitt & 34 & $\mathrm{~F}$ & Abdominal EN SOE & Sul & POS & POS A & NEG & NEG & NEG & $22,30 \%$ & NEG & NEG & NEG \\
\hline :B 12281/04 & L. Burkitt & 6 & $\mathrm{M}$ & Abdominal EN SOE & Sudeste & POS & POS A & NEG & POS & NEG & $7,70 \%$ & NEG & NEG & NEG \\
\hline ;B 13201/04 & L. Burkitt & 48 & M & Linf. cervical & Sudeste & POS & POS A & NEG & POS & POS & $12,50 \%$ & POS & NEG & NEG \\
\hline ;B 13410/04 & L. Burkitt & 6 & M & Nasofaringe & Nordeste & POS & NEG & NEG & POS & NEG & $14,70 \%$ & POS & NEG & NEG \\
\hline :B 14849/04 & L. Burkitt & 10 & $\mathrm{~F}$ & Tireóide & Sudeste & NEG & NEG & NEG & POS & NEG & $13,20 \%$ & NEG & NEG & NEG \\
\hline ;B 14905/04 & L. Burkitt & 26 & $\mathrm{~F}$ & Linf. SOE & Nordeste & POS & POS A & NEG & POS & NEG & $2,60 \%$ & NEG & NEG & NEG \\
\hline :B 15071/04 & L. Burkitt & 3 & $\mathrm{~F}$ & Abdominal EN SOE & Nordeste & POS & POS A & NEG & POS & NEG & $14,90 \%$ & NEG & NEG & NEG \\
\hline ;B 15453/04 & L. Burkitt & 37 & M & Palato & Nordeste & POS & NEG & NEG & POS & NEG & $4,90 \%$ & NEG & POS & NEG \\
\hline ;B 15997/04 & L. Burkitt & 5 & $\mathrm{M}$ & Abdominal EN SOE & Sudeste & NEG & POS A & NEG & POS & NEG & $10,70 \%$ & NEG & NEG & NEG \\
\hline ;B 16160/04 & L. Burkitt & 37 & M & Omento & Sudeste & POS & NEG & NEG & POS & NEG & $20,70 \%$ & NEG & POS & NEG \\
\hline :B 16713/04 & L. Burkitt & 33 & $\mathrm{M}$ & Apêndice cecal & Sudeste & POS & NEG & NEG & POS & POS & $17,80 \%$ & NEG & NEG & NEG \\
\hline ;B 16886/04 & L. Burkitt & 21 & M & Linf. submandibular & Nordeste & POS & POS A & NEG & POS & POS & $8,95 \%$ & NEG & NEG & NEG \\
\hline ;B 16983/04 & L. Burkitt atípico & 15 & $\mathrm{M}$ & Abdominal EN SOE & Nordeste & POS & POS A & NEG & POS & NEG & $11,30 \%$ & NEG & NEG & NEG \\
\hline :B 17182/04 & L. Burkitt & 37 & $\mathrm{~F}$ & Tireóide & Sul & POS & NEG & NEG & POS & NEG & $3,50 \%$ & NEG & NEG & NEG \\
\hline :B 17262/04 & L. Burkitt & 40 & M & Parede torácica SOE & Nordeste & POS & NEG & NEG & POS & NEG & $11,40 \%$ & NEG & POS & NEG \\
\hline ;B 2505/05 & L. Burkitt & 25 & $\mathrm{~F}$ & Linf. inguinal & Sudeste & POS & POS A & NEG & POS & NEG & $10,40 \%$ & NEG & NEG & NEG \\
\hline ;B 4227/05 & L. Burkitt & 5 & $\mathrm{M}$ & Abdominal EN SOE & Nordeste & POS & POS A & NEG & POS & NEG & $10,50 \%$ & NEG & NEG & NEG \\
\hline ;B 4504/05 & L. Burkitt & 32 & M & Linf. axilar & Sudeste & POS & POS A & 1 & POS & NEG & $10 \%$ & NEG & NEG & POS \\
\hline ;B 4558/05 & L. Burkitt & 13 & $\mathrm{~F}$ & Ovário & Norte & POS & POS A & NEG & POS & NEG & $10,70 \%$ & POS & NEG & NEG \\
\hline ;B 4739/05 & L. Burkitt & 46 & $\mathrm{~F}$ & Linf. inguinal & Sul & POS & NEG & NEG & POS & POS & $16,60 \%$ & NEG & NEG & NEG \\
\hline ;B 5308/05 & L. Burkitt & 26 & $\mathrm{M}$ & Vértebra & Nordeste & POS & NEG & NEG & POS & NEG & $3 \%$ & NEG & POS & NEG \\
\hline ;B 5531/05 & L. Burkitt & 20 & M & Fígado & Centro-Oeste & POS & POS A & NEG & POS & NEG & $2,80 \%$ & NEG & NEG & NEG \\
\hline ;B 6290/05 & L. Burkitt & 6 & M & Abdominal EN SOE & Sul & NEG & NEG & NEG & NEG & NEG & $9,80 \%$ & POS & NEG & NEG \\
\hline ;B 6573/05 & L. Burkitt & 27 & $\mathrm{M}$ & Linf. inguinal & Sudeste & POS & NEG & NEG & POS & POS & $20,50 \%$ & NEG & NEG & NEG \\
\hline ;B 7227/05 & L. Burkitt & 6 & $\mathrm{M}$ & Íleo & Sudeste & NEG & NEG & NEG & POS & POS & $16,90 \%$ & NEG & NEG & NEG \\
\hline ;B 7320/05 & L. Burkitt plasm. & 23 & $\mathrm{M}$ & Estômago & Norte & NEG & POS A & NEG & POS & POS & $16,80 \%$ & NEG & NEG & NEG \\
\hline ;B 7574/05 & L. Burkitt & 5 & $\mathrm{M}$ & Linf. cervical & Nordeste & POS & POS A & NEG & POS & NEG & $8,30 \%$ & NEG & NEG & NEG \\
\hline ;B 7929/05 & L. Burkitt & 49 & M & Ceco & Nordeste & POS & POS A & NEG & POS & NEG & $9,10 \%$ & NEG & NEG & NEG \\
\hline ;B 8522/05 & L. Burkitt & 23 & $\mathrm{~F}$ & Ovário & Sul & POS & POS A & NEG & POS & NEG & $15,20 \%$ & NEG & NEG & NEG \\
\hline ;B 9090/05 & L. Burkitt & 9 & $\mathrm{M}$ & Abdominal EN SOE & Nordeste & POS & POS A & NEG & POS & NEG & $20 \%$ & NEG & NEG & NEG \\
\hline ;B 9531/05 & L. Burkitt atípico & 15 & M & Íleo terminal & Sul & POS & NEG & NEG & POS & POS & $3,20 \%$ & POS & NEG & NEG \\
\hline ;B 9815/05 & L. Burkitt & 7 & M & Abdominal EN SOE & Nordeste & POS & POS A & NEG & POS & NEG & $8,60 \%$ & NEG & NEG & NEG \\
\hline :B 9970/05 & L. Burkitt plasm. & 30 & M & Fígado & Sudeste & POS & NEG & NEG & POS & NEG & $4,20 \%$ & NEG & NEG & NEG \\
\hline ;B 10041/05 & L. Burkitt & 56 & $\mathrm{~F}$ & Fígado & Sul & POS & NEG & NEG & POS & POS & $19,30 \%$ & NEG & POS & NEG \\
\hline :B 10102/05 & L. Burkitt & 40 & $\mathrm{~F}$ & Reto & Nordeste & POS & POS B & NEG & POS & NEG & $9,80 \%$ & NEG & POS & NEG \\
\hline :B 10676/05 & L. Burkitt & 6 & $\mathrm{M}$ & Intestino SOE & Nordeste & NEG & NEG & NEG & POS & NEG & $6,40 \%$ & NEG & NEG & NEG \\
\hline
\end{tabular}

L.,linfoma; F, feminino; M, masculino; NEG, negativo; POS, positivo; I, inconclusivo; linf.; linfonodo; EN, extranodal; SOE, sem outra especificação; NR, não referido; m, meses; plasm, plasmacitóide. 
Continuação - Anexo: Resultados gerais dos casos de Linfoma de Burkitt

\begin{tabular}{|c|c|c|c|c|c|c|c|c|c|c|c|c|c|c|}
\hline ASO & D. ORIGINAL & IDADE & SEXO & L. LESÃO & REGIÃO & $\mathrm{BCL}-6$ & ISH-EBV & LMP-1 & PAX-5 & MUM1 & FISH MYC & p53 & p63 & HIV \\
\hline ; 12366/05 & L. Burkitt & 3 & $\mathrm{~F}$ & Região pélvica SOE & Nordeste & POS & POS A & NEG & POS & POS & $17,20 \%$ & POS & NEG & NEG \\
\hline ;B 13222/05 & L. Burkitt & 44 & M & Couro cabeludo & Sudeste & POS & POS A & NEG & POS & NEG & $17,20 \%$ & NEG & NEG & POS \\
\hline ;B 14325/05 & L. Burkitt & 14 & M & Abdominal EN SOE & Sul & POS & NEG & NEG & POS & POS & $14,80 \%$ & NEG & NEG & NEG \\
\hline :B 15251/05 & L. Burkitt & 81 & $\mathrm{~F}$ & Abdominal EN SOE & Sul & POS & NEG & NEG & POS & POS & $11,20 \%$ & NEG & NEG & NEG \\
\hline ;B 15624/05 & L. Burkitt & 5 & M & Íleo & Nordeste & NEG & POS B & NEG & POS & NEG & $3,60 \%$ & NEG & NEG & NEG \\
\hline :B 15972/05 & L. Burkitt & 4 & M & Amígdala & Sudeste & POS & NEG & NEG & POS & POS & $21,80 \%$ & POS & NEG & NEG \\
\hline ;B 16017/05 & L. Burkitt & 21 & M & Linf. cervical & Nordeste & POS & NEG & NEG & POS & POS & $15,30 \%$ & POS & NEG & NEG \\
\hline :B 16525/05 & L. Burkitt & 8 & M & Intestino grosso & Norte & NEG & POS B & NEG & POS & POS & $10,30 \%$ & NEG & NEG & NEG \\
\hline :B 17358/05 & L. Burkitt & 25 & M & Duodeno & Sudeste & POS & POS A & NEG & POS & NEG & $13,10 \%$ & NEG & NEG & POS \\
\hline ;B 17459/05 & L. Burkitt & 2 & M & Mesentério & Nordeste & NEG & NEG & NEG & POS & NEG & $18,80 \%$ & NEG & NEG & NEG \\
\hline ;B 17890/05 & L. Burkitt & 29 & $\mathrm{~F}$ & Linf. axilar & Sudeste & POS & POS A & NEG & POS & NEG & $22,10 \%$ & NEG & NEG & NEG \\
\hline :B 18127/05 & L. Burkitt atípico & 43 & M & Linf. cervical & Sul & POS & NEG & NEG & POS & POS & $3,20 \%$ & POS & POS & NEG \\
\hline :B 19347/05 & L. Burkitt & 40 & $\mathrm{M}$ & Linf. cervical & Sul & POS & POS A & NEG & POS & NEG & $20,60 \%$ & NEG & NEG & NEG \\
\hline ;B 1/06 & L. Burkitt & 52 & $\mathrm{~F}$ & Tu abdominal & Nordeste & POS & POS A & NEG & POS & POS & $16,20 \%$ & NEG & NEG & POS \\
\hline :B 274/06 & L. Burkitt & 14 & M & Mesentério & Sul & POS & NEG & NEG & POS & NEG & $19,30 \%$ & NEG & NEG & NEG \\
\hline ;B 718/06 & L. Burkitt & 7 & M & Cólon & Nordeste & POS & NEG & NEG & POS & POS & $15,90 \%$ & NEG & NEG & NEG \\
\hline :B 951/06 & L. Burkitt & 3 & $M$ & Intestino delgado & Sul & POS & POS A & NEG & POS & NEG & $15,80 \%$ & NEG & NEG & NEG \\
\hline ;B 1832/06 & L. Burkitt plasm. & 22 & $\mathrm{M}$ & Linf. inguinal & Nordeste & POS & POS B & NEG & POS & NEG & $14,70 \%$ & NEG & NEG & NEG \\
\hline ;B 2263/06 & L. Burkitt & 58 & M & Nasofaringe & Nordeste & POS & POS A & NEG & POS & NEG & $6,10 \%$ & NEG & NEG & NEG \\
\hline ;B 2523/06 & L. Burkitt & 2 & $\mathrm{M}$ & Glândula salivar & Sudeste & POS & POS A & NEG & POS & POS & $15,40 \%$ & NEG & NEG & POS \\
\hline ;B 3232/06 & L. Burkitt & 39 & $M$ & Linf. inguinal & Sul & POS & NEG & NEG & POS & NEG & $15,70 \%$ & NEG & NEG & NEG \\
\hline ;B 4636/06 & L. Burkitt & 42 & M & Íleo & Sudeste & POS & NEG & NEG & POS & NEG & $3,20 \%$ & NEG & NEG & POS \\
\hline ;B 6265/06 & L. Burkitt & 41 & M & Linf. axilar & Sul & POS & POS A & NEG & POS & NEG & $15,50 \%$ & NEG & POS & NEG \\
\hline ;B 7449/06 & L. Burkitt & 13 & $\mathrm{~F}$ & Linf. cervical & Sul & POS & NEG & NEG & POS & POS & $18,60 \%$ & NEG & NEG & NEG \\
\hline ;B 7618/06 & L. Burkitt & 6 & M & Linf. retroperitoneal & Sudeste & POS & POS A & NEG & POS & NEG & $21,10 \%$ & NEG & NEG & NEG \\
\hline ;B 7916/06 & L. Burkitt & 34 & M & Linf. cervical & Sul & NEG & NEG & NEG & POS & POS & $6,70 \%$ & NEG & NEG & NEG \\
\hline ;B 8939/06 & L. Burkitt & 10 & M & Intestino SOE & Sudeste & POS & NEG & NEG & POS & NEG & $15,30 \%$ & POS & NEG & NEG \\
\hline :B 9495/06 & L. Burkitt & 74 & $\mathrm{~F}$ & Linf. retroperitoneal & Sul & POS & NEG & NEG & POS & NEG & $17,40 \%$ & NEG & NEG & NEG \\
\hline :B 10447/06 & L. Burkitt atípico & 3 & M & Fígado & Nordeste & POS & NEG & NEG & POS & NEG & $21,80 \%$ & NEG & NEG & NEG \\
\hline ;B 10859/06 & L. Burkitt & 23 & M & Cólon & Sul & POS & NEG & NEG & POS & POS & $18,80 \%$ & NEG & NEG & NEG \\
\hline ;B 11122/06 & L. Burkitt & 3 & M & Intestino SOE & Nordeste & POS & POS A & NEG & POS & NEG & $15 \%$ & NEG & NEG & NEG \\
\hline ;B 11636/06 & L. Burkitt atípico & 67 & $\mathrm{M}$ & Linf. retroperitônio & Centro-Oeste & POS & NEG & NEG & POS & NEG & $3,60 \%$ & POS & NEG & NEG \\
\hline :B 12607/06 & L. Burkitt & 7 & $\mathrm{~F}$ & Linf. cervical & Nordeste & POS & NEG & NEG & POS & NEG & $6,70 \%$ & POS & NEG & POS \\
\hline :B 13768/06 & L. Burkitt plasm. & 17 & M & Linf. omento & Sudeste & POS & NEG & NEG & POS & NEG & $8,20 \%$ & NEG & NEG & NEG \\
\hline ;B 13773/06 & L. Burkitt & 3 & M & Intestino SOE & Nordeste & POS & POS A & NEG & POS & NEG & $6 \%$ & NEG & NEG & NEG \\
\hline :B 14086/06 & L. Burkitt & 30 & $\mathrm{M}$ & Mesentério & Centro-Oeste & POS & POS B & NEG & POS & NEG & $17,10 \%$ & NEG & NEG & POS \\
\hline ;B 15619/06 & L. Burkitt & 51 & $\mathrm{~F}$ & Linf. cervical & Nordeste & POS & POS A & NEG & POS & NEG & $10,60 \%$ & NEG & NEG & NEG \\
\hline ;B 15643/06 & L. Burkitt & 6 & M & Abdominal EN SOE & Nordeste & POS & POS A & NEG & POS & POS & $18,60 \%$ & NEG & NEG & NEG \\
\hline ;B 15971/06 & L. Burkitt & 4 & $\mathrm{~F}$ & Intestino SOE & Sudeste & POS & POS A & POS & POS & NEG & $9 \%$ & POS & NEG & NEG \\
\hline
\end{tabular}

L.,linfoma; F, feminino; M, masculino; NEG, negativo; POS, positivo; I, inconclusivo; linf.; linfonodo; EN, extranodal; SOE, sem outra especificação; NR, não referido; m, meses; plasm, plasmacitóide. 
Continuação - Anexo: Resultados gerais dos casos de Linfoma de Burkitt

\begin{tabular}{|c|c|c|c|c|c|c|c|c|c|c|c|c|c|c|}
\hline ASO & D. ORIGINAL & IDADE & SEXO & L. LESÃO & REGIÃO & BCL-6 & ISH-EBV & LMP-1 & PAX-5 & MUM1 & FISH MYC & p53 & p63 & HIV \\
\hline ; 16792/06 & L. Burkitt & 4 & $M$ & Fígado & Norte & POS & NEG & NEG & POS & POS & $12 \%$ & NEG & NEG & NEG \\
\hline ;B 17126/06 & L. Burkitt & 2 & $\mathrm{~F}$ & Linf. cervical & Nordeste & POS & POS A & NEG & POS & NEG & $4,30 \%$ & NEG & NEG & NEG \\
\hline ;B 18062/06 & L. Burkitt & 3 & $\mathrm{~F}$ & Linf. SOE & Norte & POS & POS A & NEG & POS & NEG & $14,80 \%$ & NEG & NEG & NEG \\
\hline :B 18070/06 & L. Burkitt & 5 & $\mathrm{M}$ & Mesentério & Norte & POS & POS A & NEG & POS & NEG & $19,90 \%$ & NEG & NEG & NEG \\
\hline ;B 18179/06 & L. Burkitt & 5 & $\mathrm{M}$ & Abdominal EN SOE & Nordeste & POS & POS A & NEG & POS & NEG & $20 \%$ & NEG & NEG & NEG \\
\hline :B 18425/06 & L. Burkitt & 9 & $\mathrm{M}$ & Região pélvica SOE & Nordeste & NEG & POS A & NEG & POS & POS & $20,30 \%$ & POS & NEG & NEG \\
\hline ;B 18592/06 & L. Burkitt & 4 & $M$ & Intestino SOE & Sul & POS & POS A & NEG & POS & POS & $21,60 \%$ & POS & NEG & NEG \\
\hline ;B 18885/06 & L. Burkitt & 9 & $\mathrm{M}$ & Pâncreas & Norte & POS & POS B & NEG & POS & NEG & $8 \%$ & POS & NEG & NEG \\
\hline ;B 20154/06 & L. Burkitt & 11 & $\mathrm{~F}$ & Abdominal EN SOE & Sul & POS & NEG & NEG & NEG & POS & $43,20 \%$ & POS & NEG & NEG \\
\hline :B 20780/06 & L. Burkitt & 51 & $\mathrm{M}$ & Linf. axilar & Norte & POS & POS A & NEG & POS & NEG & $14,60 \%$ & NEG & NEG & POS \\
\hline ;B 1921/07 & L. Burkitt & 11 & $M$ & Ceco & Sudeste & POS & POS A & NEG & POS & NEG & $11,10 \%$ & NEG & NEG & NEG \\
\hline ;B 2007/07 & L. Burkitt & 4 & $\mathrm{M}$ & Jejuno/íleo & Norte & NEG & NEG & NEG & POS & NEG & $5 \%$ & NEG & NEG & NEG \\
\hline ;B 2098/07 & L. Burkitt & 5 & $\mathrm{~F}$ & Abdominal EN SOE & Nordeste & POS & POS A & NEG & POS & NEG & $18 \%$ & POS & NEG & NEG \\
\hline ;B 2325/07 & L. Burkitt & 6 & M & Mandíbula & Sudeste & POS & POS A & NEG & POS & POS & $20,10 \%$ & NEG & NEG & NEG \\
\hline ;B 3092/07 & L. Burkitt & 4 & $\mathrm{M}$ & Abdominal EN SOE & Sudeste & POS & POS B & NEG & POS & NEG & $5,00 \%$ & NEG & NEG & NEG \\
\hline ;B 3996/07 & L. Burkitt & 4 & $\mathrm{M}$ & Linf. cervical & Sul & POS & POS B & NEG & POS & POS & $13,20 \%$ & NEG & NEG & NEG \\
\hline ;B 4052/07 & L. Burkitt & 7 & $\mathrm{M}$ & Abdominal EN SOE & Sudeste & POS & POS B & NEG & POS & POS & $16,70 \%$ & NEG & NEG & NEG \\
\hline ;B 4053/07 & L. Burkitt & 5 & $\mathrm{M}$ & Região íleo-cecal & Sudeste & NEG & POS B & NEG & POS & NEG & $4,00 \%$ & NEG & NEG & NEG \\
\hline ;B 4057/07 & L. Burkitt & 6 & $\mathrm{M}$ & Abdominal EN SOE & Sudeste & POS & POS A & NEG & POS & NEG & $5,90 \%$ & NEG & NEG & NEG \\
\hline ;B 4059/07 & L. Burkitt & 12 & $\mathrm{M}$ & Íleo & Sudeste & POS & NEG & NEG & POS & POS & $2,40 \%$ & NEG & NEG & NEG \\
\hline ;B 4061/07 & L. Burkitt & 12 & $\mathrm{~F}$ & Para-ovariana & Sudeste & POS & NEG & NEG & POS & POS & $20,10 \%$ & NEG & NEG & NEG \\
\hline ;B 4171/07 & L. Burkitt & 29 & $\mathrm{M}$ & Linf. cervical & Nordeste & POS & NEG & NEG & POS & POS & $18,00 \%$ & NEG & NEG & NEG \\
\hline ;B 5331/07 & L. Burkitt & 4 & $\mathrm{~F}$ & Abdominal EN SOE & Nordeste & POS & POS A & NEG & POS & NEG & $8,40 \%$ & NEG & NEG & NEG \\
\hline ;B 5694/07 & L. Burkitt plasm. & 3 & $\mathrm{M}$ & Íleo terminal & Nordeste & POS & POS A & NEG & POS & NEG & $4,20 \%$ & NEG & NEG & NEG \\
\hline ;B 5932/07 & L. Burkitt & 14 & $\mathrm{M}$ & Linf. cervical & Nordeste & NEG & NEG & NEG & POS & POS & $4,30 \%$ & POS & NEG & NEG \\
\hline ;B 6344/07 & L. Burkitt & 5 & $\mathrm{M}$ & Intestino delgado & Sudeste & POS & POS A & NEG & POS & POS & $19,80 \%$ & NEG & NEG & NEG \\
\hline ;B 6717/07 & L. Burkitt & 16 & $\mathrm{M}$ & Abdominal EN SOE & Centro-Oeste & POS & NEG & NEG & POS & POS & $18,80 \%$ & POS & NEG & NEG \\
\hline ;B 7843/07 & L. Burkitt & 39 & $\mathrm{M}$ & Linf. axilar & Sudeste & POS & NEG & NEG & POS & NEG & $18,40 \%$ & NEG & NEG & NEG \\
\hline ;B 8058/07 & L. Burkitt & 7 & $\mathrm{~F}$ & Abdominal EN SOE & Centro-Oeste & POS & NEG & NEG & POS & NEG & $21,90 \%$ & NEG & NEG & NEG \\
\hline ;B 9176/07 & L. Burkitt & 9 & M & Intestino delgado & Sudeste & NEG & NEG & NEG & POS & NEG & $2,50 \%$ & NEG & NEG & NEG \\
\hline ;B 9502/07 & L. Burkitt & 3 & $\mathrm{M}$ & Intestino delgado & Sudeste & POS & POS A & NEG & POS & NEG & $12,80 \%$ & NEG & NEG & NEG \\
\hline ; 9504/07 & L. Burkitt & 10 & $M$ & Linf. SOE & Sudeste & POS & NEG & NEG & POS & POS & $25,10 \%$ & NEG & NEG & NEG \\
\hline ;B 9822/07 & L. Burkitt & 45 & $\mathrm{M}$ & Linf. cervical & Sul & NEG & NEG & NEG & POS & NEG & $18,90 \%$ & NEG & NEG & NEG \\
\hline :B 10225/07 & L. Burkitt & 14 & $\mathrm{M}$ & Linf. cervical & Sudeste & POS & NEG & 1 & 1 & NEG & $2,30 \%$ & I & 1 & NEG \\
\hline ;B 10782/07 & L. Burkitt & 10 & $\mathrm{~F}$ & Fossa ilíaca direita & Sudeste & I & POS A & NEG & POS & 1 & $15,50 \%$ & NEG & NEG & NEG \\
\hline ;B 11383/07 & L. Burkitt & 37 & $\mathrm{M}$ & Linf. cervical & Sul & POS & POS A & NEG & POS & NEG & $18,20 \%$ & NEG & NEG & NEG \\
\hline ;B 11467/07 & L. Burkitt & 9 & $\mathrm{M}$ & Abdominal EN SOE & Sudeste & POS & POS A & NEG & POS & NEG & $13,40 \%$ & POS & NEG & NEG \\
\hline :B 12472/07 & L. Burkitt & 7 & $\mathrm{M}$ & Intestino grosso & Nordeste & POS & POS A & NEG & POS & NEG & $2,20 \%$ & NEG & NEG & NEG \\
\hline ;B 12913/07 & L. Burkitt & 7 & M & íleo & Centro-Oeste & POS & POS A & NEG & POS & NEG & $13,50 \%$ & POS & NEG & NEG \\
\hline
\end{tabular}

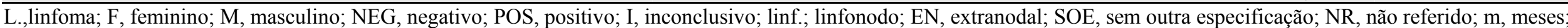
plasm, plasmacitóide. 
Conclusão - Anexo: Resultados gerais dos casos de Linfoma de Burkitt

\begin{tabular}{|c|c|c|c|c|c|c|c|c|c|c|c|c|c|c|}
\hline ASO & D. ORIGINAL & IDADE & SEXO & L. LESÃO & REGIÃO & BCL-6 & ISH-EBV & LMP-1 & PAX-5 & MUM1 & FISH MYC & p53 & p63 & HIV \\
\hline $\bar{B}$ 13405/07 & L. Burkitt & 56 & $\mathrm{~F}$ & Mama & Nordeste & POS & NEG & NEG & POS & POS & $3,80 \%$ & NEG & NEG & $\overline{N E G}$ \\
\hline ;B 13643/07 & L. Burkitt & 10 & $\mathrm{M}$ & Orofatinge & Nordeste & POS & NEG & NEG & POS & POS & $12,60 \%$ & NEG & NEG & NEG \\
\hline ;B 14011/07 & L. Burkitt & 14 & $\mathrm{~F}$ & Linf. cervical & Sudeste & POS & NEG & NEG & POS & NEG & $5,60 \%$ & NEG & NEG & NEG \\
\hline ;B 14012/07 & L. Burkitt & 11 & M & Abdominal EN SOE & Sudeste & POS & NEG & NEG & POS & POS & $22,70 \%$ & POS & NEG & NEG \\
\hline ;B 14013/07 & L. Burkitt & 11 & $\mathrm{M}$ & Mandíbula & Sudeste & POS & NEG & NEG & POS & POS & $19,30 \%$ & POS & NEG & NEG \\
\hline :B 15080/07 & L. Burkitt & 14 & $\mathrm{M}$ & Íleo terminal & Sudeste & POS & NEG & NEG & POS & POS & $15,50 \%$ & NEG & NEG & NEG \\
\hline ;B 15244/07 & L. Burkitt & 6 & M & Abdominal EN SOE & Nordeste & POS & POS B & NEG & POS & NEG & $15,20 \%$ & NEG & NEG & NEG \\
\hline ;B 15307/07 & L. Burkitt & 37 & M & Linf. axilar & Sudeste & POS & POS A & NEG & POS & NEG & $12,60 \%$ & NEG & POS & POS \\
\hline ;B 15902/07 & L. Burkitt & 5 & $M$ & Abdominal EN SOE & Norte & POS & POS A & NEG & POS & POS & $19,90 \%$ & NEG & NEG & NEG \\
\hline :B 15968/07 & L. Burkitt & 4 & $\mathrm{M}$ & Nasofaringe & Nordeste & POS & NEG & NEG & POS & POS & $10,60 \%$ & NEG & NEG & NEG \\
\hline ;B 16234/07 & L. Burkitt & 3 & $\mathrm{~F}$ & Linf. cervical & Centro-Oeste & POS & POS A & NEG & POS & NEG & $15 \%$ & NEG & NEG & NEG \\
\hline :B 16477/07 & L. Burkitt & 4 & M & Abdominal EN SOE & Nordeste & POS & POS A & NEG & POS & POS & $18,70 \%$ & NEG & NEG & NEG \\
\hline ;B 16770/07 & L. Burkitt & 13 & M & Intestino delgado & Centro-Oeste & POS & NEG & NEG & POS & NEG & $4,80 \%$ & NEG & NEG & NEG \\
\hline ;B 17276/07 & L. Burkitt & 3 & $\mathrm{M}$ & Cavidade oral & Nordeste & POS & POS A & NEG & POS & NEG & $11,40 \%$ & NEG & NEG & NEG \\
\hline :B 18276/07 & L. Burkitt & 3 & $\mathrm{~F}$ & Abdominal EN SOE & Centro-Oeste & POS & POS A & NEG & POS & NEG & $17,30 \%$ & NEG & NEG & NEG \\
\hline :B 18444/07 & L. Burkitt & 16 & M & Abdominal EN SOE & Nordeste & POS & NEG & NEG & POS & POS & $19,20 \%$ & NEG & NEG & NEG \\
\hline :B 18951/07 & L. Burkitt & 4 & $\mathrm{M}$ & Epíplon & Sul & POS & NEG & NEG & POS & POS & $18,60 \%$ & POS & NEG & NEG \\
\hline ;B 19149/07 & L. Burkitt & 10 & M & NR & Nordeste & POS & POS A & NEG & POS & NEG & $13,60 \%$ & NEG & NEG & NEG \\
\hline ;B 19152/07 & L. Burkitt & 12 & $M$ & NR & Nordeste & POS & POS A & NEG & POS & NEG & $12 \%$ & NEG & NEG & NEG \\
\hline :B 19154/07 & L. Burkitt & 8 & $\mathrm{M}$ & Abdominal EN SOE & Nordeste & POS & POS A & NEG & POS & NEG & $10,40 \%$ & NEG & NEG & NEG \\
\hline :B 19155/07 & L. Burkitt & 79 & $\mathrm{M}$ & Linf. cervical & Nordeste & POS & POS A & NEG & POS & NEG & $2,80 \%$ & NEG & NEG & NEG \\
\hline :B 19156/07 & L. Burkitt & 24 & $\mathrm{~F}$ & NR & Nordeste & POS & NEG & NEG & NEG & NEG & $3,60 \%$ & NEG & NEG & NEG \\
\hline ;B 19158/07 & L. Burkitt & 7 & $\mathrm{~F}$ & Intestino SOE & Nordeste & NEG & POS A & NEG & POS & POS & $12,90 \%$ & POS & NEG & NEG \\
\hline :B 19159/07 & L. Burkitt & 7 & $\mathrm{~F}$ & Ovário & Nordeste & 1 & NEG & NEG & I & NEG & $3,60 \%$ & NEG & NEG & NEG \\
\hline ;B 19160/07 & L. Burkitt & 7 & $\mathrm{M}$ & Abdominal EN SOE & Nordeste & POS & POS A & NEG & POS & NEG & $20 \%$ & NEG & NEG & NEG \\
\hline :B 19161/07 & L. Burkitt & 6 & $\mathrm{M}$ & Abdominal EN SOE & Nordeste & POS & POS A & NEG & POS & NEG & $14,50 \%$ & NEG & NEG & NEG \\
\hline ;B 19162/07 & L. Burkitt & 13 & $\mathrm{~F}$ & Intestino delgado & Nordeste & POS & NEG & NEG & POS & NEG & $17,70 \%$ & NEG & NEG & NEG \\
\hline ;B 19163/07 & L. Burkitt & 71 & $\mathrm{~F}$ & Linf. cervical & Nordeste & POS & POS A & NEG & POS & POS & $19,50 \%$ & POS & NEG & NEG \\
\hline ;B 19164/07 & L. Burkitt & 3 & $\mathrm{~F}$ & Abdominal EN SOE & Nordeste & POS & POS B & NEG & POS & NEG & $7,90 \%$ & NEG & NEG & NEG \\
\hline :B 19165/07 & L. Burkitt & 6 & $\mathrm{~F}$ & Região íleo-cecal & Nordeste & POS & NEG & NEG & POS & POS & $13,60 \%$ & NEG & NEG & NEG \\
\hline :B 19167/07 & L. Burkitt & $7 \mathrm{~m}$ & $\mathrm{M}$ & Intestino SOE & Nordeste & POS & POS A & NEG & POS & NEG & $21,60 \%$ & NEG & NEG & NEG \\
\hline ;B 19168/07 & L. Burkitt & 3 & $\mathrm{M}$ & NR & Nordeste & POS & POS A & NEG & POS & POS & $21,60 \%$ & NEG & NEG & NEG \\
\hline ;B 19201/07 & L. Burkitt & 3 & $\mathrm{~F}$ & Abdominal EN SOE & Norte & POS & POS A & NEG & POS & POS & $11,30 \%$ & POS & NEG & NEG \\
\hline ;B 19213/07 & L. Burkitt & 3 & $\mathrm{M}$ & Abdominal EN SOE & Norte & POS & POS A & NEG & POS & POS & $16,10 \%$ & NEG & NEG & NEG \\
\hline ;B 19771/07 & L. Burkitt & 12 & $\mathrm{M}$ & Linf. cervical & Nordeste & POS & POS A & NEG & POS & NEG & $15 \%$ & NEG & NEG & NEG \\
\hline :B 19878/07 & L. Burkitt & 5 & $\mathrm{M}$ & Abdominal E SOE & Sudeste & POS & NEG & NEG & POS & POS & $21,90 \%$ & POS & NEG & NEG \\
\hline ;B 19981/07 & L. Burkitt & 13 & $\mathrm{M}$ & Linf. axilar & Centro-Oeste & POS & POS B & NEG & POS & NEG & $16 \%$ & NEG & NEG & NEG \\
\hline :B 20588/07 & L. Burkitt & 55 & $\mathrm{M}$ & Linf. axilar & Nordeste & POS & NEG & NEG & POS & NEG & $8,30 \%$ & NEG & NEG & POS \\
\hline P 6764/07 & L. Burkitt & 7 & $\mathrm{M}$ & Fígado & Sudeste & POS & NEG & NEG & POS & POS & $12,80 \%$ & NEG & NEG & NEG \\
\hline
\end{tabular}

L.,linfoma; F, feminino; M, masculino; NEG, negativo; POS, positivo; I, inconclusivo; linf.; linfonodo; EN, extranodal; SOE, sem outra especificação; NR, não referido; $m$, meses; plasm, plasmacitóide. 


\section{REFERÊNCIAS}

Araujo I, Foss HD, Bittencourt A, Hummel M, Demel G, Mendonca N, et al. Expression of Epstein-Barr virus-gene products in Burkitt's lymphoma in Northeast Brazil. Blood. 1996;87:5279-86.

Bacchi CE, Bacchi MM, Rabenhorst SH, Soares FA, Fonseca LE Jr, Barbosa HS, et al. AIDS-related lymphoma in Brazil. Histopathology, immunophenotype, and association with Epstein-Barr virus. Am J Clin Pathol. 1996;105:230-7.

Bacchi MM, Bacchi CE, Alvarenga M, Miranda R, Chen YY, Weiss LM. Burkitt's lymphoma in Brazil: strong association with Epstein-Barr virus. Mod Pathol. 1996;9:63-7.

Barriga F, Kiwanuka J, Alvarez-Mon M, Shiramizu B, Huber B, Levine P, et al. Significance of chromosome 8 breakpoint location in Burkitt's lymphoma: correlation with geographical origin and association with Epstein-Barr virus. Curr Top Microbiol Immunol. 1988;141:128-37. 
Bellan C, Lazzi S, Hummel M, Palummo N, de Santi M, Amato T, et al. Immunoglobulin gene analysis reveals 2 distinct cells of origin for EBVpositive and EBV-negative Burkitt lymphomas. Blood. 2005;106:1031-6.

Bench AJ, Erber WN, Folllows GA, Scott MA. Molecular genetic analysis of haematological malignancies II: Mature lymphoid neoplasms. Int J Lab Hematol. 2007;29:229-60.

Bhatia KG, Gutiérrez MI, Huppi K, Siwarski D, Magrath IT. The pattern of p53 mutations in Burkitt's lymphoma differs from that of solid tumors. Cancer Res. $1992 ; 52: 4273-6$

Blum KA, Lozanski G, Byrd JC. Adult Burkitt leukemia and lymphoma. Blood. 2004;104:3009-20.

Boerma ER, van Imhoff GW, Appel IM, Veeger NJ, Kluin PM, KluinNelemans JC. Gender and age-related differences in Burkitt lymphoma-epidemiological and clinical data from The Netherlands. Eur $J$ Cancer. $2004 ; 40: 2781-7$ 
Braga WS, Souza RA, Silva EB, Fonseca JC, Tosta CE. Coinfection between hepatitis B virus and malaria: clinical, serologic and immunologic aspects. Rev Soc Bras Med Trop. 2006;39:27-31.

Burkitt D. A sarcoma involving the jaws in African children. $\mathrm{Br} J$ Surg: $1958 ; 46: 218-23$.

Burkitt D, O'Conor GT. Malignant lymphoma in African children. I. A clinical syndrome. Cancer: 1961;14:258-69.

Carbone A, Gloghini A, Cozzi MR, Capello D, Steffan A, Monini P, et al. Expression of MUM1/IRF4 selectively clusters with primary effusion lymphoma among lymphomatous effusions: implications for disease histogenesis and pathogenesis. Br J Haematol. 2000;111:247-57.

Carbone A, Gloghini A, Larocca LM, Capello D, Pierconti F, Canzonieri V, et al. Expression profile of MUM1/IRF4, BCL-6, and CD138/syndecan-1 defines novel histogenetic subsets of human immunodeficiency virus-related lymphomas. Blood. 2001;97:744-51. 
Cesarman E, Chang Y, Moore PS, Said JW, Knowles DM. Kaposi's sarcomaassociated herpesvirus-like DNA sequences in AIDS-related body-cavitybased lymphomas. N Engl J Med. 1995;332:1186-91.

Cesarman E, Knowles DM. The role of Kaposi's sarcoma-associated herpesvirus (KSHV/HHV-8) in lymphoproliferative diseases. Semin Cancer Biol. 1999;9:165-74.

Cesarman E, Nador RG, Bai F, Bohenzky RA, Russo JJ, Moore OS, et al. Kaposi's sarcoma-associated herpesvirus contains G protein-coupled receptor and cyclin D homologs which are expressed in Kaposi's sarcoma and malignant lymphoma. J Virol. 1996;70:8218-23.

Chadburn A, Hyjek E, Mathew S, Cesarman E, Said J, Knowles DM. KSHVpositive solid lymphomas represent an extra-cavitary variant of primary effusion lymphoma. Am J Surg Pathol. 2004;28:1401-16.

Chang Y, Cesarman E, Pessin MS, Lee F, Culpepper J, Knowles D, et al. Identification of herpesvirus-like DNA sequences in AIDS-associated Kaposi's sarcoma. Science. 1994;266:1865-9. 
Chen WG, Chen YY, Bacchi MM, Bacchi CE, Alvarenga M, Weis LM. Genotyping of Epstein-Barr virus in Brazilian Burkitt's lymphoma and reactive lymphoid tissue. Type A with a high prevalence of deletions within the latent membrane protein gene. Am J Pathol. 1996;148:17-23.

Chuang SS, Huang WT, Hsieh PP, Jung YC, Ye H, Du MQ, et al. Sporadic paediatric and adult Burkitt lymphomas share similar phenotypic and genotypic features. Histopathology. 2008;52:427-35.

Chuang SS, Ye H, Du MQ, Lu CL, Dogan A, Hsieh PP, et al. Histopathology and immunohistochemistry in distinguishing Burkitt lymphoma from diffuse large B-cell lymphoma with very high proliferation index and with or without a starry-sky pattern: a comparative study with EBER and FISH. Am J Clin Pathol. 2007;128:558-64.

Cogliatti SB, Novak U, Henz S, Schmid U, Moller P, Barth TF, et al. Diagnosis of Burkitt lymphoma in due time: a practical approach. $\mathrm{Br} J$ Haematol. 2006;134:294-301.

Cohen JI. Epstein-Barr virus infection. N Engl J Med. 2000;343:481-92. 
Coura JR, Amaral RS. Epidemiological and control aspects of schistosomiasis in Brazilian endemic areas. Mem Inst Oswaldo Cruz. 2004;99:13-19.

Dave SS, Fu K, Wright GW, Lam LT, Kluin P, Boerma EJ, et al. Molecular diagnosis of Burkitt's lymphoma. N Engl J Med. 2006;354:2431-42.

Deyrup AT. Epstein-Barr virus-associated epithelial and mesenchymal neoplasms. Hum Pathol. 2008;39:473-83.

Di Como CJ, Urist MJ, Babayan I, Drobnjak M, Hedvat CV, Teruya-Feldstein $\mathrm{J}$, et al. p63 expression profiles in human normal and tumor tissues. Clin Cancer Res. 2002 ;8:494-501.

Diebold J, Jaffe ES, Raphael M, Warnke RA. Burkitt lymphoma. In: Jaffe ES, Harris NL, Stein H, Vardiman, JW, editores. Pathology and genetics of tumours of haematopoietic and lymphoid tumours - World Health Organization Classifications of Tumours. Lyon, France: IARC press; 2001. p.181-4. 
Du MQ, Diss TC, Liu H, Ye H, Hamoudi RA, Cabeçadas J, et al. KSHV- and EBV-associated germinotropic lymphoproliferative disorder. Blood. 2002;100:3415-8.

Du MQ, Liu H, Diss TC, Ye H, Hamoudi RA, Dupin N, et al. Kaposi sarcomaassociated herpesvirus infects monotypic (IgM lambda) but polyclonal naive B cells in Castleman disease and associated lymphoproliferative disorders. Blood. 2001;97:2130-6.

Epstein MA. The origins of EBV research: discovery and characterization of the virus. In: Robertson ES. Epstein-Barr virus. Norfolk, UK: Caister Academic Press; 205. p.1-14.

Epstein MA, Achong BG, Barr YM. Virus particles in cultured lymphoblasts from Burkitt's lymphoma. Lancet. 1964;1:702-3.

Fagundes LA, de Oliveira RM, Amaral R. Childhood lymphosarcoma in the state of Rio Grande do Sul, Brazil. Report of 20 cases histologically similar to Burkitt's tumor. Cancer. 1968;22:1283-91. 
Falini B, Fizzotti M, Pucciarini A, Bigerna B, Marafioti T, Gambacorta M, et al. A monoclonal antibody (MUM1p) detects expression of the MUM1/IRF4 protein in a subset of germinal center B cells, plasma cells, and activated T cells. Blood. 2000;95:2084-92.

Farrel PJ, Cludts I, Stuhler A. Epstein-Barr virus genes and cancer cells. Biomed Pharmacother. 1997;51:258-67.

Ferry JA. Burkitt's lymphoma: clinicopathologic features and differential diagnosis. Oncologist. 2006;11:375-83.

Figueira-Silva CM, Pereira FE. Prevalence of Epstein-Barr virus antibodies in healthy children and adolescents in Vitória, State of Espírito Santo, Brazil. Rev Soc Bras Med Trop. 2004;37:409-12.

Fischer TK, Lima D, Rosa R, Osório D, Boing AF. A mortalidade infantil no Brasil: série histórica entre 1994-2004 e associação com indicadores sócioeconômicos em municípios de médio e grande porte. Medicina (Ribeirão Preto). 2007;40:559-66. 
Flores ER. The roles of p63 in cancer. Cell Cycle. 2007;6:300-4.

Frost M, Newell J, Lones MA, Tripp SR, Cairo MS, Perkins SL. Comparative immunohistochemical analysis of pediatric Burkitt lymphoma and diffuse large B-cell lymphoma. Am J Clin Pathol. 2004;121:384-92.

Gaidano G, Ballerini P, Gong JZ, Inghirami G, Neri A, Newcomb EW. et al. p53 mutations in human lymphoid malignancies: association with Burkitt lymphoma and chronic lymphocytic leukemia. Proc Natl Acad Sci USA. 1991;88:5413-7.

Gaidano G, Carbone A. MUM1: a step ahead toward the understanding of lymphoma histogenesis. [editorial]. Leukemia. 2000;14:563-6.

Glickman JN, Howe JG, Steitz JA. Structural analysis of EBER1 and EBER2 ribonucleoprotein particles present in Epstein-Barr virus infected cells. J Virol. 1988;62:902-11. 
Goldschmidts WL, Bhatia K, Johnson JF, Akar N, Gutiérrez MI, Shibata D, et al. Epstein-Barr virus genotypes in AIDS-associated lymphomas are similar to those in endemic Burkitt's lymphomas. Leukemia. 1992;6:875-8.

Gualco G, Weiss LM, Bacchi CE. Expression of p63 in anaplastic large cell lymphoma but not in classical Hodgkin lymphoma. Hum Pathol. 2008;39:1505-10.

Gutiérrez MI, Bhatia K, Barriga F, Diez B, Murriel FS, de Andreas ML et al. Molecular epidemiology of Burkitt's lymphoma from South America: differences in breakpoint location and Epstein-Barr virus association from tumors in other world regions. Blood. 1992;79:3261-6.

Haralambieva E, Boerma EJ, van Imhoff, Rosati S, Schuuring E, MullerHermelink HK, et al. Clinical, immunophenotypic, and genetic analysis of adult lymphomas with morphologic features of Burkitt lymphoma. Am J Surg Pathol. 2005;29:1086-94.

Haralambieva E, Schuuring E, Rosati S, van Noesel C, Jansen P, Appel I, et al. Interphase fluorescence in situ hybridization for detection of $8 q 24 / \mathrm{MYC}$ 
breakpoints on routine histologic sections: validation in Burkitt lymphomas from three geographic regions. Genes Chromosomes Cancer. 2004;40:10-8.

Harris NL, Horning SJ. Burkitt's lymphoma - the messages from microarrays. [editorial]. N Engl J Med. 2006;354:2495-8.

Hassan R, Klumb CE, Felisbino FE, Guiretti, DM, White LR, Stefanoff CG, et al. Clinical and demographic characteristics of Epstein-Barr virus-associated childhood Burkitt's lymphoma in Southeastern Brazil: epidemiological insights from an intermediate risk region. Haematologica. 2008;93:780-3.

Hassan R, White LR, Stefanoff CG, de Oliveira DE, Felisbino FE, Klumb CE, et al. Epstein-Barr virus (EBV) detection and typing by PCR: a contribution to diagnostic screening of EBV-positive Burkitt's lymphoma. Diagn Pathol. 2006;7:1-17.

Hedvat CV, Teruya-Feldstein J, Puig P, Capodieci P, Dudas M, Pica M, et al. Expression of p63 in diffuse large B-cell lymphoma. Appl Immunohistochem Mol Morphol. 2005;13:237-42. 
Howe JR, Klimstra DS, Cordon-Cardo C. DNA extraction from paraffinembedded tissues using a salting-out procedure: a reliable method for PCR amplification of archival material. Histol Histopathol. 1997;12:595-601.

His ED, Gascoyne RD. Diffuse aggressive B-cell lymphomas. In: His ED Goldblum JR, editores. Hematopathology. Phyladelphia:Churchill Livingstone; 2007. p259-82.

Hummel M, Bentink S, Berger H, Klapper W, Wessendorf S, Barth TF, et al. A biologic definition of Burkitt's lymphoma from transcriptional and genomic profiling. N Engl J Med. 2006;354:2419-30.

Jarviluoma A, Ojala PM. Cell signaling pathways engaged by KSHV. Biochim Biophys Acta. 2006;1766:140-58.

Kelly GL, Rickinson AB. Burkitt lymphoma:revisiting the pathogenesis of a virus-associated malignancy. Hematology Am Soc Hematol Educ Program. $2007 ; 2007: 277-84$. 
Klumb CE. Biologia e patogênese dos linfomas não Hodgkin de origem B na infância: uma revisão. Revista Brasileira de Cancerologia. 2001;47:291-301.

Klumb CE, Hassan R, De Oliveira DE, De Resende LM, Carriço MK, De Almeida Dobbin J, et al. Geographic variation in Epstein-Barr virusassociated Burkitt's lymphoma in children from Brazil. Int $J$ Cancer. 2004;108:66-70.

Klumb CE, Hassan R, Zalcberg IR, Resende LM, carriço MK, Maia RC. p53 protein expression does not correlate with EBV status in childhood B nonHodgkin lymphomas. Pediatr Blood Cancer. 2004;43:115-9.

Kocialkowski S, Pezzella F, Morrison H, Jones M, Laha S, Harris AL, et al. Mutations in the p53 gene are not limited to classic 'hot spots' and are not predictive of p53 protein expression in high-grade non-Hodgkin's lymphoma. Br J Haematol. 1995;89:55-60.

Koduru PR, Raju K, Vadmal V, Menezes G, Shah S, Susin M, et al. Correlation between mutation in P53, p53 expression, cytogenetics, histologic type, and survival in patients with B-cell non-Hodgkin's lymphoma. Blood. 1997;90:4078-91; 
Laurent $C$, Meggetto F, Brousset $P$. Human herpesvirus 8 infections in patients with immunodeficiencies. Hum Pathol. 2008;39:983-93.

Lazzi S, Bellan C, Amato T, Palummo N, Cardone C, D'Amuri A, et al. Kaposi's sarcoma-associated herpesvirus/human herpesvirus 8 infection in reactive lymphoid tissues: a model for KSHV/HHV-8-related lymphomas? Hum Pathol. 2006;37:23-31.

Lazzi S, Ferrari F, Nyongo A, Palummo N, de Milito A, Zazzi M, et al. HIVassociated malignant lymphomas in Kenya (Equatorial Africa). Hum Pathol. 1998;29:1285-9.

Leder P, Battey J, Lenoir G, Moulding C, Murphy W, Potter H, et al. Translocations among antibody genes in human cancer. Science. $1983 ; 222: 765-71$.

Leich E, Hartmann EM, Burek C, Ott G, Rosenwald A. Diagnostic and prognostic significance of gene expression profiling in lymphomas. APMIS. 2007;115:1135-46. 
Leoncini L, Delsol G, Gascoyne RD, Harris NL, Pileri SA, Piris MA, et al. Aggressive B-cell lymphomas: a review based on the workshop of the XI Meeting of the European Association for Haematopathology. Histopathology. 2005;46:241-55.

Marigo C, Muller H, Davies JN. Survey of cancer in children admitted to a Brazilian charity hospital. J Natl Cancer Inst. 1969;43:1231-40.

Martinez-Delgado B, Robledo M, Arranz E, Infantes F, Echezarreta G, Marcos B, et al. Correlation between mutations in p53 gene and protein expression in human lymphomas. Am J Hematol. 1997;55:1-8.

Naresh KN. MUM1 expression dichotomises follicular lymphoma into predominantly, MUM1-negative low-grade and MUM1-positive high-grade subtypes. Haematologica. 2007;92:267-8.

Natkunam Y, Warnke RA, Montgomery K, Falini B, van De Rijn M. Analysis of MUM1/IRF4 protein expression using tissue microarrays and immunohistochemistry. Mod Pathol. 2001;14:686-94. 
Navarro WH, Kaplan LD. AIDS-related lymphoproliferative disease. Blood. 2006;107-13-20.

Niedobitek G, Agathanggelou A, Rowe M, Jones EL, Jones DB, Turyaguma $P$, et al. Heterogeneous expression of Epstein-Barr virus latent proteins in endemic Burkitt's lymphoma. Blood. 1995;86:659-65.

Nylander K, Vojtesek B, Nenutil R, Lindgren B, Roos G, Zhanxiang W, et al. Differential expression of p63 isoforms in normal tissues and neoplastic cells. J Pathol. 2002;198:417-27.

O'Conor GT. Malignant lymphoma in African children. II. A pathological entity. Cancer. 1961;14:270-83:

Pak F, Pyakural P, Kokhaei P, Kaaya E, Pourfathollah AA, Selivanova G, et al. HHV-8/KSHV during the development of Kaposi's sarcoma: evaluation by polymerase chain reaction and immunohistochemistry. J Cutan Pathol. $2005 ; 32: 21-7$ 
Park $\mathrm{CK}$, Oh $\mathrm{YH}$. Expression of p63 in reactive hyperplasias and malignant lymphomas. J Korean Med Sci. 2005;2:752-8.

Pizza M, Bruniera P, Luporini SM, Marcelino da Silva HR, Borsato ML, de Castro $\mathrm{HC}$, et al. Detection of Epstein-Barr virus in children and adolescents with Burkitt's lymphoma by in situ hybridization using tissue microarrays. Hematology. 2008;13:114-8.

Ponzoni M, Arrigone G, Doglioni G. New transcription factors in diagnostic hematopathology. Adv Anat Pathol. 2007;14:25-35.

Rezk SA, Weiss LM. Epstein-Barr virus-associated lymphoproliferative disorders. Hum Pathol. 2007;38:1293-304.

Rickinson A. Epstein-Barr virus. Virus Res. 2002;82:109-13.

Rodig SJ, Vergilio JA, Shahsafaei A, Dorfman DM. Characteristic expression patterns of TCL1, CD38, and CD44 identify aggressive lymphomas harboring a MYC translocation. Am J Surg Pathol. 2008;32:113-22. 
Rosenwald A, Ott G. Burkitt lymphoma versus diffuse large B-cell lymphoma. Ann Oncol. 2008;19:67-9.

Sandlund JT, Fonseca T, Leimig T, Verissimo L, Ribeiro R, Lira V, et al. Predominance and characteristics of Burkitt lymphoma among children with non-Hodgkin lymphoma in northeastern Brazil. Leukemia. 1997;11:743-6.

Sankoh AJ, Huque MF, Dubey SD. Some comments on frequently used multiple endpoint adjustment methods in clinical trials. Statistics in Medicine. 1997;16:2529-42.

Shiramizu B, Barriga F, Neequaye J, Jafri A, Dalla-Favera R, Neri A, et al. Patterns of chromosomal breakpoints locations in Burkitt's lymphoma: relevance to geography and Epstein-Barr virus associations. Blood. 1991;77:1516-26.

Siebert R, Matthiesen P, Harder S, Zhang Y, Botowski Y, Zuhlke-Jenisch R, et al. Application of interphase fluorescence in situ Hybridization for the detection of the Burkitt translocation $\mathrm{t}(8 ; 14)(\mathrm{q} 24 ; \mathrm{q} 32)$ in B-cell lymphomas. Blood. 1998;91:984-90.

Sixbey JW, Nedrud JG, Raad-Traub N, Hanes RA, Pagano JS. Epstein-Barr virus replication in oropharyngeal epithelial cells. $N$ Engl $J$ Med. $1984 ; 310: 1225-30$. 
Soulier J, Grollet L, Oksenhendler E, Cacoub P, Cazals-Hatem D, Babinet P, et al. Kaposi's sarcoma-associated herpesvirus-like DNA sequences in multicentric Castleman's disease. Blood. 1995;86:1276-80.

Spina M, Tirelli U, Zagonel V, Gloghini A, Volpe R, Babare R, et al. Burkitt's lymphoma in adults with and without human immunodeficiency virus infection: a single-institution clinicopathologic study of 75 patients. Cancer. 1998;82:766-74.

Stewart B. HIV-associated Burkitt lymphoma: case presentations and review. AIDS Read. 2006;16:647-7,654-8.

Tao Q, Ambinder RF. Lack of Kaposi's sarcoma-associated virus (KSHV) and detection of human herpes virus 6 and 7 by PCR in African Burkitt's lymphoma from HIV-negative patients [letter]. Hum Pathol. 1999;30:1269-70.

Tsuboi K, lida S, Inagaki H, Kato M, Hayami $\mathrm{Y}$, Hanamura I, et al. MUM1/IRF4 expression as a frequent event in mature lymphoid malignancies. Leukemia. 2000;14:449-56.

Tumwine LK, Campidelli C, Righi S, Neda S, Byarugaba W, Pileri SA. B-cell non-Hodgkin lymphomas in Uganda: an immunohistochemical appraisal on tissue microarray. Hum Pathol. 2008;39:817-23. 
Van Dongen JJ, Langerak AW, Bruggemann M, Evans PA, Hummel M, Lavender FL, et al. Design and standardization of PCR primers and protocols for detection of clonal immunoglobulin and T-cell receptor gene recombinations in suspect lymphoproliferations: report of the BIOMED-2 Concerted Action BMH4-CT98-3936. Leukemia. 2003;17:2257-317.

Vegga F, Chang CC, Medeiros LJ, Udden MM, Cho-Vega JH, Lau CC, et al. Plasmablastic lymphomas and plasmablastic plasma cell myelomas have nearly identical immunophenotypic profiles. Mod Pathol. 2005;18:806-15.

Villuendas R, Piris MA, Orradre JL, Mollejo M, Algara P, Sanchez L, et al. P53 protein expression in lymphomas and reactive lymphoid tissue. J Pathol. 1992;166:235-41.

Wada M, Bartram CR, Nakamura H, Hachiya M, Chen DL, Borenstein J, et al. Analysis of p53 mutations in a large series of lymphoid hematologic malignancies of childhood. Blood. 1993;82:3163-9.

Williams H, Crawford DH. Epstein-Barr virus: the impact of scientific advances on clinical practice. Blood.2006;107:862-9.

Young LS, Yao QY, Rooney CM, Sculley TB, Moss DJ, Rupani H, et al. New type B isolates of Epstein-Barr virus from Burkitt's lymphoma and from normal individuals in endemic areas. J Gen Virol. 1987;68:2853-62. 
Yustein JT, Dang CV. Biology and treatment of Burkitt's lymphoma. Curr Opin Hematol. 2007;14:375-81. 
APÊNDICE 


\section{APROVAÇÃO}

A Comissão de Ética para Análise de Projetos de Pesquisa - CAPPesq da Diretoria Clínica do Hospital das Clínicas e da Faculdade de Medicina da Universidade de São Paulo, em sessão de 22.06.05, APROVOU o Protocolo de Pesquisa $n^{\circ}$ 441/05, intitulado: "KSHV/HHV-8 em Doenças Hematopoiéticas" apresentado pelo Departamento de PATOLOGIA.

Cabe ao pesquisador elaborar e apresentar à CAPPesq, os relatórios parciais e final sobre a pesquisa (Resolução do Conselho Nacional de Saúde n 196, de 10.10.1996, inciso IX. 2, letra "c")

Pesquisador(a) Responsável: Prof. Dr. Carlos Eduardo Bacchi Pesquisador (a) Executante: Dr. Eduardo Moreira de Queiroga

CAPPesq, 22 de Junho de 2005.

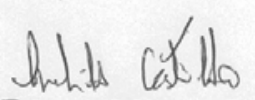

PROF. DR. EUCLIDES AYRES DE CASTILHO Presidente da Comissão de Ética para Análise de Projetos de Pesquisa 


\title{
Viral Studies in Burkitt Lymphoma
}

\author{
Association With Epstein-Barr Virus but Not HHV-8 \\ Edraardo M. Queiroga, $M D{ }^{l}$ Gabriela Gualco, $M D,{ }^{l}$ Luctmara Chioato, $P h D,{ }^{1}$ William J. Hamington, J, MD, ${ }^{2}$ \\ Iguaracyra Arajo, MD, ${ }^{3}$ Lawence $\mathrm{M}$. Weiss, $\mathrm{MD},{ }^{4}$ and Carlos E. Bacchi, $\mathrm{MD}^{l}$
}

Key Words: Burkitt hymphoma; Kaposi sarcoms-associated herpesvirus; Human herpesvifus B; KSHVIPHV-B; LANA proteinc, HIV, Immunohistochemistry: Polymerase chain reaction; PCR

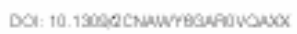

\section{A bst a c t}

Burkitt lymphoma (BL) is a highly aggressive non-Hodgkin lymphoma, composed of a monomorphic population of medium-sized B cells with a high proliferation rate and a consistent $\mathrm{MYC}$ translocation. Epstein-Barr virus (EBV) has been associated with $B L$ with different frequencies depending on the clinical variant. Kaposi sarcoma-associated herpesvirus, or human herpesvirus 8 (HHV-8), infects a wide range of normal cells, having a well-established role in the pathogenesis of various neoplasms, including Kaposi sarcoma, primary effusion lymphoma, multicentric Castleman disease (MCD) and MCD-associated plasmablastic lymphoma. In secondary immunodeficiencies, such as HIV-I infection and organ transplantation, $H H V-8$ is considered an opportunistic pathogen linked to the development of lymphomas in patients with AIDS and HIV+ patients. We studied the association of $E B V$ and $H H V-8$ by immunohistochemical analysis, in situ hybridization, and polymerase chain reaction in a large number of well-characterized BLs. EBV was present in $45.0 \%$ of all BL cases with higher incidence in the pediatric group; most cases were EBV type A. We found no association of $B L$ with $H H V-8$ in $E B V+B L$ or in $E B V-$ cases, including the HIV $+B L$ group.
Burkitt lymphoma (BL) is a highly aggressive non-Hodgkin lymphoma with endemic, sporadic, and immunodeficiency-associated clinical variants composed of a monomorphic population of medium-sized B cells with a high proliferation rate and having a consistent $M Y C$ translocation ${ }^{1,2}$ Viral infections, in particular Epstein-Barr virus (EBV), have been associated with $\mathrm{BL}$; it is well established that this association occurs with different frequencies depending on the clinical variant. ${ }^{3} \mathrm{EBV}$ is present in the majority of endemic cases of BL and nearly $30 \%$ of cases of sporadic BL. ${ }^{1}$ In Brazil, a high association of EBV with BL has been demonstrated in tropical areas, especially in the northeast region. ${ }^{45}$

Kaposi sarcoma-associated herpesvirus, or human berpesvirus (HHV)-8, is a virus able to infect mammalian cells, including lymphoid cells, dendritic oells, and fibroblasts. Several neoplasms have been associated with HHV-8, including Kaposi sarcoma, primary effusion lymphoma, multicentric Castleman disease (MCD), and MCD-associated plasmablastic lymphoma $6-8$

In the context of seoondary immunodeficiencies, such as HIV-1 infection and organ transplantation, HHV-8 is considered an opportunistic pathogen that has been linked to the development of lymphoproliferative diseases, including lymphomas and related diseases. ${ }^{9}$ HHV-8 has also been reported in association with lymphomas in patients with AIDS and HIV+ patients. ${ }^{10}$ In common variable immunodeficiency, a primary immunodeficiency disorder of unknown etiology. patients have a high risk of B-cell lymphomas; HHV-8 has been identified in at least some of the associated lymphomas and is considered an important factor in their pathogenesis." Du et $\mathrm{al}^{1 \mathrm{H}}$ demonstrated monotypic HHV-8+ plasmablasts in MCD and MCD-associated plasmablastic lymphomas. 
HHV-8-associated lymphomas have included cases of naive cell origin, germinal center (GC) and post-GC cells, unlike EBV-associated lymphomas, which are generally more restricted to GC or post-GC origin. ${ }^{12,13}$ HHV -8 and EBV ooinfection has been documented in primary effusion lymploma and in the setting of Castleman disease, typically asscciated with an immunosuppressed state. ${ }^{14}$

In the literature, there is scarce information on the association of HHV-8 with BL in HIV + and HIV- patients, and it is generally limited to data concerning African populations. Lazzi et al, ${ }^{15}$ in a study of East African patients, evaluated 16 BL cases and detected HHV-8 in nonneoplastic lymphoid cells in 1 case of an HIV- patient with a lymph node partially involved by BL. The molecular analysis in microdissected HHV-8 + cells in this case showed absence of clonality. It is worth menticeing that in this BL case, there was no association with Kaposi sarcoma. In a previous study on HIVassociated malignant lymphomas, also in African patients, Lazzi et al ${ }^{16}$ analyzed 29 cases of BL, with none showing HHV-8 by polymerase chain reaction (PCR). In 10 eases of African BL, Tao and Ambinder ${ }^{17}$ did not find HHV-8 or HHV -7 but found HHV- 6 in 3 cases studied.

We studied the association of EBV and HHV-8 in a large number of well-characterized BL cases in a Brazilian population.

\section{Materials and Methods}

\section{Case Material and Clinical Data}

We retrospectively obtained 311 cases of $\mathrm{BL}$ from the files of Consultoria em Patologia, a large reference consultation service in anatomic pathology located in Botucatu, São Paulo State, Brazil The study group included all cases of BL. with available representative formalin-fixed, paraffinembedded (FFPE) blocks received in onsultation between
June 1997 and May 2007. Nodal and extranodal BL cases were included. Clinical data, including sex, age at diagnosis, and tumor location, were obtained from the referring pathologists and oncologists. We reviewed available H\&E-stained slides of each case, and representative areas were selected for incorporation into tissue microarrays (TMAs). Morphologic subchassification of the cases was performed acoording to variants recognized by the World Health Organization classification $^{1}$

\section{TMA Construction}

Six TMA blocks were oonstructed by using a tissue arrayer (Beecher Instruments, Sun Prairie, WI). Each individual case was represented by 3 tumor oores of $0.6 \mathrm{~mm}$ that were taken from the original paraffin blocks. Serial sections of $3 \mu \mathrm{m}$ were cut from the tissue array blocks and used for immunohistochemical analysis. Proper positive and negative control cores for each marker were also included in the array block to provide adequacy of the antibodies used in the immunohistochemical studies as follows tonsil (CD3, CD10, $\mathrm{CD} 20$, bel-2, bel-6, and $\mathrm{Ki}-67$ ), lymphoblastic lymphoma (terminal deoxynucleotidyl transferase), EBV+ Hodgkin lymphoma (EBV latent membrane protein [LMP]-1), and Kaposi sarooma and HHV-8-AIDS-related non-BL (Kaposi sarcoma-associated berpesvirus/HHV-8).

\section{Inmunohistochemical Analysis and In Situ Hybridization}

An immunohistochemical study was performed for each TMA using Novolink polymer (Nowocastra, Newcastle upon Tyne, England) as the detection system, and an epitoperetrieval method was applied as needed for each specific antibody, diaminobenzidine was the chromogen. Primary antibodies used were anti-CD20, anti-CD3, anti-CD10, antibcl-6, anti-Ki-67, anti-bcl-2, anti-EBV-LMP, and antiHHV-8 latent muclear antigen (LANA), for this last marker, only cells with a salt-and-pepper granular nuclear pattern of immunostaining were considered positive ITable $1 \mathbf{~ I}$

ITable 1 I

Primury Antibedies Used for Immunohistochemical Stnining in Paruffin Sectiens

\begin{tabular}{|c|c|c|c|c|}
\hline Antigen & Clone & DEludion & Antigen Retrieval" & Source \\
\hline $\begin{array}{l}\text { CD20 } \\
\text { CDO } \\
\text { CD10 } \\
\text { bel-2 } \\
\text { bel-B } \\
\text { Ki-67 } \\
\text { LANA of human herpesvirus B (ORF-73) } \\
\text { TdT } \\
\text { LMP1 }\end{array}$ & $\begin{array}{l}\text { L28 } \\
\text { SP7 } \\
5608 \\
124 \\
\text { PG-DBP } \\
\text { MIB-1 } \\
\text { LN-E3 } \\
\text { Polyclonal } \\
\text { CS1 } 4 \text {. }\end{array}$ & $\begin{array}{l}1: 1,200 \\
1: 200 \\
1: 100 \\
1: 400 \\
1: 100 \\
1: 4,800 \\
1: 30,000 \\
1: 1,000 \\
1: 500\end{array}$ & $\begin{array}{l}\text { MW, CB } \\
\text { S, CB } \\
\text { S, CB } \\
\text { MW, CB } \\
T+\text { S, TRIS } \\
\text { PC, CB } \\
\text { PC, CB } \\
\text { PC, EDTA } \\
\text { S, CB }\end{array}$ & $\begin{array}{l}\text { DAKO, Carpinteria, CA } \\
\text { NeolMarkers/Lab Vision, Fremont, CA } \\
\text { Novocastra, Newcastle upon Tyme. England } \\
\text { DAKO } \\
\text { DAKO } \\
\text { DAKO } \\
\text { Advanoed Biotechnologies, Columbia, MD } \\
\text { DAKO } \\
\text { DAKO }\end{array}$ \\
\hline
\end{tabular}

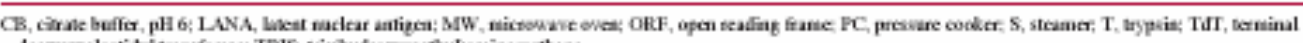

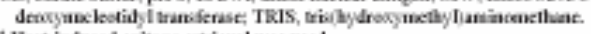

Heat-induced quilope setrieral we tool. 
HHV-8-associated lymphomas have included cases of naive cell origin, germinal center (GC) and post-GC cells, unlike EBV-associated lymphomas, which are generally more restricted to GC or post-GC origin. ${ }^{12,13}$ HHV-8 and EBV coinfection bas been documented in primary effusion lymphoma and in the setting of Castleman disease, typically asscciated with an immunosuppressed state. ${ }^{14}$

In the literature, there is scarce information on the association of HHV-8 with BL in HIV+ and HIV- patients, and it is generally limited to data concerning African populations. Lazzi et al, ${ }^{15}$ in a study of East African patients, evaluated $16 \mathrm{BL}$ cases and detected HHV-8 in nonneoplastic lymphoid cells in 1 case of an HIV- patient with a lymph node partially involved by $\mathrm{BL}$. The molecular analysis in microdissected HHV-8+ cells in this case showed absence of clonality. It is worth menticeing that in this BL case, there was no association with Kaposi sarcoma. In a previous study on HIVasscciated malignant lymphomas, also in African patients, Lazzi et al $^{16}$ analyzed 29 cases of BL, with none showing HHV-8 by polymerase chain reaction (PCR). In 10 cases of African BL, Tao and Ambinder ${ }^{17}$ did not find HHV-8 or HHV -7 but found HHV 6 in 3 cases studied.

We studied the association of EBV and HHV-8 in a large number of well-characterized BL cases in a Brazilian population.

\section{Materials and Methods}

\section{Case Material and Clinical Data}

We retrospectively obtained 311 cases of $\mathrm{BL}$ from the files of Consultoria em Patologia, a large reference consultation service in anatomic pathology located in Botucatu, São Paulo State, Brazil. The study group included all cases of BL with available representative formalin-fixed, paraffinembedded (FFPE) blocks received in consultation between
June 1997 and May 2007. Nodal and extranodal BL cases were inchuded. Clinical data, including sex, age at diagnosis, and tumor location, were obtained from the referring pathologists and conologists. We reviewed available H\&E-stained slides of each case, and representative areas were selected for incorporation into tissue microarrays (TMAs). Morphologic subclassification of the cases was performed acoording to variants recognized by the World Health Organization classificatice."

\section{TMA Construction}

Six TMA blocks were oonstructed by using a tissue arrayer (Beecher Instruments, Sun Prairie, WI). Each individual case was represented by 3 tumor oores of $0.6 \mathrm{~mm}$ that were taken from the original paraffin blocks. Serial sections of $3 \mu \mathrm{m}$ were cut from the tissue array blocks and used for immunohistochemical analysis. Proper positive and negative control cores for each marker were also included in the array block to provide adequacy of the antibodies used in the immunohistochemical studies as follows: tonsil (CD3, CD10, CD20, bcl-2, bel-6, and $\mathrm{Ki}-67$ ), lymphoblastic lymphoma (terminal deoxynucleotidyl transferase), EBV+ Hodgkin lymphoma (EBV latent membrane protein [LMP]-1), and Kaposi sarcoma and HHV-8-AIDS-related non-BL (Kaposi sarcoma-associated berpesvirus/HHV-8).

Inmunohistochemical Analysis and In Situ Hybridization

An immunohistochemical study was performed for each TMA using Novolink polymer (Nowocastra, Newcastle upon Tyne, England) as the detection system, and an epitoperetrieval method was applied as needed for each specific antibody; diaminobenzidine was the chromogen. Primary antibodies used were anti-CD20, anti-CD3, anti-CD10, antibcl-6, anti-Ki-67, anti-bel-2, anti-EBV-LMP, and antiHHV-8 latent muclear antigen (LANA), for this last marker, only cells with a salt-and-pepper granular nuclear pattern of immunostaining were considered positive ITable II.

ITable II

Primury Antibodies Used for Immunohistochemical Stnining in Paruffin Sections

\begin{tabular}{|c|c|c|c|c|}
\hline Antigen & Clone & DLution & Antigen Retrieval" & Source \\
\hline $\mathrm{CD} 20$ & L.28 & $1: 1,200$ & MW, CB & DAKO, Carpinteria, CA \\
\hline CDO & SP7 & $1: 200$ & S. CB & NeolMarkers/Lab Vieion, Fremont, CA \\
\hline CD10 & $5 \in C 8$ & $1: 100$ & $\mathrm{~s}, \mathrm{CB}$ & Novocastra, Newcrstle upon Tyne, England \\
\hline $\mathrm{bcl}-2$ & 124 & $1: 400$ & MW. CB & DAKO \\
\hline bet- 8 & PG-BAP & 1:100 & $T+S$, TRIS & DAKO \\
\hline $\mathrm{K}-67$ & MIB-1 & 1:4:800 & $P C, C B$ & DAKO \\
\hline LANA of human herpesvirus B (ORF-73) & LN-E3 & $1: 30,000$ & $\mathrm{PC}, \mathrm{CB}$ & Advanced Biotechnologies, Colurrbia, MD \\
\hline Tot & Pohplonal & $1: 1,000$ & PC, EDTA & DAKO \\
\hline LMP1 & $\operatorname{cs} 1-4$ & $1: 500$ & $\mathrm{~S}, \mathrm{CB}$ & DAKO \\
\hline
\end{tabular}

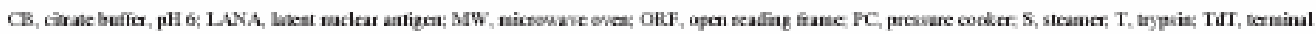

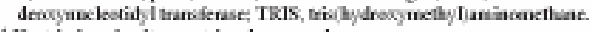

" Heat-indused cpinope setrieval was nied. 
Sections from all TMAs were examined for the expression of Epstein-Barr viral early RNA (EBER) by in situ hybridization (ISH) using an EBER-1 probe, consistent with a 30-base oligonucleotide complementary to a portion of the EBERI gene. Briefly, the slides were deparaffinized, dehydrated, predigested with Pronase (Sigma, St Louis, MO), and hybridized overnight at a concentration of $0.25 \mathrm{ng} /$ $\mu \mathrm{L}$ of probe. After washing, detection was accomplished by using the avidin-biotin immunoperoxidase method with $3^{\prime}, 3$ diaminobenzidine as the chromogen, without nickel chloride added for color enhancement. A brown or black color in the nucleus over background levels was considered a positive reaction. ${ }^{5}$ Appropriate positive (cases of $\mathrm{EBV}+\mathrm{BL}$ and $\mathrm{EBV}+$ Hodgkin lymphoma) and negative control (EBV- tissue) cores were also included in the array.

\section{Molecular Study}

Molecular analysis for HHV-8 was performed in 32 cases, including 9 known HIV+ BLs and 23 HIV- BLs. The cases in the HIV-BL group were selected in a randon manner. DNA isolation was performed as follows: FFPE histologic sections were submitted to deparaffinization by suocessive xylene baths and dehydration with $100 \%$ ethanol. After digestion of the material with Proteinase $\mathrm{K}$ at $50^{\circ} \mathrm{C}$ for 4 to 6 hours, $50 \mu \mathrm{L}$ of a saturated sodium chloride solution ( -6 $\mathrm{mol} / \mathrm{L}$ ) was added, and, after mixing for 30 seconds, the mixture was centrifuged at $4,000 \mathrm{rpm}$ for 15 minutes. The supernatant was removed to a fresh tube, and one-tenth volume of $3 \mathrm{~mol} / \mathrm{L}$ sodium acetate was added, followed by 2.5 volumes of $100 \%$ ethanol. Samples were placed at $-20^{\circ} \mathrm{C}$ overnight and centrifuged at $4^{\circ} \mathrm{C}$ for 30 minutes at $14,000 \mathrm{rpm}$. Pellets were washed with $1 \mathrm{~mL}$ of $70 \%$ ethanol and resuspended in $50 \mu \mathrm{L}$ of sterile water. ${ }^{18}$ Size control PCR was performed to investigate the quality of the extracted DNA, using a set of control primers that amplify products by $100,200,300,400$, and up to 600 base pairs (bp), depending on the integrity of the extracted DNA. ${ }^{19}$

The presence of HHV- 8 was detected by PCR amplificaticen of a 233-bp fragment from ORF (open reading frame) -26 (capsid antigen). In each $25-\mu \mathrm{L}$ PCR reaction, 100 ng of DNA, $0.3 \mu \mathrm{moL} / \mathrm{L}$ of $5^{\prime}$ and $3^{\prime}$ oligonucleotide primers (KS330 forward AGCCGAAAGGATTCCACCAT and reverse TCCGTGTTGTCTACGTCCAG), $0.2 \mathrm{mmol} / \mathrm{L}$ of deoxynucleoside triphosphate (dNTP), $2.5 \mu \mathrm{L}$ of $10 \times \mathrm{PCR}$ buffer, 1.25 U of Platinum Taq DNA polymerase (Invitrogen, Carlsbad, CA), and $3.0 \mathrm{mmol} / \mathrm{L}$ of magnesium chloride were used. PCR was initiated by 1 cycle at $95^{\circ} \mathrm{C}$ for 2 minutes, followed by 35 cycles of 30 seoconds at $93^{\circ} \mathrm{C}, 25$ seconds at $60^{\circ} \mathrm{C}$, and 30 seconds at $72^{\circ} \mathrm{C}$ and further followed by a 5-minute extension at $72^{\circ} \mathrm{C}$, acoording to Pak et al. ${ }^{20}$

Subtyping for EBV, by PCR amplification of the EBNA2 region, was performed in 131 cases. In 3 other EBV+ ISH cases, there was insufficient material in the paraffin block to proceed with PCR. Two primers encompassed this region (E2 up, 5'-AGGCTGCCCACCCTGAGGAT-3' and E2 low, 5'-GCCACCTGGCAGCCCTAAAG-3') containing a 16-bp deletion in EBV type A, yielding an amplification product with 170- and 186-bp fragment lengths for types A and B, respectively. In some cases, a seminested reamplification was performed using the E2 up and E2R low (5'-GCTGOCACCTGGCGGAAT-3') primers, rendering amplification products of 111 and 127 bp for types A and B, respectively. In each 25- $\mu \mathrm{L}$ PCR reaction, $100 \mathrm{ng}$ of DNA, $02 \mu \mathrm{mol} / \mathrm{L}$ of $5^{\prime}$ and 3' oligonucleotide primers, $0.2 \mathrm{mmol} / \mathrm{L}$ of dNTP, $2.5 \mu \mathrm{L}$ of 10x PCR buffer, 1.25 U of Platinum Taq DNA polymerase (Invitrogen), and $1.5 \mathrm{mmol} / \mathrm{L}$ of magnesium chloride were used. The mixture was subjected to 35 cycles of amplification (30 seoonds at $96^{\circ} \mathrm{C}, 30$ seconds at $60^{\circ} \mathrm{C}$, and 1 minute at $72^{\circ} \mathrm{C}$ in a PTC 200 thermocycler [MJ Research, Watertown, $\mathrm{MA}$ ]) Before cycling, the samples were denatured at $96^{\circ} \mathrm{C}$ for 2 minutes. After the last cycle, the polymerization step was extended by 10 minutes, according to Araujo et al. ${ }^{4}$

PCR-amplified products for both studies were analyzed in a $7 \%$ polyacrylamide gel with silver staining ( 5 minutes in a fixative solution, $5 \%$ acetic acid and $10 \%$ of ethanol; 5 minutes in silver solution, $0.2 \%$ silver nitrate in fixative solution; and 5 minutes in developer solution, $3 \%$ sodium hydroxide and $0.5 \%$ formaldehyde).

\section{Results}

\section{Clinical Feature:}

Of the 311 patients with BL, $221(71.1 \%)$ were male and $90(28.9 \%)$ were female. Of the patients, $149(47.9 \%)$ were 16 years or younger, and $143(46.0 \%)$ were older than 16 years; the age was unknown in 19 cases. The mean age was 23.1 years (range, 2-95 years). Extranodal BL constituted 201 (64.6\%) of the cases, and primary lymph node involvement was observed in $99(31.8 \%)$ of the cases; in 11 cases, it was not possible to determine nodal vs extranodal presentation. Extranodal primary disease was found in a higher proportion of pediatric patients $(112 / 149[75.2 \%])$ than adults (80r143 $[55.9 \%]), 11$ cases in the extranodal group did not bave age information available.

\section{Morphologic Features}

In the original material reviewed to select the areas for TMA, 309 cases of BL showed entirely diffuse architecture, and rare cases exhibited a focal nodular pattem ( 2 cases). Most of the cases showed cytologic features of the "classic" subtype (271/311 [87.1\%]) limuge 1AI, 28 (9.0\%) of the cases showed histologic features of atypical BL, and $12(3.9 \%)$ 

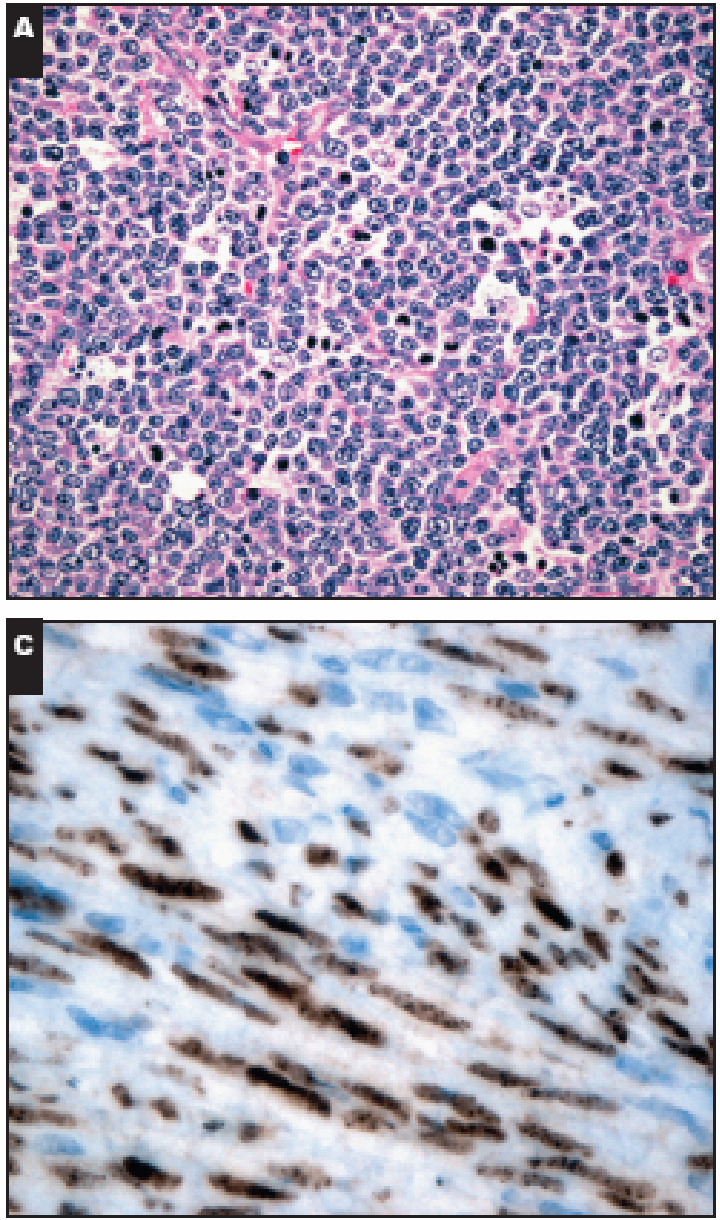

showed plasmacytoid differentiation.

\section{Immunohistochenical Analysis and ISH}

All cases had an immunophenotype oonsistent with BL, as described in the World Health Organization classification. ${ }^{.}$ CD20 and CD10 were positive in all cases; bel-6 positivity was found in 250 cases ( $80.4 \%$ ) and was more frequent in the pediatric than in the adult population bel- 2 was negative in all cases.

ISH for EBV showed 134 positive cases (45.0\%), the majority in the pediatric population $(76[56.7 \%])$ and 52 (38.8\%) in patients older than 16 years. In $6 \mathrm{EBV}+\mathrm{BL}$ cases, the age was unknown. In the pediatric group, $39(51 \%)$ were $\mathrm{EBV}+$, in the adult group, $36.3 \%$ were EBV+. In 13 cases, ISH for EBV was inoonclusive because there was insufficient neoplastic tissue available in the oores.

None of the cases showed nuclear granular positivity for

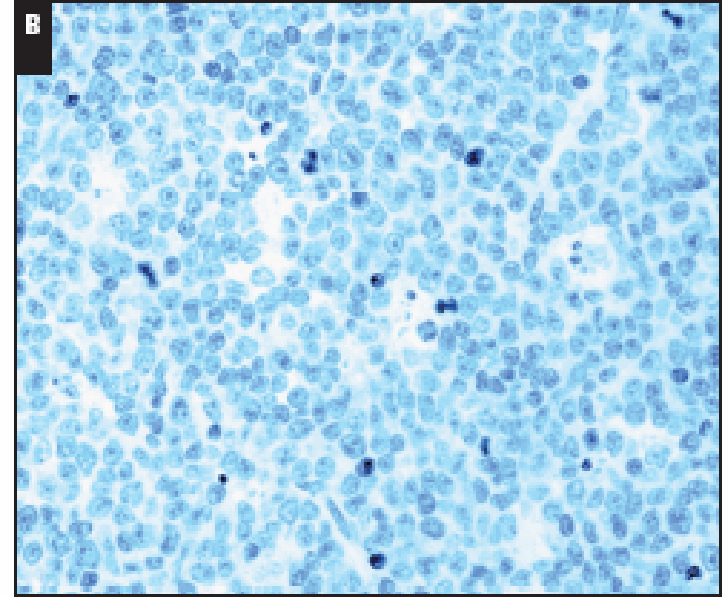

IImage II A, Classical Burkitt lymphoma in an HV+ patient. Prominent starry-sky pattern $\left(H \& E_{1} \times 200\right)$. B. Negative immunodetection for human herpesvirus-8 (latent nuclear antigen [LANA]-1) ( $\times 200)$. C. Kaposi sarcoma (positive control sample) showing positive nuclear immunostaining for LANAA $(x 400)$.

LANA protein with HHV-8 antibody IInage IBI. LMP-1 expression was not observed in any of the cases. All positive control samples for LMP-1 and LANA protein showed the expected immunostaining reactivity Imuge $\mathbf{~ I C I}$

\section{Molecular Analysis}

Molecular analysis for HHV-8 was performed in 32 cases, including 9 known HIV+ and 23 HIV-BLs; 19 were EBV-, and the other 13 cases presented EBV infection. No BL case had HHV-8 viral DNA, including cases of sporadic BL and HIV-associated BL IImage $2 \mathbf{I}$.

EBV molecular subtyping analysis showed that 96 (73.3\%) of 131 cases were EBV type A. The rest were type B $(27[20.6 \%])$. It is worth noting that in 8 cases $(6.1 \%)$, the DNA obtained from the FFPE blocks had less than $100 \mathrm{bp}$, giving inconclusive results for the EBV subtyping PCR analysis. No case showed both EBV subtypes in the same sample. 

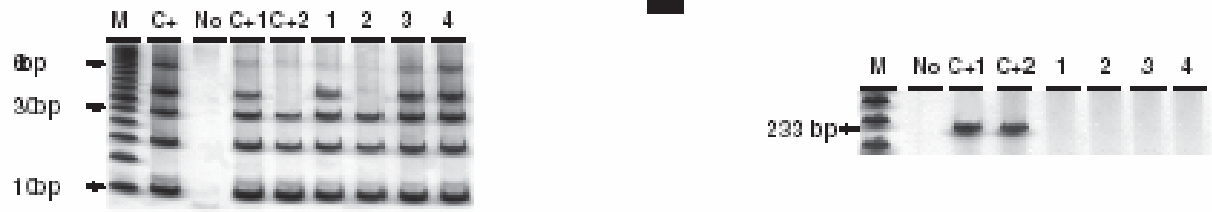

IImuse 2l Human herpesvirus (HHV-8 DNA detection by polymerase chain reaction (PCA). A, Size contral PCR. B. HHV-8specific PCR. C+, DNA extracted from peripheral blood: C+1, positive HHV-8 Kaposi sarcoma; C+2, positive HHV-8-AIDSrelated nan-Burkitt lymphoma: M, DNA molecular weight marker; Na. DNA absence: 1-2, HN+ Burkitt lymphoma cases; 3-4, HIV-Burkitt lymphoma.

\section{Discussion}

The spectrum of HHV-8-associated lymphoid tumors is different from that associated with EBV. ${ }^{21,22}$ HHV -8 is closely associated with Kaposi sarcoma but is associated with only a few categories of lymphoproliferative diseases, mostly cocurring in HIV-infected patients, with primary effusion lymphoma (PEL), a nonsolid B-cell lymphoma, having the most significant association. Extranodal marginal zone lymphoma, multiple myeloma, Kikuchi disease, and bemophagocytic syndrome are lymphoproliferative disorders with a variable and generally infrequent association with HHV $-8.6,23-27$ In contrast, the evidence strongly supports a role for EBV in the patbogenesis of a wide spectrum of human lymphoid malignancies, including B- and T-cell lymphomas, natural killer nooplasms, and Hodgkin lymphoma and nonbematologic tumors such as nasopharyngeal carcinoma and gastric tumors. ${ }^{1,12,13}$

In BL, EBV has been demonstrated in up to $100 \%$ of the endemic form and in only $15 \%$ to $30 \%$ of sporadic cases in the United States. ${ }^{1}$ In some parts of the world (North Africa and South America), the incidence is intermediate between true sporadic and endemic variants. ${ }^{1}$ In Brazil, there are limited data about the frequency of EBV in cases of BL. Previous studies showed that the frequency of EBV in cases of Brazilian BL varied from $58 \%$ to $87 \%, 4,28-30$ It is important to emphasize that in the 5 previous studies on $\mathrm{BL}$ in Brazil, all EBV+ cases were described in the pediatric population only. Our study on BL showed 134 EBV+ cases $(45.0 \%)$, with 76 cases $(56.7 \%)$ occurring in patients in the age group of 16 years or younger and 52 cases $(38.8 \%$ ) in patients older than 16 years, which represents $36.4 \%$ of the adult group. To the best of our knowledge, this is the first study in Brazil reporting the frequency of EBV in adult cases of BL. Our overall results place Brazil as a country with intermediate association of BL with EBV. ${ }^{1}$

EBV strains can be categorized into 2 types ( $A$ and $B$ ), and different geographic prevalence of these strains has been observed. ${ }^{4}$ By studying the EBNA-2 gene, we determined that 96 (73.3\%) of 131 cases contained type A EBV and 27 (20.6\%) contained type B EBV. The simultaneous presence of both types of EBV in the same tumoe was not observed in any sample. This pattern, with a predominance of type $\mathrm{A}$, is similar to that observed in sporadic cases and previous studies of Brazilian BL ${ }^{431}$ and different from the pattern described in BL oocurring in Equatorial Africa. ${ }^{32}$ LMP-1 was negative according to the highly restricted pettern of EBV latent proteins observed in BL. ${ }^{33}$

HHV-8-associated lymphomas include cases of naive cell origin, GC and post-GC cells, unlike EBV-associated lymphomas, which are of GC of post-GC origin. ${ }^{12,13}$ Moreover, HHV-8 and EBV coinfections have been documented in the setting of primary effusion lympboma and Castleman disease, typically associated with an immunosuppressed state. 14,34,35

The biologic heterogeneity of AIDS-non-Hodgkin lymphoma is highlighted by their histogenetic differenoes. HHV8-associated lymphomas, which often develop in persons with advanoed AIDS, present predominantly as PEL. HHV-8 has also been recently detected in solid extracavitary-based lymphomas. ${ }^{36-38}$ The HHV-8-associated solid lymphomas are unusual lymphomas that oocur more specifically in HIV+ patients, are extracavitary and arise in nodal and/or extranodal sites, and sometimes are associated with coinfection with EBV; histologically, they usually display PEL-like morphologic features and a plasma cell-related phenotype.

Lazzi et al, ${ }^{15,16}$ in different studies of African patients (East Africa), found no ease with tumoral lymphoid cells infected by HHV-8 in 16 and 29 BL cases, respectively. Tao and Ambinder ${ }^{17}$ studied HHV-8, HHV-7, and HHV-6 DNA in 10 cases of BL in Africa and found only HHV-6 in 3 of their cases.

Molecular identification of HHV-8 is known to produce false-positive and false-negative results. ${ }^{34}$ The latter is thought, in part, to be related to HHV-8 sequence variation, which can range up to $35 \%$ in certain regions of the viral 
genome. On the other hand, L.ANA immunohistochemical studies are thought to be a more reliable marker of HHV- 8 infection. In the present study, we found no evidence for HHV- 8 in BL, including cases with HIV+ status using immunohistochemical and molecular methods. We were, however, able to confirm the association of EBV with BL, found in $45.0 \%$ of the cases of BL in the present series. In no case was coinfection of EBV and HHV-8 found.

Fram the 'Pathology Reference Lab, Rotucatu, Salo Paulo, Brazil;, ${ }^{2}$ University of Miami Miller Schood of Medicine and Syhester Cancer Center, Fogarty International Center (AIDS and Tuberculosis Program), Miami, FZ; ${ }^{3}$ Prof. Edgard Sevtos University Hospital, Salvador, Brazil; and ' ${ }^{4}$ Divisian of Pathology, Ciry of Hope National Medical Center, Duane, CA

Supported by grants SROJCA082274 and 5RO/CA//2217 frown the National Cancer Insfitute (Dr Harringtonj and the ADS Malignavey Consontium (Nationa' Cancer brstituel Bethesala, MD.

Address reprint reguests to Dr Bocchi: Consultoria em Patologia, Rwa Major Leovidas Candorso, 739, Botucatu, Säo Paulo, 18602-010, Brazil.

\section{References}

1. Jaffe ES, Harris NL, Stein H, et al, eds. Pathology atd Genctics of Tumours of Haematopoletic and Lymphoid Tissucs Lyon, Fence: IARC Press; 2001. World Health Ongenization Classifoation of Tumosers.

2. Hummel M, Bentiak S, Berger $H$, et al. A biologic definition of Butkitt's hymphoma from transcriptional and genomic peofiling. N End J Med. 2006;354:2419.2430.

3. Copliatti SB, Nonak U, Hena S, et al. Dingnosis of Butkitt lymphoena in due time: a practical approach. By $\mathrm{J}$ Hacmasol. $2006-134: 294,301$

4. Araujo I, Foss HD, Bittencourt A, et al. Expression of Epstein Barr viruspene products in Budkitt's hmphoma in Northeast Beail. Blood. 1996; $87=5279-5286$.

5. Bachi MM, Bacchi CE, Akvrenga M, et al. Burkitr's hymphoena in Brazil: strong association with Epstein-Barr virus. Mod Pazhol. 1996;9-6367.

6. LCF, Ye H, Liu H, et al. Fatal HHV.8-associated hemophayocytic syadrome in an HIV-negative immunocoenpetent patient with plaseabblastic vatiant of multicentric Castleman disezse (plasmablastic microlymphoma). Am J Surg Pazbol. 2006;30:123127-

7. Falkhari FD, Jeone JH, Kanan Y, et al. The latencyasociated nuclear antipen of Kaposi sarcoma-associated herpesirus induces B cell hyperplasia and lymphoma. J Clin lnesst. 2006-116:735.742.

8. Carbone A, Gloghini A. KSHV/HHV8swociated lymphomas. Bi J Haematal 2008;140:13:24.

9. Whent WH, Cool CD, Morimoto Y, et al Possible role of human berpesvirus 8 in the lymphoprolifentive disonders in common variable immunodeficiency. ) Exp Med $2005 ; 202: 479484$

10. Carbone A, Gloghini A, Vaccher E, et al. Kaposi's sarcoeaaassociated herpes virus/human herpesirus tppe 8-positive solid lymptomas. J Mol Diagn 2005; 7:17-27.
11. Du MQ. Liu H, Diss TC, et al. Kaposi sarcoma-associated berpessirus inferts monotypic (IgM lambda) but polydoeal naive $B$ cells in Castleman disease and associated lymphoprolifentive disonders. Blood. 2001;97:2130-2136.

12. Feak D, Cesarman E, Liu YF, et al. Postreasplantation lymphoprolifenative disonders frequently contain type A and not type B Epstein-Barr virus. Blood. 1995;85:1396-1403.

13. Kippers R, Klein U, Hanseanen ML, et al. Cellular orizin of buman Bcell lyomptomas. N Engl J Med 1999,341:1520.1529.

14. Herndadez JL Gónez-Román J, RamosEstebanez C et al Human herpesvious and Epstein-Barr virus colafection in localised Castleman disease during peegnancy. Haematologica. 2005;90(suppl):ECR 35.

15. Lazzi S, Bellan C, Amato T, et al. Kaposi's sarcoma-associated berpesvirus/human herpevirus 8 infection in reactive lymphoid tissues a model for KSHV/HHV-8-related lymphomad Hum Parbol. 2006,37:23.31.

16. Lazzi S, Fernari F, Nyongo A, et al. HIV-associated malienant lymphomas in Kenya (Equatorial Africa). How Padbol. $1998 ; 29: 1285.1280$

17. Tao Q, Ambinder RF. Lack of Kapoel's samoena-associated virus (KSHV) and detection of human berpes virus 6 and 7 by PCR in African Burkitt's lymphoma from HIV-nequative patients [letter]. Hum Pathol. 1999,30-1269-1270.

18. Howe JR, Klimstra DS, CordonCardo C. DNA extraction from paraffin-embedded tissues using a salting-out procedure: a reliable method for PCR amplification of archival material. Hisad Heropathal 1997;12:595601.

19. van Dongen JJM, Langenak AW, Brupremana M, et al. Desiga and standardization of PCR primers and protocols for detertion of donal imenuoplobulin and Toell receptor gene recombinations in suppert hmphoproliferations seport of the BIOMED.2 Concerted Action BMH4.CT98.3936. Lukamile. 2003; 17:2257-2317.

20. Pak F, Pyakural P, Kolhaci P, et al. HHV-8/KSHV during the developenent of Kaposi's sarcoma evaluation by polymerase hain reaction and immunohistochenistry. J Cutan Pathol. 2005;32:21-27.

21. Carbone A, Gloghini A, Vacher E, et al. KSHV/HHV.8 associated hmph node based lymphomas in HIV seronegative subjectse report of two cases with anaplastic lage oell morphology and plasmablastic immunophenotype. J Clat Pathol 2005;58:1039-1045.

22. Carboee A. KSHV/HHV's associated Kaposi's sarcoma in lymph nodes concurrent with Epsteio-Barr virus associated Hodekia lympboma. J Cín Pathol 2005;58:626628.

23. Seaith KJ, Skelton HG. Human herpesvins $8 \mathrm{DNA}$ sequences in peraphieust the role of the virus in cacogenic and autoimmune manifestarices |letterl. Anch Desmedol. 1998,134:751.

24. Yamasaki S, lino T, Nakamura M, et al. Detection of human berpesvirus 8 in periphesal blood mononuclear oells froen adult Japacese patients with multicentric Castleman's disease. By) Hasmawl. 2003;120:471-477.

25. Fredricls DN, Martin TM, Edwads AO, et al. Human berpesvirus 8 and sarcoidosis. Clin Infect Dis 2002;34:559560.

26. Marioni G, Marchese-Rapona R, Marino F, et al. MALT-type lymphoma and Warthin's tumour presenting in the same parotid gland. Acta Owlaryngol. 2004;124:318323.

27. Tedeschi R, Luostarinea T, De Paoli P, et al. Joint Nordic prospective study oe human herpesirus 8 and multiple myeloma risk. By f Cancer. 2005,93-834-837. 
28. Gutiecres ML Phatia K, Barries T, et al. Moleculas epidemiology of Budirt's lymphoma from South America: differences in breakpoint location and Epsteis-Barr virus association from tumos in other word sorions. Blood 1992.79.3261.3266

29. Sandlund JI, Fonseca T, Leimig T, et al. Predominance and chasacteristics of Burkitt lymphoma amone children with noe-Hodpkin hmphoma in northeastem Beazil. Lukemia. $1997 ; 11=743.746$.

30. Klumb CE, Hassan R. De Olivein DE, et al. Gecermaphic variation in Epstein-Barr virus-associated Burkitt's lyeaphoea in childrea from Breal. Int J Cancer. 2004,108:66-70.

31. Chen WG, Chen YY, Bacchi MM, et al Genonpine of Epstein-Barr virus in Brazilian Burkitr's lymptoma and reactive lymphoid tissue: type A with a high pervalence of deletions within the lateat menbese protein gene. Am ) Pathol 1996-148:17-23.

32. Youne LS, Yao QY, Roponey CM, et al. Nea type B isolate of Epstein-Barr virus from Burkitr's lymphoma and normal indwiduals in enderaic aress. J Gen Virol. 1987-68:28532862.
33. Resk SA, Weiss LML Epstein-Barr vines-associated 1үmphoprolifenative disonders. Hum Pathol. 2007:38:12931304.

34. Carbone A, Gloehini A. AIDS-related lyonphomas from pathogenesis to patholon?. Ber J Hacmatad. 2005;130.662-670.

35. Burmeister T, Schwartz S, Horst HA, et al Molecular beteroreneity of spondic adult Burkitt.type leukemia/ lymphoma as revealed by PCR and cytogenetics: comelation with morpbology, inamosology and clinical features. Lublemila 2005:19:1391-1398.

36. Carbone A, Gloghini A. HHV-8-associated lymphoeas: stateof-theart review. Acta Haemawl. 2007:117:129-131.

37. Du MQ, Dis TC, Liu H, et al. KSHV-and EBVassociated germinotropic lymphopeoliferative disorder. Blood $2002 ; 100-3415,3418$

38. Dupin N, Diss T7, Kellam P, et al. HHV.8 is associated with a plasmablastic variant of Castleman disease that is linked to HHV-8 positive plaseablastic lymphoeaa. Blood 2000; $95: 1406-1412$ 
AJCP Manuscript ID AJCP-2008-05-0210.R1

Dear Dr. Queiroga,

Your revised manuscript entitled "BURKITT LYMPHOMA IN BRAZIL IS CHARACTERIZED BY GEOGRAPHICALLY DISTINCT CLINICOPATHOLOGICAL FEATURES" has been reviewed by members of our editorial board. I am pleased to inform you that it has been accepted for publication in the American Journal of Clinical Pathology.

Your paper is being prepared for publication, and you will receive galley proofs of it in due course.

If you have not done so already, please complete, including the manuscript ID (AJCP-2008-05-0210.R1), and return the attached copyright forms and disclosure forms. (fax: 312.541.4998)

Thank you for your support of the Journal, and for the opportunity to publish this interesting work

Sincerely,

Mark R. Wick, MD

Editor-In-Chief

American Journal of Clinical Pathology

ASCP • 33 West Monroe • Suite 1600 • Chicago, IL 60603

FAX: 312.541 .4998

16-Jun-2008 
Hematopathology / BURKITT LYMPHOMA IN BRAZIL

Queiroga et al / BURKITT LYMPHOMA IN BRAZIL

Hematopathology / ORIGINAL ARTICLE

\title{
Burkitt Lymphoma in Brazil Is Characterized by
} Geographically Distinct Clinicopathologic Features

Eduardo M. Queiroga, MD, ${ }^{1,2}$ Gabriela Gualco, MD, ${ }^{1}$ Lawrence M. Weiss, MD, ${ }^{3}$ Dirk P. Dittmer, PhD, ${ }^{4}$ Iguaracyra Araujo, MD, ${ }^{5}$ Claudette E.N. Klumb, MD, ${ }^{6}$ William J. Harrington $J$ r, MD, ${ }^{7}$ and Carlos E. Bacchi, $\mathrm{MD}^{1,2}$

Key Words: Burkitt lymphoma; Brazil; Epstein-Barr virus; Tissue microarray; p53; p63; Immunohistochemistry, Polymerase chain reaction

\begin{abstract}
Burkitt lymphoma (BL) is a highly aggressive non-Hodgkin lymphoma with a consistent MYC translocation. Epstein Barr virus (EBV) has been associated with BL at different frequencies, depending on the clinical variant and geographic regions. This is a large-scale study of BL in Brazil, including 234 patients from 5 geographic regions that are widely disparate socioeconomically, including pediatric (61.1\%) and adult (37.6\%) populations. EBV was present in $52.6 \%$ of all BL cases, varying from $29 \%(12 / 42)$ in the South to $76 \%$ (13/17) in the North. Most of the cases were EBV type A. The frequency was higher in the pediatric group, and EBV association within this age range predominated in all regions except the South. Expression of p53 protein was observed in $16.2 \%$, and only rare cases showed p63 expression. BL in Brazil is regionally distinct and has a low incidence of p53 overexpression and a higher-than-expected association with EBV in sporadic cases.
\end{abstract}


Burkitt lymphoma (BL) is a highly aggressive non-Hodgkin lymphoma (NHL) first described by Burkitt in 1958 in African children from areas holoendemic for malaria. ${ }^{1}$ BL is composed of a monomorphic population of medium-sized B cells with basophilic cytoplasm and an extremely high proliferative rate. ${ }^{2}$ Morphologically, in addition to classical BL, the World Health Organization (WHO) recognizes 2 cytologic variants: BL with plasmacytoid differentiation and atypical $\mathrm{BL} /$ Burkitt-like. The latter is characterized by greater pleomorphism in nuclear size and shape than the classical type.

Immunophenotypically, all types are similar and express CD20, CD10, bcl-6, and membranous IgM but not IgD, bcl-2, or terminal deoxynucleotidyl transferase (TdT). The Ki-67 proliferation index generally approaches $100 \%{ }^{3}$ All cases carry a translocation involving the c-MYC gene at $8 \mathrm{q} 24$ with the immunoglobulin heavy chain $(l G H)$ gene on $14 \mathrm{q} 32(80 \%)$ or, less commonly, with the $\kappa$ light chain locus $(I G K)$ at $2 \mathrm{p} 11(15 \%)$ or the $\lambda$ light chain locus $(I G L)$ at $22 \mathrm{q} 11(5 \%) .{ }^{4,5}$ This brings the proto-oncogene under the influence of powerful immunoglobulin promoters, resulting in deregulated MYC transcription. ${ }^{6}$ TP53 mutations have also been reported in BL, although these appear to be more frequent in BL cell lines. ${ }^{7}$

Three main clinical variants of BL have been described: endemic, sporadic, and immunodeficiencyassociated. Endemic BL refers to the form that occurs in African children, usually 4 to 7 years old. The tumor frequently involves the mandible and other facial bones (50\% of cases), as well as kidneys, gastrointestinal tract, ovaries, breast, and other extranodal sites. The incidence of BL in Africa is estimated to be 50 times higher than in the United States. ${ }^{8}$ Sporadic BL occurs worldwide and accounts for $1 \%$ to $2 \%$ of all lymphomas in Western Europe and United States and approximately $30 \%$ to $50 \%$ of all childhood lymphomas. In sporadic BL, the abdomen, especially the ileocecal area, is the most common site of involvement. ${ }^{2}$ The immunodeficiency-associated variant is frequently observed in the setting of HIV infection and has also been reported in allograft recipients and in congenital immunodeficiency. BL accounts for about a third of NHL in HIV+ patients. ${ }^{9}$ BL in an HIV+ patient generally occurs in patients with relatively high CD4 counts, in contrast with large cell immunoblastic lymphoma, and often represents the initial AIDS-defining illness. ${ }^{8,9}$ 
Epstein-Barr virus (EBV), a member of the human herpesvirus family, was initially isolated from a cultured BL cell line by Epstein et $\mathrm{al}^{10}$ in 1964 and was the first description of a virus involved in the pathogenesis of a human tumor. ${ }^{8}$ EBV has since been linked to many human neoplasms, including hematopoietic (including B-cell and T-cell natural killer and Hodgkin lymphomas), epithelial (nasopharyngeal carcinoma, a subset of gastric carcinoma), and mesenchymal (inflammatory pseudotumor of the liver and HIV-associated smooth muscle neoplasms) tumors. ${ }^{11}$ The association between $\mathrm{BL}$ and $\mathrm{EBV}$ occurs at varying frequencies depending on the clinical variant. $\mathrm{EBV}$ is present in the majority of endemic cases of BL (up to $100 \%$ ), in fewer than $30 \%$ of cases of sporadic $\mathrm{BL},{ }^{2}$ and in $30 \%$ to $40 \%$ of AIDS-related BL. ${ }^{12}$ Small studies in Brazil and other South American countries have suggested that this association is intermediate between sporadic and endemic variants. ${ }^{13-19}$

Brazil is the largest country in South America, located at $+5^{\circ} 17^{\prime}$ to $-33^{\circ} 45^{\prime}$ latitude and $-34^{\circ} 48^{\prime}$ to $73^{\circ} 60^{\prime}$ longitude, and has a population of 180 million people. Brazil is characterized by widely disparate socioeconomic conditions among its citizens and regional climatic variation. The country is divided into 5 geographic regions: North, Northeast, Central West, South, and Southeast IFigure $1 \mathbf{l}$. The South is generally more affluent, while the North and Northeast are less so. Similarly, tropical and infectious diseases are more common in the latter areas. ${ }^{20,21}$ There are few epidemiologic and no large-scale studies of BL in Brazil, and previously published works on association of EBV with BL

have been predominantly focused on pediatric BL from the Northeast, ${ }^{15,16}$ Southeast,,${ }^{13,14,17,18}$ and South. ${ }^{19}$ In the present study, we report the clinical features, immunophenotype, tumor suppressor (p53 and p63) protein expression profile, and association with EBV (by in situ hybridization [ISH] and polymerase chain reaction [PCR]) in 234 well-characterized cases of BL from all 5 geographic regions of Brazil in pediatric and adult populations. To perform this extensive analysis, we used tissue microarrays (TMAs) generated from our extensive tumor bank.

Materials and Methods

\section{Case Material and Clinical Data}

The initial study population was from a total of 595 cases of high-grade B-cell lymphoma with a tentative diagnosis of BL selected from the archives of Consultoria em Patologia, a large national reference consultation service in anatomic pathology located in Botucatu, Brazil, between June 1997 
and December 2007. In 99 cases, paraffin blocks were not available and these cases were excluded from the study. In the remaining 496 cases, the original H\&E-stained and immunostained slides of each case were reviewed by 3 of us (E.M.Q., G.G., and C.E.B.), and representative areas were selected for the construction of the TMAs. After immunohistochemical analysis, all bcl-2+ and CD10- cases were excluded (135 cases; bcl-2+ cases are being analyzed in another study). Another 127 cases were also excluded from the study after fluorescence in situ hybridization (FISH) analysis as these cases showed inconclusive results or had results inconsistent with BL (exclusion criteria are explained later). In total, 234 cases of BL, confirmed by morphologic, immunohistochemical, and molecular analyses, are described in this report. Nodal and extranodal BL cases were included. Clinical data including sex, age at diagnosis, anatomic location of the tumor, and HIV status were obtained from the referring pathologists or oncologists and/or pathology reports. A morphologic subclassification of the cases was performed based on variants included in the 2001 WHO classification. ${ }^{2}$ This study was approved as a whole by the Ethical Committee of University of São Paulo Medical School, São Paulo, Brazil.

\section{TMA Construction}

Eight TMA blocks were constructed using a tissue arrayer (Beecher Instruments, Sun Prairie, WI). The number of cases in each TMA block varied from 19 to 84 (not including control cores). Each individual case was represented by 3 tumor cores of $0.6 \mathrm{~mm}$ that had been obtained from the original paraffin blocks. Proper positive and negative control cores for each marker were also included in the array block: tonsil (CD20, CD3, CD10, bcl-2, bcl-6, Ki-67, PAX-5, CD5, and CD23), EBV+ Hodgkin lymphoma (latent membrane protein [LMP]-1 and EBV early RNA [EBER1]), tonsillar squamous epithelium (p63), breast ductal carcinoma showing p53 overexpression (p53), and lymphoblastic lymphoma (TdT).

\section{Immunohistochemical Analysis and ISH}

Immunohistochemical analysis was performed for each TMA using Novolink polymer (Novocastra, Newcastle upon Tyne, England) as the detection system, and an epitope-retrieval method was applied as needed for each specific antibody; diaminobenzidine was the chromogen. The primary antibodies used reacted against the following antigens: CD20, CD3, CD10, bcl-6, Ki-67, bcl-2, EBV-LMP-1, 
PAX-5, TdT, CD5, CD23, p53, and p63 ITable 1I. For p53 and p63 immunostaining, only tumors with more than $10 \%$ and more than $5 \%$, respectively, of neoplastic cells showing nuclear expression were considered positive. For p63 immunostaining, cases were divided into 4 groups according to the following scores: negative, $5 \%$ or fewer; $1+$, more than $5 \%$ to $10 \% ; 2+$, more than $10 \%$ to $50 \%$; and $3+$, more than $50 \%$.

Sections from all TMAs were examined for the expression of EBER1 by ISH using a 30-base oligonucleotide EBER1 probe complementary to a portion of the EBER1 gene, as previously described. ${ }^{14}$ Appropriate positive (cases of EBV+ BL and EBV+ Hodgkin lymphoma) and negative control (EBV- tissue) cores were also included in the arrays.

\section{PCR Study for EBV Typing}

Subtyping for EBV by PCR amplification of the EBV-encoded nuclear antigen (EBNA)2 region was performed in 123 cases. DNA isolation was performed as follows: formalin-fixed, paraffin-embedded histologic sections were submitted to deparaffinization by successive xylene baths and dehydration with $100 \%$ ethanol. After digestion and DNA purification, ${ }^{22}$ PCR was performed to investigate the quality of the extracted DNA, using a set of control primers for human genes that amplify products by $100,200,300,400$, and up to 600 base pairs (bp) depending on the integrity of the extracted DNA. ${ }^{23}$ For EBV typing, 2 primers encompassing a region (E2 up, 5'-AGGCTGCCCACCCTGAGGAT-3' and E2 low, 5'-GCCACCTGGCAGCCCTAAAG-3') containing a 16-bp deletion in EBV type A were used. PCR with these primers yields amplification product of 170- and 186-bp fragment length for types A and B, respectively. In some cases, a seminested reamplification was performed using the E2 up and E2R low (5'-GCTGCCACCTGGCGGAAT-3') primers rendering amplification products of $111 \mathrm{bp}$ and $127 \mathrm{bp}$ for types A and B, respectively, according to Araujo et al. ${ }^{15}$

PCR-amplified products for both studies were analyzed in a 7\% polyacrylamide gel by silver staining.

\section{Fluorescence In Situ Hybridization}

FISH was performed using a 3- $\mu$ m-thick tissue section of each array block, as previously described. ${ }^{3}$ For the detection of breakpoints in the c-MYC locus, the LSI MYC Dual-Color Break-apart Rearrangement probe (Vysis, Abbott, United States) was applied. The slides were evaluated using 
SpectrumOrange and SpectrumGreen filters (Chroma Technology, Fuerstenfeldbruck, Germany) on a Zeiss Axio Imager M1 fluorescence microscope (Carl Zeiss, Göttingen, Germany) and the assistance of Isis FISH Imaging Software (Metasystems, Altlussheim, Germany). Using an extended focus-tile sampling method, tiles with distant unpaired signals ( $\geq 10$ pixels in distance) were considered positive, and the percentage of tiles containing positive signals was calculated. The threshold for positivity was established from a group of immunophenotypically characterized cases (tonsils) that did not contain the translocation. A positive case was defined as a case in which the mean number of positive tiles detected was 3 SDs above the mean of this negative control group. ${ }^{24}$ The threshold established was $2.19 \%$ (the mean of this negative control group was $0.73 \%$ ).

\section{Statistical Analysis}

Calculations were performed using $\mathrm{R}$ (http://www.r-project.org), version 2.5.1, on a Macintosh computer with OS v.10.5.2 (Apple, Cupertino, CA). Significance was calculated using the Fisher exact test for factor comparisons and a general linear model (logistic regression) for comparisons involving age.

\section{Results}

\section{Clinical Features}

Of the 234 BL cases (CD10+ and bcl-2-), $173(73.9 \%)$ were in males and $61(26.1 \%)$ in females (male/female ratio 2.8:1). The patients ranged in age from 7 months to 81 years (mean, 19.1 years). The distribution of the cases in age subgroups is shown in IFigure 2l. There was no statistically significant age difference between male and female patient cohorts. In 3 cases (1.3\%), the age was unknown. Of the patients, $143(61.1 \%)$ were 16 years or younger (pediatric group) and 88 (37.6\%) were older than 16 years adult group). Extranodal BL comprised $67.9 \%$ of the cases (159 cases), while primary lymph node involvement was observed in $28.6 \%$ of the cases (67 cases). In 8 cases (3.4\%) it was not possible to determine nodal or extranodal involvement. In the extranodal cases, the most common site of involvement was the gastrointestinal tract (59 cases); 49 cases were referred to as extranodal abdominal tumor without further specification; involvement of liver, oropharynx/nasopharynx, jaw/maxilla, ovaries, and central nervous system were observed in 7, 6, 5, 4, 
and 2 cases, respectively. Among the patients with primary lymph node disease, the most common sites of involvement were the cervical region (32 cases) and the axilla (15 cases). In the pediatric population, primary extranodal disease was observed in 113 cases (79.0\%); in contrast, the adult population had extranodal involvement in 43 cases (49\%).

The distribution of the cases in each of the 5 geographic regions of the country (including mean age, age range, sex, age group, site of involvement, association with EBV by ISH, and EBV typing by PCR) is summarized in Figure 1 and ITable $2 \mathbf{l}$. As expected, EBER1 positivity was inversely associated with increased age $(P \leq .006)$, but was not significantly associated with sex. In contrast with the other regions, in the South and Central West regions, the number of cases of the adult group was greater than the number of pediatric cases. In these 2 geographical regions (South and Central West), extranodal involvement (14 cases and 6 cases, respectively) in the adult group (26 cases and 9 cases, respectively) was more frequent than a nodal presentation (12 cases and 3 cases, respectively).

Among the 234 cases, $14(6.0 \%)$ were known to be in HIV+ patients. The clinical features of this group of patients, including association with EBV and morphologic type, are given in ITable 31. The age at the time of diagnosis ranged from 2 to 55 years (mean, 34 years). Overall, and as expected, HIV positivity was associated with increased age $(P \leq .005)$. There were 11 men $(79 \%)$ and 3 women (21\%), and nodal involvement (8 cases [57\%]) was more frequent than an extranodal presentation (6 cases $[43 \%])$.

\section{Morphologic Features}

In the original material reviewed to select the areas for TMA, approximately $99 \%$ of BLs showed diffuse architecture, and only rare cases exhibited a focal nodular pattern (2 cases). Most of the cases were of classic type (213 [91.0\%]) characterized by a monotonous proliferation of medium-sized cells with round nuclei, multiple nucleoli, deeply basophilic cytoplasm, and numerous mitotic figures with a starry-sky pattern Image 1AI. Morphologic variants were distributed as follows: plasmacytoid differentiation, 7 cases (3.0\%); and atypical BL, 14 cases (6.0\%). All HIV+ cases BL exhibited classic morphologic features. 


\section{Immunohistochemical Analysis and ISH}

All cases had an immunophenotype consistent with BL according to the 2001 WHO classification, ${ }^{2}$ ie, CD20+, CD10+, bcl-6+/-, Ki-67 >95\%, CD3-, and bcl-2-. CD20 and CD10 were positive in all cases; bcl-6 was positive in 203 cases (86.8\%), and PAX-5 expression was observed in 225 cases (96.2\%). TdT and bcl-2 were negative in all cases. All 44 cases studied with antibodies against CD5 and CD23 showed negative results. LMP-1 expression was observed in only $1(0.4 \%)$ of 234 cases. Nuclear expression of p63 protein was seen in 9 cases $(3.8 \%)$, all classified as $1+$. Expression of p53 protein (above the cutoff of 10\%) was noted in 38 cases (16.2\%) IImage 1BI. In only 1 case was there coexpression of p63 and p53. All control cores showed the expected immunostaining expression pattern. A higher proportion of EBER1+ BLs were bcl- $6+(P \leq .06$ overall). This effect was even more pronounced in HIV-cases in the pediatric group $(P \leq .04)$. Of note, p53 positivity, which is customarily interpreted as accumulation of mutant p53, was inversely correlated with EBV status.

ISH for EBV was positive in 123 cases $(52.6 \%)$. In each of these cases, all or virtually all of the neoplastic cells stained for EBER1 IImage 1CI. The majority of the EBV+ cases were in the pediatric group (83 cases $[67.5 \%])$, and 38 cases $(30.9 \%)$ occurred in patients older than 16 years. In 2 EBV+ BLs, the age was unknown (1.6\%). In the pediatric group (143 cases), 58.0\% were EBV+, while in the adult group (88 cases), 38 cases $(43 \%)$ were EBV+. The mean age of patients in the EBV+ group was 16 years, while the mean age in patients in the EBV- group was 23 years. In 1 case, ISH for EBV was inconclusive owing to lack of sufficient neoplastic tissue in the cores.

The lowest association between BL and EBV was seen in cases from the South region of Brazil, where $12(29 \%)$ of 42 were EBV+. In the other regions, this association varied from 47\% (Central West, 8 cases) to $76 \%$ (North, 13 cases). In the group of known $14 \mathrm{HIV}+$ cases, 10 were EBV+ (71\%).

\section{PCR Study for EBV Typing}

The EBV molecular subtyping analysis in the $123 \mathrm{EBV}+$ cases by ISH showed that $95(77.2 \%)$ of the cases were EBV type A, and 24 (19.5\%) were type B. In 4 cases (3.3\%), the DNA obtained from the paraffin blocks was too degraded and yielded inconclusive results for EBV subtyping. No case demonstrated both EBV subtypes in the same sample IImage $2 \mathbf{r}$. 
EBV type A was predominant in 4 of the 5 geographic regions of Brazil. The only exception was observed in the Central West region, which revealed an equal distribution of EBV types A and B in the $8 \mathrm{EBV}+\mathrm{BLs}$ (Table 2). Also, a predominance of EBV type A $(8 / 10[80 \%])$ was found in HIV+ BL (Table 3).

\section{Fluorescence In Situ Hybridization}

All 361 cases of the 8 TMA blocks were studied by FISH using the LSI MYC Dual-Color Break-apart Rearrangement probe. However, 127 were excluded, most of them (89 cases) owing to poorly fixed material. Only 38 of the 127 excluded cases demonstrated results inconsistent with BL, ie, mean number of positive tiles fewer than $2.19 \%$. In the remaining 234 cases, the range for positive signals obtained was $2.2 \%$ to $43.2 \%$ (mean, $12.5 \%$ ) Image 1DI.

\section{Discussion}

BL is an aggressive B-cell lymphoma with a variable incidence in different geographic regions of the world. According to Rabkin et $\mathrm{al}^{25}$ in endemic areas (Equatorial Africa), the incidence rate varies between 5 and 10 per 100,000 children younger than 15 years, while in the United States this value is closer to 2 per million. In Brazil, the epidemiologic status of BL remains to be elucidated. ${ }^{17}$ Previous studies on BL in this country have been predominantly from the Northeast, ${ }^{15,16}$ Southeast, ${ }^{13,14,17,18}$ and South, ${ }^{19}$ with an emphasis on the pediatric population. This is the first large-scale study of BL in Brazil, including pediatric and adult populations, and also the first to analyze cases from the Central West and North regions. Brazil is a remarkably diverse country. The South and Southeast regions are more developed socioeconomically and have greater percentages of European descendants. The North includes the Amazon rain forest and is endemic for malaria and other tropical and infectious diseases. ${ }^{20}$ It should be emphasized, however, that the cases of BL studied herein were received as consultations cases. So, a bias in the number of cases from different regions could influence the low number of cases from the North region. In further studies, we intend to refine the characterization of $\mathrm{BL}$ in the North region of Brazil where malaria is a health public problem.

In our study of $\mathrm{BL}$, there was a male predominance (male/female ratio, $2.8: 1)$, and pediatric cases $(\mathrm{n}=$ 143) outnumbered adult cases $(n=88)$. We also observed a higher frequency of extranodal (159 
cases) than nodal (67 cases) involvement. In the cases with extranodal involvement, intra-abdominal organs were affected in $129(81.1 \%)$ of 159 cases, while in only 5 cases $(3.1 \%)$ was jaw/maxilla the initial site. This is clearly distinct from the typical mandibular presentation found in Africa., ${ }^{2,8,12}$ Lymph node involvement was more common among the adult than the pediatric population, in concordance with the literature. ${ }^{26}$ Therefore, in this extensive analysis of BL from Brazil, the clinical features were similar to the sporadic form of BL seen in the United States and Europe., ${ }^{2,26,27}$ Only in the Central West and South regions did the adult group outnumber the pediatric group.

It is well established that there is a significant association of BL with EBV with a variable frequency, depending on the clinicopathologic variant. EBV is present in the majority of endemic cases of BL (up to $100 \%$ ) and in only $15 \%$ to $30 \%$ of sporadic cases from the United States. ${ }^{2,12,28}$ In Brazil, there are few studies that have analyzed the frequency of association of EBV in BL. Araujo et al ${ }^{15}$ and Sandlund et $\mathrm{al}^{16}$ studied this association in the Northeast region of Brazil in a pediatric population and reported that $87 \%$ ( 47 of 54 cases) and 73\% (8 of 11 cases), respectively, were EBV+. In our study, in this geographic region, we observed a lower frequency of association between EBV and BL $(63 \% ; 54$ $\mathrm{EBV}+$ cases of $86 \mathrm{BL}$ cases evaluated), although this included adult and pediatric cases. In the Southeast region, Gutierrez et al, ${ }^{13}$ Bacchi et $a l,{ }^{14}$ Klumb et al, ${ }^{17}$ and Hassan et al ${ }^{18,29}$ obtained different frequencies of association between $\mathrm{BL}$ and $\mathrm{EBV}$, varying from $58 \%$ to $72 \%$. In this particular region, we observed that half of the cases of BL were EBV+ (36/72 cases). The South region had the lowest frequency of association (29\%), a result that is similar to sporadic BL in developed countries. ${ }^{2,28}$ However, in a previous study in this same region, Haralambieva et $\mathrm{al}^{19}$ reported that $50 \%$ of their $\mathrm{BL}$ cases were $\mathrm{EBV}+$. In the Central West region, $47 \%$ of the cases were EBV+. The highest frequency of association was observed in the North, in which $76 \%$ of the cases of BL were EBV+. This establishes the existence of a substantial group of classical, non-AIDS associated BL cases in Brazil that occurs at a frequency that is much higher than that of EBV-, sporadic BL cases as observed in the United States and Europe.

Our study on BL showed a total of $123 \mathrm{EBV}+$ cases (by ISH) in the overall population (52.6\%) and, as previously demonstrated in Brazil, ${ }^{15,17}$ the $\mathrm{EBV}+$ group (mean age, 16 years) was younger than the EBV- group (mean age, 23 years). These results, and those of previous studies, ${ }^{2} 12$ demonstrate that Brazil as a country has an intermediate association of BL with $\mathrm{EBV}$, although this association is much 
more pronounced in the more tropical regions. Among adult cases of BL in our series, there was a notably higher percentage of EBV+ tumors than has been reported among sporadic variants of the tumor in the United States and Europe ${ }^{30}$ Therefore, the pathogenesis of adult cases of BL in Brazil and other equatorial countries may differ from that seen in wealthier nations. This also may have important therapeutic implications, given that antiviral nucleosides may have activity in EBVassociated lymphomas. ${ }^{31,32}$

EBV strains can be categorized into 2 types (A and B), and a geographic prevalence of these strains has been observed. ${ }^{15}$ Analysis of the coding region of the EBNA2 gene in endemic BL has revealed a high prevalence of both EBV types. Type B EBV is also identified at high frequency in healthy people in Equatorial Africa, ${ }^{33}$ while type A EBV is almost exclusively found in the peripheral blood of people from developed Western countries ${ }^{34}$ and is more frequently found in sporadic $\mathrm{BL}^{35}$. It is also known that patients with AIDS have an increased prevalence of infection with type B EBV. ${ }^{35,36}$ By studying the EBNA2 gene, we determined that 95 (77.2\%) of the EBV+ BLs contained type A EBV and $24(19.5 \%)$ contained type B EBV, a pattern intermediate between that observed in endemic $\mathrm{BL}^{33}$ and North American cases. ${ }^{35}$ The South region of Brazil showed the lowest percentage of EBV type B (only $8 \%$ ), a result similar to sporadic BL in the United States. ${ }^{35}$ In contrast, the Central West region showed the highest percentage of EBV type B (50\%; 4 cases), a pattern similar to that found in endemic BL. ${ }^{33}$ The distribution of EBV strains in the Northeast and Southeast regions (Table 2) revealed similar results to previous reports in these same geographic regions. ${ }^{15,17,18,29}$ Among our 14 $\mathrm{HIV}+\mathrm{BLs}, 10$ were EBV+ (by ISH) and only 2 cases (20\%) were EBV type B, in contrast with results reported in the literature. ${ }^{35,36}$

A relationship between immunodeficiency and neoplasia had been recognized for longer than a decade before the emergence of the AIDS epidemic. ${ }^{37}$ HIV infection is associated with a high incidence of NHL (100-400 times higher than among the general population), Kaposi sarcoma, anal human papillomavirus, and cervical carcinoma. The 2 most common of this NHL are diffuse large Bcell lymphoma and $\mathrm{BL},{ }^{9}$ the latter being the first NHL to be described in association with HIV infection and corresponding to about $30 \%$ of NHLs in HIV+ patients. $^{8}$ Our HIV-associated BL showed a male/female ratio of 3.6:1. Among the $14 \mathrm{HIV}+$ BL cases, 12 were adults with only 2 pediatric cases, and nodal involvement at diagnosis was more frequent than extranodal involvement. 
Studies $^{38,39}$ have demonstrated that the frequency of EBV association in HIV-associated BL varies from $25 \%$ to $50 \%$. In 1996, we studied 24 AIDS-related lymphoma cases in Brazil, ${ }^{40} 5$ were BLs and all were in adults. Only 2 cases (40\%) were EBV+. In this study, we observed a greater association between EBV and HIV-associated BL (71\%; 10 cases) as compared with the findings of previous studies ${ }^{38,39,40}$ but similar to the frequency reported by Lazzi et al, ${ }^{41}$ in Africa, who demonstrated 6 EBV+ cases (75\%) among 8 HIV-associated BLs.

Most EBV + BL cases (whether endemic, sporadic, or AIDS-associated) typically display more restricted forms of latency, usually latency type I, only expressing EBER1 and EBER2 and EBNA1, ${ }^{11,12}$ and, as we and others showed, at least the EBV BART microRNAs. ${ }^{42}$ LMP-1 is not typically expressed in BL. In our study, only 1 case of BL was positive for LMP-1 protein by immunohistochemical analysis in a few cells. Similar results have also been described in the literature; Niedobitek et $\mathrm{al}^{43}$ observed expression of LMP-1 protein in a variable proportion of tumor cells in 2 cases of endemic BL. In Brazil, Araujo et $\mathrm{al}^{15}$ and Chen et $\mathrm{al}^{34}$ reported LMP-1 expression in 2 cases and 1 case of $\mathrm{BL}$, respectively. At this point, the significance of this observation with regard to clinical prognosis, outcome, or molecular mechanism remains to be elucidated.

TP53 (also called $p 53$ ) is a key tumor suppressor gene that is mutated or lost in approximately $50 \%$ of all human cancer cases worldwide, including hematologic malignancies. It is activated in response to a variety of cellular and genotoxic stress conditions, leading to the induction of growth arrest, apoptosis, DNA repair, senescence, and differentiation. ${ }^{44}$ It has been reported that $30 \%$ of endemic BL tumors and up to $70 \%$ of long-established BL lines carry mutations in $p 53 .{ }^{12}$

Bhatia et $\mathrm{al}^{45}$ found $p 53$ mutations in $37 \%$ of cases of BL from Argentina and Brazil and concluded that the presence of mutated $p 53$ in $\mathrm{BL}$ is independent of the geographic origin of the tumor, the $8 ; 14$ chromosomal breakpoint locations, and EBV association. Studies have shown that in some high-grade NHLs, the occurrence of positive immunostaining does not reflect point mutations in the $p 53$ gene and vice versa. ${ }^{46}$ Villuendas et $\mathrm{al}^{47}$ found overexpression of p53 protein in $5(63 \%)$ of $8 \mathrm{BL}$ cases, and Klumb et $\mathrm{al}^{48}$ reported p53 overexpression in $13(46 \%)$ of 28 pediatric BL cases, although the mutation was demonstrated, by PCR, in only 7 of these 13 cases. In our study, p53 protein expression was observed in 38 cases $(16.2 \%)$, fewer than in previous studies. This lower percentage can be 
explained, in part, by the cutoff of $10 \%$ used herein, while previous studies used a cutoff of $5 \% .{ }^{47,48}$ More important, we studied a far greater number than any of the prior studies, which we believe yields a more accurate representation of p53 expression in BL (at least in Brazil).

We have sequenced primary pediatric BL cases obtained from the Northeast region of Brazil. The first 13 cases analyzed were wild-type by sequence (data not shown). We also noted a trend toward p53 overexpression in EBER1 ISH-negative BLs. Therefore, the association between mutant $p 53$ and BL may be less than originally thought, and other mechanisms, such as EBV viral genes or epigenetic modifications, may inactivate the p53 pathway. Alternatively, the p53 pathway may be evaded by MYC mutations, as has been demonstrated in a BL animal model. ${ }^{49}$

p63 is a transcription factor that contains multiple isoforms with various biologic activities. ${ }^{50}$ The $p 63$ gene locus at chromosome $3 \mathrm{q} 28$ bears significant homology to the tumor suppressor gene $p 53$ and to the related gene $p 73$. Both $p 63$ and $p 73$, considered $p 53$-related genes, encode various isoforms with transactivation, DNA binding, and tetramerization domains. ${ }^{51}$ p63 protein exhibits a consistent expression pattern in normal tissues such as squamous epithelia, urothelium, basal cells of prostatic and breast glands, and reticular epithelium of the normal thymus and also in a subset of lymphocytes in the germinal center of morphologically normal lymph nodes. ${ }^{52,53}$ Among hematolymphoid neoplasms, p63 expression has been reported in blast crisis in chronic myelogenous leukemia, ${ }^{54}$ follicular lymphoma, diffuse large B-cell lymphoma, ${ }^{51}$ isolated cases of chronic lymphocytic leukemia, marginal cell lymphoma, ${ }^{52}$ and in $44 \%$ of anaplastic large cell lymphoma. ${ }^{55}$ There are few articles reporting the expression of p63 in lymphoid malignancies, and, to the best of our knowledge, this is the first study to evaluate its expression in a large number of BL cases. We observed that only 9 (3.8\%) of the $234 \mathrm{BL}$ cases expressed p63 protein, and coexpression of protein p53 and p63 was observed in only 1 case.

In this study of the largest number of cases from Latin America analyzed to date, we have demonstrated that BL in Brazil is diverse and regionally distinct. EBV association is sporadic, and, perhaps, HIV-associated BL is higher than seen in the United States and Europe. Overexpression of p53 was infrequently observed, and dysfunction of this critical tumor suppressor in BL may be linked 
to other factors rather than inactivating mutations. Prospective studies of BL in patients undergoing standardized chemotherapy regimens are now underway.

From the ${ }^{l}$ Pathology Reference Lab, Botucatu, São Paulo and ${ }^{2}$ University of São Paulo Medical School, São Paulo, Brazil; ${ }^{3}$ Division of Pathology, City of Hope National Medical Center, Duarte, CA; ${ }^{4}$ Department of Microbiology and Immunology, Lineberger Comprehensive Cancer Center, University of North Carolina, Chapel Hill; ${ }^{5}$ Professor Edgard Santos University Hospital, Salvador, Bahia, Brazil; ${ }^{6}$ National Cancer Institute, Rio de Janeiro, Brazil; and ${ }^{7}$ University of Miami Miller School of Medicine and Sylvester Cancer Center, Fogarty International Center (AIDS and Tuberculosis Program), Miami, FL.

Supported in part by grants 5R01CA082274, 5R01CA121935, 5R01CA112217 (to W.J.H.), and DE018304 (to D.P.D.) from the National Cancer Institute (NCI), Bethesda, MD, the NCI AIDS Malignancy Consortium, and the University of Miami Fogarty AITRP grant D43TW000017.

Manuscript received May 6, 2008; accepted June 16, 2008.

Address reprint requests to Dr Bacchi: Consultoria em Patologia, Rua Major Leonidas Cardoso, 739, Botucatu, SP, 18602-010, Brazil.

Acknowledgments: We thank Lucimara Chioato, Ph and Luciana Hayashi da Silva, MS, for the molecular biology studies. We also thank Marcio Montes and Luciana Ricardi for FISH technical assistance.

\section{References}

1. Burkitt D. A sarcoma involving the jaws in African children. Br J Surg. 1958;46:218-223.

2. Jaffe ES, Harris NL, Stein H, et al, eds. Pathology and Genetics of Tumours of Haematopoietic and Lymphoid Tissues. Lyon, France: IARC Press; 2001. World Health Organization Classification of Tumours.

3. Chuang SS, Ye H, Du MQ, et al. Histopathology and immunohistochemistry in distinguishing Burkitt lymphoma from diffuse large B-cell lymphoma with very high proliferation index and with or without a starry-sky pattern: a comparative study with EBER and FISH. Am J Clin Pathol. 2007;128:558-564.

4. Leder P, Battey J, Lenoir G, et al. Translocations among antibody genes in human cancer. Science. 1983;222:765-771.

5. Bench AJ, Erber WN, Follows GA, et al. Molecular genetic analisis of haematological malignancies, II: mature lymphoid neoplasms. Int J Lab Hematol. 2007;29:229-260.

6. Shiramizu B, Barriga F, Neeguaye J, et al. Patterns of chromosomal breakpoint locations in Burkitt's lymphoma: relevant to geography and Epstein-Barr virus associations. Blood. 1991;77:1516-1526. 
7. Gaidano G, Ballerini P, Gong JZ, et al. p53 mutations in human lymphoid malignancies: association with Burkitt lymphoma and chronic lymphocytic leukemia. Proc Natl Acad Sci U S A. 1991;88:5413. 5417.

8. Ferry JA. Burkitt's lymphoma: clinicopathologic features and differential diagnosis. Oncologist. 2006;11:375-383.

9. Navarro WH, Kaplan LD. AIDS-related lymphoproliferative disease. Blood. 2006;107:13-20.

10. Epstein MA, Achong BG, Barr YM. Virus particles in cultured lymphoblasts from Burkitt's lymphoma. Lancet. 1964;1:702-703.

11. Rezk SA, Weiss LM. Epstein-Barr virus-associated lymphoproliferative disorders. Hum Pathol. 2007;38:1293-1304.

12. Kelly GL, Rickinson AB. Burkitt lymphoma: revisiting the pathogenesis of a virus-associated malignancy. Hematology Am Soc Hematol Educ Program. 2007;2007:277-284.

13. Gutierrez MI, Bhatia K, Barriga T, et al. Molecular epidemiology of Burkitt's lymphoma from South America: differences in breakpoint location and Epstein-Barr virus association from tumors in other world regions. Blood. 1992;79:3261-3266.

14. Bacchi MM, Bacchi CE, Alvarenga M, et al. Burkitt's lymphoma in Brazil: strong association with Epstein-Barr virus. Mod Pathol. 1996;9:63-67.

15. Araujo I, Foss HD, Bittencourt A, et al. Expression of Epstein-Barr virus-gene products in Burkitt's lymphoma in Northeast Brazil. Blood. 1996;87:5279-5286.

16. Sandlund JT, Fonseca T, Leimig T, et al. Predominance and characteristics of Burkitt lymphoma among children with non-Hodgkin lymphoma in northeastern Brazil. Leukemia. 1997;11:743-746.

17. Klumb CE, Hassan R, De Oliveira DE, et al. Geographic variation in Epstein-Barr virusassociated Burkitt's lymphoma in children from Brazil. Int J Cancer. 2004;108:66-70.

18. Hassan R, Klumb CE, Felisbino FE, et al. Clinical and demographic characteristics of EpsteinBarr virus-associated childhood Burkitt's lymphoma in Southeastern Brazil: epidemiological insights from an intermediate risk region. Haematologica. 2008;93:780-783.

19. Haralambieva E, Schuuring E, Rosati S, et al. Interphase fluorescence in situ hybridization for detection of 8q24/MYC breakpoints on routine histologic sections: validation in Burkitt lymphoma from three geographic regions. Genes Chromosomes Cancer. 2004;40:10-18.

20. Braga WS, Souza RA, Silva EB, et al. Coinfection between hepatitis B virus and malaria: clinical, serologic and immunologic aspects. Rev Soc Bras Med Trop. 2006;39:27-31. 
21. Coura JR, Amaral RS. Epidemiological and control aspects of schistosomiasis in Brazilian endemic areas. Mem Inst Oswaldo Cruz. 2004;99:13-19.

22. Howe JR, Klimstra DS, Cordon-Cardo C. DNA extraction from paraffin-embedded tissues using a salting-out procedure: a reliable method for PCR amplification of archival material. Histol Histopathol. $1997 ; 12: 595-601$.

23. van Dongen JJM, Langerak AW, Bruggemann M, et al. Design and standardization of PCR primers and protocols for detection of clonal immunoglobulin and T-cell receptor gene recombinations in suspect lymphoproliferations: report of the BIOMED-2 Concerted Action BMH4-CT98-3936. Leukemia. 2003;17:22572317.

24. Cogliati SB, Novak U, Hens S, et al. Diagnosis of Burkitt lymphoma in due time: a practical approach. Br J Haematol. 2006;134:294-301.

25. Rabkin CS, Ward MH, Maans A, et al. Epidemiology of non-Hodgkin's lymphoma. In: Magrath IT, ed. The Non-Hodgkin's Lymphomas. 2nd ed. London, England: Arnold; 1997:171-186.

26. Boerma EG, van Imhoff GW, Appel IM, et al. Gender and age-related differences in Burkitt lymphoma: epidemiological and clinical data from the Netherlands. Eur J Cancer. 2004;40:2781-2787.

27. Magrath IT. Therapy of the small non-cleaved cell lymphoma. In: Magrath IT, ed. The NonHodgkin's Lymphomas. 2nd ed. London, England: Arnold; 1997:779-781.

28. Barriga F, Kiwanuka J, Alvarez-Mon M, et al. Significance of chromosome 8 breakpoint location in Burkitt's lymphoma: correlation with geographical origin and association with Epstein-Barr virus. Curr Top Microbiol Immunol. 1988;141:128-137.

29. Hassan R, White LR, Stefanoff CG, et al. Epstein-Barr virus (EBV) detection and typing by PCR: a contribution to diagnostic screening of EBV-positive Burkitt's lymphoma. Diagn Pathol. 2006;1:17.

30. Spina M, Tirelli U, Zagonel V, et al. Burkitt's lymphoma in adults with and without human immunodeficiency virus infection: a single-institution clinicopathologic study of 75 patients. Cancer. 1998; 82:766774.

31. Kurokawa M, Ghosh SK, Ramos JC, et al. Azidothymidine inhibits NF-kappaB and induces Epstein-Barr virus gene expression in Burkitt lymphoma. Blood. 2005;106:235-240.

32. Feng WH, Hong G, Delecluse HJ, et al. Lytic induction therapy for Epstein-Barr virus-positive B-cell lymphomas. J Virol. 2004;78:1893-1902.

33. Young LS, Yao QY, Rooney CM, et al. New type B isolate of Epstein-Barr virus from Burkitt's lymphoma and normal individuals in endemic areas. J Gen Virol. 1987;68:2853-2862. 
34. Chen WG, Chen YY, Bacchi MM, et al. Genotyping of Epstein-Barr virus in Brazilian Burkitt's lymphoma and reactive lymphoid tissue: type A with a high prevalence of deletions within the latent membrane protein gene. Am J Pathol. 1996;148:17-23.

35. Goldschmidts WL, Bhatia K, Johnson JF, et al. Epstein-Barr virus genotypes in AIDS-associated lymphomas are similar to those in endemic Burkitt's lymphomas. Leukemia.1992;6:875-878.

36. Boyle MJ, Sewel WA, Sculley TB, et al. Subtypes of Epstein-Barr virus in human immunodeficiency virus-associated non-Hodgkin lymphoma. Blood. 1991;78:3004-3011.

37. Gatti RA, Good RA. Occurrence of malignancy in immunodeficiency disease: a literature review. Cancer. 1971;28:89-98.

38. Hamilton-Dutoit SJ, Raphael M, Audouin J, et al. In situ demonstration of Epstein-Barr virus small RNAs (EBER 1) in acquired immunodeficiency syndrome-related lymphomas: correlation with tumor morphology and primary site. Blood. 1993;82:619-624.

39. Raphael MM, Audouin J, Lamine M, et al. Immunophenotypic and genotypic analysis of acquired immunodeficiency syndrome-related non-Hodgkin's lymphomas: correlation with histologic features in 36 cases. French Study Group of Pathology for HIV-Associated Tumors. Am J Clin Pathol. 1994;101:773-782.

40. Bacchi CE, Bacchi MM, Rabenhorst SH, et al. AIDS-related lymphoma in Brazil: histopathology, immunophenotype, and association with Epstein-Barr virus. Am J Clin Pathol. 1996;105:230-237.

41. Lazzi S, Fwerrari F, Nyongo A, et al. HIV-associated malignant lymphomas in Kenya (Equatorial Africa). Hum Pathol. 1999;29:1285-1289.

42. Xia T, O'Hara A, Araujo I, et al. EBV microRNA in primary lymphomas and targeting of CXCL-11 by ebv-mir-BHRF1-3. Cancer Res. 2008;68:1436-1442.

43. Niedobitek G, Agathanggelou A, Rowe M, et al. Heterogeneous expression of Epstein-Barr virus latent proteins in endemic Burkitt's lymphoma. Blood. 1995;86:659-665.

44. Margalit $\mathrm{O}$, Amram $\mathrm{H}$, Amariglio N, et al. BCL6 is regulated by p53 through a response element frequently disrupted in B-cell non-Hodgkin lymphoma. Blood. 2006;107:1599-1607.

45. Bhatia KG, Gutiérrez MI, Huppi K, et al. The pattern of p53 mutations in Burkitt's lymphoma differs from that of solid tumors. Cancer Res. 1992;52:4273-4276.

46. Kocialkowski S, Pezzella F, Morrison H, et al. Mutations in the p53 gene are not limited to classic "hot spots" and are not predictive of p53 protein expression in high-grade non-Hodgkin's lymphoma. $\mathrm{Br} J$ Haematol. 1995;89:55-60. 
47. Villuendas R, Piris MA, Orradre JL, et al. p53 protein expression in lymphomas and reactive lymphoid tissue. J Pathol. 1992;166:235-241.

48. Klumb CE, Hassan R, Zalcberg IR, et al. p53 protein expression does not correlate with EBV status in childhood B non-Hodgkin lymphomas. Pediatr Blood Cancer. 2004;43:115-119.

49. Hemann MT, Bric A, Teruya-Feldstein J, et al. Evasion of the p53 tumour surveillance network by tumour-derived MYC mutants. Nature. 2005;436:807-811.

50. Flores ER. The roles of p63 in cancer. Cell Cycle. 2007;6:300-304.

51. Hedvat CV, Teruya-Feldstein J, Puig P, et al. Expression of p63 in diffuse large B-cell lymphoma. Appl Immunohistochem Mol Morphol. 2005;13:237-242.

52. Di Como CJ, Urist MJ, Babayan I, et al. p63 expression profiles in human normal and tumor tissues. Clin Cancer Res. 2002;8:494-501.

53. Nylander K, Vojtesek B, Nenutil R, et al. Differential expression of p63 isoforms in normal tissues and neoplastic cells. J Pathol. 2002;198:417-427.

54. Yamaguchi H, Inokuchi K, Sakuma Y, et al. Mutation of the $p 51 / p 63$ gene is associated with blastic crisis in chronic myeloid leukemia. Leukemia. 2001;15:1729-1734.

55. Gualco G, Weiss LM, Bacchi CE. Expression of p63 in anaplastic large cell lymphoma but not in classical Hodgkin lymphoma. Hum Pathol. 2008;39:1505-1510. 


\section{ITable 11}

Primary Antibodies Used for Immunohistochemical Staining in Paraffin Sections of Burkitt Lymphoma Cases*

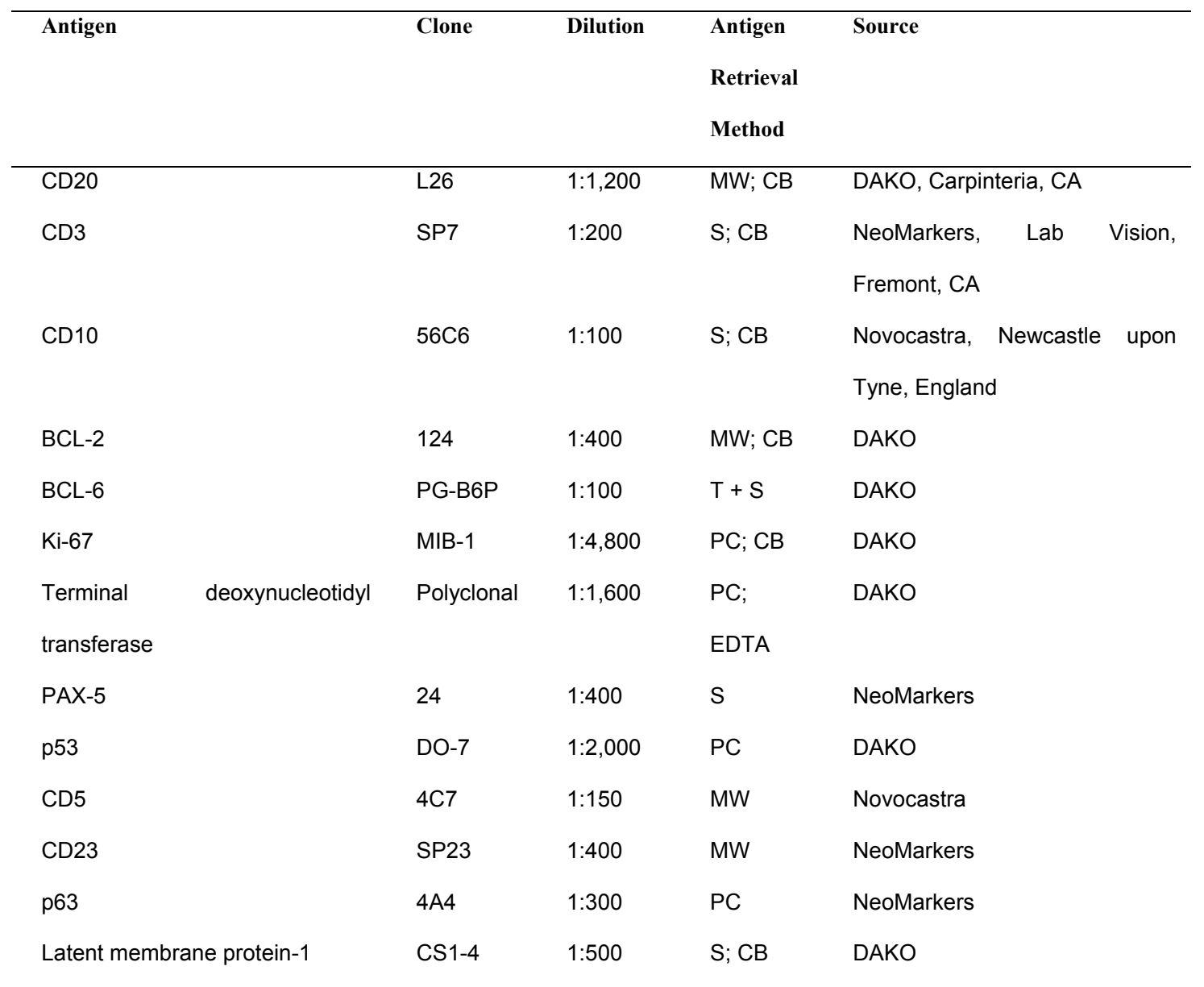

CB, citrate buffer, $\mathrm{pH}$ 6; MW, microwave oven; PC, pressure cooker; S, steamer; T, trypsin.

${ }^{*}$ Heat-induced epitope retrieval was used. 
ITable 2 】

Distribution of Burkitt Lymphoma Cases in Each Geographic Region*

\begin{tabular}{|c|c|c|c|c|c|c|}
\hline & $\begin{array}{l}\text { Northeast (n } \\
=\quad 86\end{array}$ & $\begin{array}{l}\text { Central } \\
\text { West }(n=\end{array}$ & $\begin{array}{l}\text { South }(n= \\
42[17.9 \%])\end{array}$ & $\begin{array}{l}\text { Southeast }(\mathrm{n} \\
=\quad 72\end{array}$ & $\begin{array}{l}\text { North }(n= \\
17[7.3 \%])\end{array}$ & $\begin{array}{l}\text { Total }(\mathrm{n}= \\
\text { 234) }\end{array}$ \\
\hline & $[36.7 \%])$ & $17[7.3 \%])$ & & $[30.8 \%])$ & & \\
\hline \multicolumn{7}{|l|}{ Age } \\
\hline Mean (y) & 15.4 & 27.5 & 28.6 & 18.3 & 10.3 & 19.1 \\
\hline Range & 7 mo-79 y & $3-75 y$ & $3-81$ y & $2-80 y$ & $3-51 y$ & 7 mo-81 y \\
\hline \multicolumn{7}{|l|}{ Sex } \\
\hline Male & $64(74)$ & $12(71)$ & $29(69)$ & $54(75)$ & $14(82)$ & 173 (73.9) \\
\hline Female & $22(26)$ & $5(29)$ & $13(31)$ & $18(25)$ & $3(18)$ & $61(26.1)$ \\
\hline $\mathrm{M} / \mathrm{F}$ ratio & 2.78 & 2.4 & 2.2 & 3 & 4.6 & 2.8 \\
\hline \multicolumn{7}{|l|}{ Age group } \\
\hline Adult & $23(27)$ & $9(53)$ & $26(62)$ & $27(38)$ & $3(18)$ & $88(37.6)$ \\
\hline Pediatric & $63(73)$ & $8(47)$ & $14(33)$ & $44(61)$ & $14(82)$ & $143(61.1)$ \\
\hline Unknown & $0(0)$ & $0(0)$ & $2(5)$ & $1(1)$ & $0(0)$ & $3(1.3)$ \\
\hline \multicolumn{7}{|l|}{ Location } \\
\hline Nodal & $23(27)$ & $5(29)$ & $15(36)$ & $21(29)$ & $3(18)$ & $67(28.6)$ \\
\hline Extranodal & $57(66)$ & $12(71)$ & $27(64)$ & $50(69)$ & $13(76)$ & 159 (67.9) \\
\hline Unknown & $6(7)$ & $0(0)$ & $0(0)$ & $1(1)$ & $1(6)$ & $8(3.4)$ \\
\hline \multicolumn{7}{|l|}{ EBV (ISH) } \\
\hline Positive & $54(63)$ & $8(47)$ & $12(29)$ & $36(50)$ & $13(76)$ & $123(52.6)$ \\
\hline \multirow[t]{2}{*}{ Negative } & $32(37)$ & $9(53)$ & $30(71)$ & $36(50)$ & $3(18)$ & $110(47.0)$ \\
\hline & $0(0)$ & $0(0)$ & $0(0)$ & $0(0)$ & $1(6)$ & $1(0.4)$ \\
\hline \multicolumn{7}{|l|}{ Inconclusive } \\
\hline \multicolumn{7}{|l|}{ EBV type } \\
\hline \multicolumn{7}{|l|}{ (PCR) } \\
\hline \multirow[t]{2}{*}{$A$} & $40 / 54(74)$ & $4 / 8(50)$ & $11 / 12(92)$ & $31 / 36(86)$ & $9 / 13(69)$ & $95 / 123$ \\
\hline & & & & & & $(77.2)$ \\
\hline \multirow[t]{3}{*}{ B } & 10/54 (19) & $4 / 8(50)$ & $1 / 12(8)$ & $5 / 36(14)$ & $4 / 13(31)$ & $24 / 123$ \\
\hline & & & & & & (19.5) \\
\hline & $4 / 54(7)$ & $0(0)$ & $0(0)$ & $0(0)$ & $0(0)$ & 4/123 (3.3) \\
\hline Inconclusive & & & & & & \\
\hline
\end{tabular}

EBV, Epstein-Barr virus; ISH, in situ hybridization; PCR, polymerase chain reaction.

${ }^{*}$ Data are given as number (percentage) or number/total (percentage) unless otherwise indicated. 


\section{ITable 3!}

Clinical Features, Morphologic Findings, and EBV Association in HIV+ Burkitt Lymphoma Group

\begin{tabular}{lllll}
\hline Case No./Sex/Age (y) & Location & EBV ISH & EBV Subtype & Morphologic Type \\
\hline 1/M/2 & Salivary gland & Positive & A & Classic \\
$2 / F / 7$ & Neck LN & Negative & - & Classic \\
3/F/25 & Axillary LN & Positive & B & Classic \\
4/M/25 & Duodenum & Positive & A & Classic \\
5/M/30 & Mesentery & Positive & B & Classic \\
6/M/32 & Axillary LN & Positive & A & Classic \\
7/M/34 & Neck LN & Negative & - & Classic \\
8/M/37 & Axillary LN & Positive & A & Classic \\
9/M/40 & Retroperitoneum & Positive & A & Classic \\
10/M/42 & lleum & Negative & - & Classic \\
11/M/44 & Skin (head) & Positive & A & Classic \\
12/M/51 & Axillary LN & Positive & A & Classic \\
13/F/52 & Abdomen & Positive & A & Classic \\
14/M/55 & Axillary LN & Negative & - & Classic \\
\hline EBV, Epstein-Barr virus; ISH, in situ hybridization; LN, lymph node. & & \\
\hline
\end{tabular}

IFigure 1I Brazilian map with the 5 geographic regions showing the distribution of Burkitt lymphoma cases and the frequency of pediatric and adult Burkitt lymphoma related to anatomic location and Epstein-Barr virus (EBV) status.

IFigure 2】 Age distribution of 234 Burkitt lymphoma cases.

IImage 1I Morphologic, immunohistochemical, in situ hybridization, and fluorescence in situ hybridization in Burkitt lymphoma. A, Classical Burkitt lymphoma with a prominent starry-sky pattern (H\&E, $\times 200)$. B, Burkitt lymphoma with high expression of p53 protein by immunohistochemical analysis (x400). C, Expression of Epstein-Barr virus (EBV) in nuclei of neoplastic cells of Burkitt lymphoma (in situ hybridization for EBV early RNA [EBER1], ×200). D, Fluorescence in situ hybridization study using a c-MYC break-apart rearrangement probe showing dissociation of the red and green signals, indicating the presence of a chromosomal breakpoint in the c-MYC locus $(\times 1,000)$.

IImage 2】 Epstein-Barr virus (EBV) molecular subtyping. A, Size control polymerase chain reaction (PCR). B, EBV subtyping specific PCR. M, DNA molecular weight marker; No, DNA absence; $C_{+B}$, positive control for EBV type B, fragment length, 186 base pairs (bp); $C_{+A}$, positive control sample for EBV type A, fragment length, $170 \mathrm{bp} ; 1-5$, positive samples for EBV. 


\section{Queiroga}

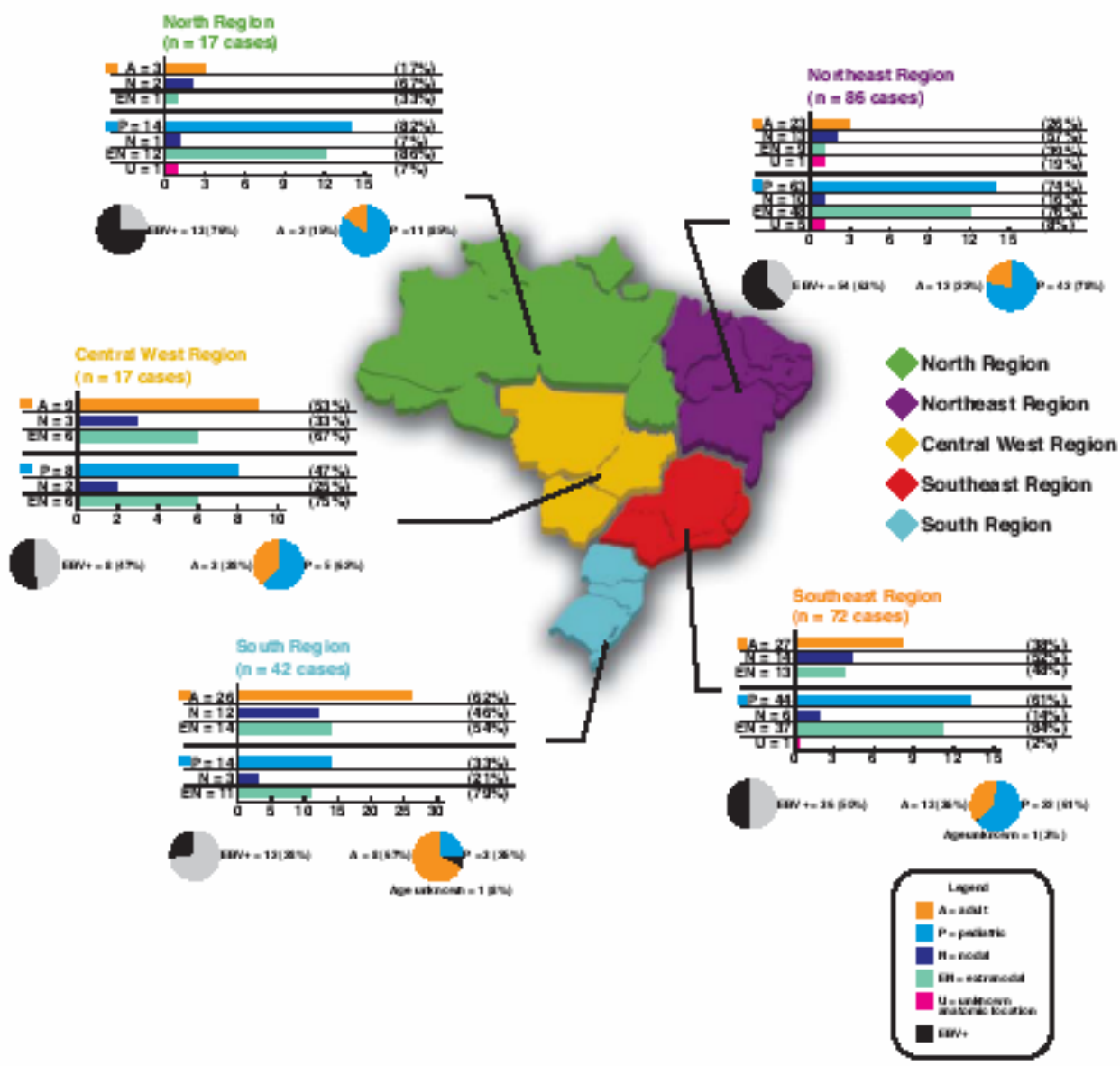

Figure 1

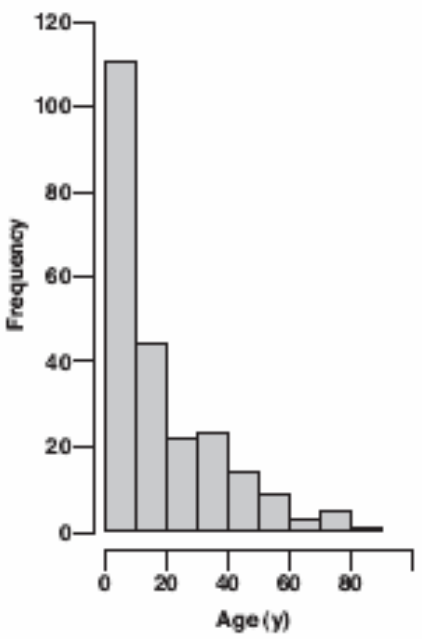

Figure 2 

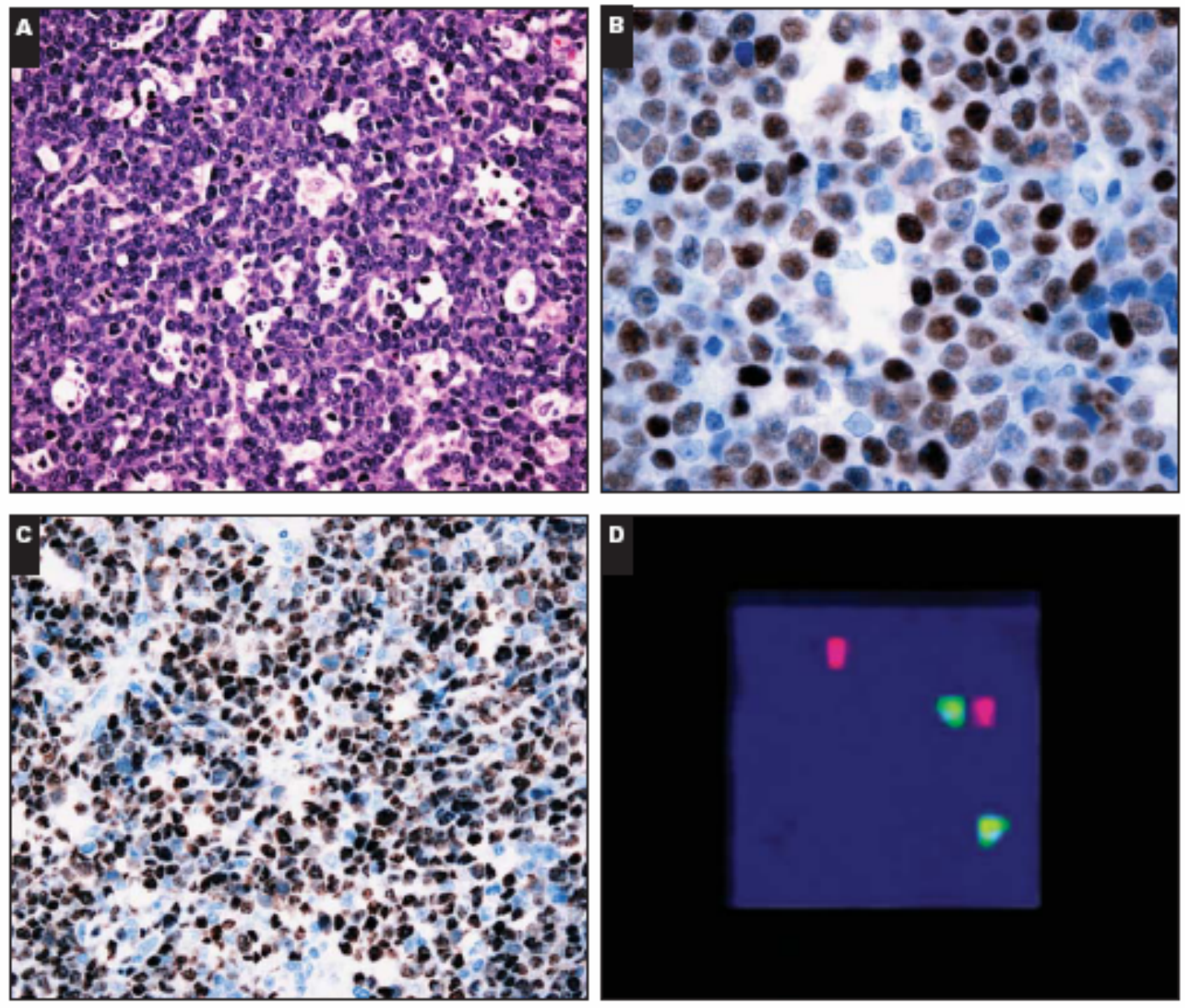

Image 1
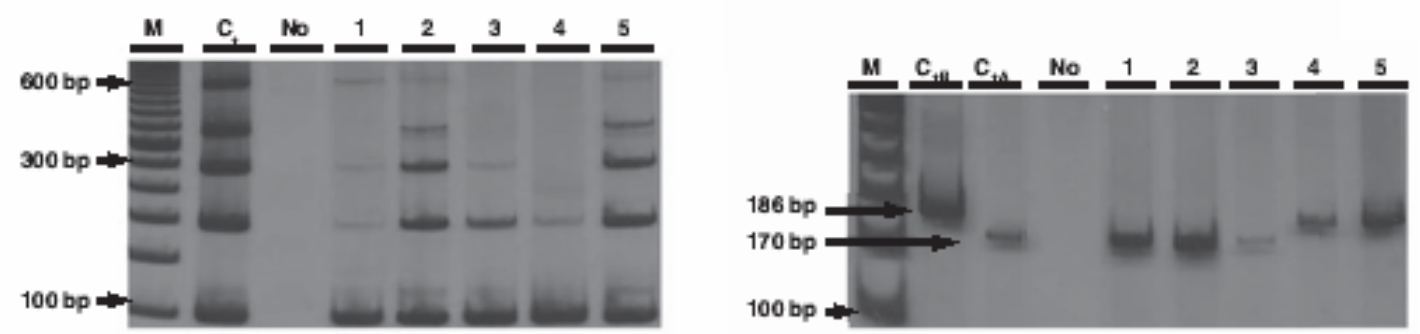

Image 2 
Ms. Ref. No.: YHUPA-D-08-00164R1

Title: FREQUENT EXPRESSION OF MUM1/IRF4 IN BURKITT LYMPHOMA Human Pathology

Dear Prof Bacchi,

I am pleased to confirm that your paper "FREQUENT EXPRESSION OF MUM1/IRF4 IN BURKITT LYMPHOMA" has been accepted for publication in Human Pathology.

You should receive galley proofs from the publisher in the near future.

Please have all authors sign and date the authors' signature form and fax it to the editorial office at 507-538-7961 as soon as possible. The form must be received before publication. A copy of the form can be downloaded at: http://ees.elsevier.com/yhupa/img/Ethics and Financial Conflict Form.doc

Thank you for submitting your work to this journal.

With kind regards,

Ricardo V. Lloyd, MD, PhD

Editor-in-Chief

Human Pathology 
Elsevier Baitorial system(tm) for Human Pathology Manuseript Draft

Manuseript Number: YHUPR-D-08-00164RI

Title: FREQUENT EXPRESSION OF MUMI/IRE4 IN BURKITT LYMPHOW

Article Type: Original Artiele

Keywords: Burkitt lymphoma; MMI/IRP4; tissue microarray; immunohistochemistry; EBV; transcription factor

Corresponding Ruthor: Prof Carlos B Bacchi, MD

Corresponding Author's Institution: Consultoria em Patologia

Eirst Author: Gabriela Gualco, MD

Order of Authors: Gabriela Gualco, MD; Bduardo M Queiroga, MD; Lawrence M Weiss, MD; claudete B Klumb, MD; Willias J Harrington, MD; Carlos E Bacchi

Mbstract: Burkitt lymphoma 〈BL\} is a highly aggressive non-Hodgkin lymphoma \{NHL) with endemic, sporadic and immunodeficiency-associated elinical variants composed of monomorphic medium-size B-cells with a high proliferation rate and a translocation involving the C-MrC locus. Classically the immunophenotype of Burkitt lymphoma has been considered to be of germinal center type. In most reports, all cases of BL are reported to be MOM1 negative. Mun expression is seen in plasma cells and in a small fraction of B cells located in the light zone of germinal centers corresponding to the final step of intra-germinal center (GC) B-cell differentiation, and in activated T-cells. Therefore, MUM1 expression may denote the final step of intra-GC B-cell differentiation at centrocyte stage, as well as the subsequent steps of B-cell maturation towards plasma cells. Unlike most normal GC B-cells, in which the expression of Mul and be1-6 are mutually exclusive, the tumor cells in approximately 50 of of MJM positive DLBCL show co-expression of bel-6, suggesting that the expression of these proteins may be deregulated. In one of the few studies in the literature, 25 BL-cases, including 19 associated with HIV; two of these cases showed occasional MUM1+ cells, less than the 20 z cut-off for positivity. We studied 222 cases of well-characterized Burkitt lymphoma with the classic phenotype and CMYC translocation, and found 90 cases \{40.5\%\} with MMn nuclear expression suggesting a late germinal center stage of differentiation. 